\title{
APPROXIMATING THE SEISMIC AMPLIFICATION EFFECTS \\ EXPERIENCED BY SOLAR TOWERS MOUNTED ON THE \\ ROOFTOPS OF LOW-RISE INDUSTRIAL BUILDINGS
}

\author{
A Thesis \\ presented to \\ the Faculty of California Polytechnic State University \\ San Luis Obispo
}

\author{
In Partial Fulfillment \\ of the Requirements for the Degree
}

Master of Science in Architecture with a Specialization in Structural Engineering

by

Peter Balla

November 1, 2013 
(C) 2013

Peter Balla

ALL RIGHTS RESERVED

ii 
TITLE:

AUTHOR:

DATE SUBMITTED:

COMMITTEE CHAIR: $\quad$ Craig Baltimore, Ph.D., P.E., S.E.

Professor of Architectural Engineering

COMMITTEE CHAIR: $\quad$ Kevin Dong, P.E., S.E.

Professor of Architectural Engineering

COMMITTEE CHAIR: $\quad$ Mary Forte, M.A. English

Professor of English 


\section{ABSTRACT \\ Approximating the Seismic Amplification Effects \\ Experienced by Solar Towers Mounted on the \\ Rooftops of Low-Rise Industrial Buildings \\ Peter Balla}

This thesis investigates the acceleration amplification experienced by solar towers mounted on the rooftops of low-rise industrial buildings during a seismic event.

Specifically, this thesis looks to assess the validity of using amplification factors adopted by the ASCE 7-05Minimum Design Loads for Buildings and Other Structures to approximate seismic acceleration amplification for roof-mounted solar towers. To investigate the validity of the ASCE 7-05 amplification factors, this thesis conducts timehistory analyses of three theoretical solar towers mounted on the roof of a case study building. The time history analyses are conducted in the finite element computer modeling program SAP 2000 using 30 historical ground motion records of varying frequency content. Based on the results of the time history analyses, modifications to the ASCE 7-05 provision specific to roof-mounted solar towers are proposed. 


\section{TABLE OF CONTENTS}

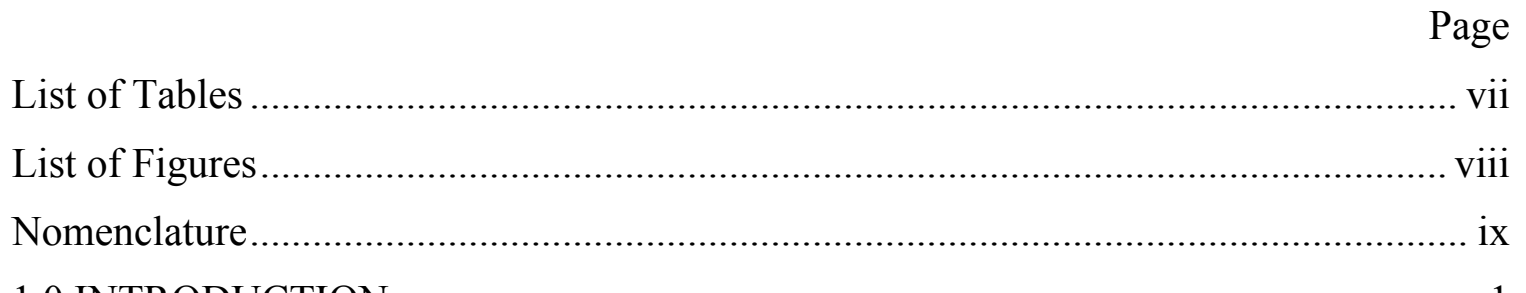

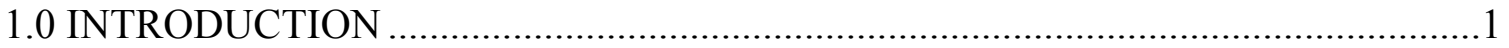

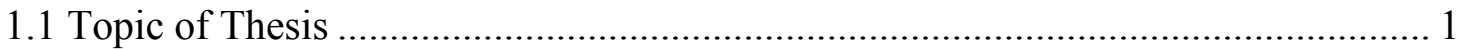

1.1.1 Introduction to Solar Power Tower Systems ................................................. 1

1.1.2 Reason for Solar Power Tower Facilities in City Areas ................................... 2

1.1.3 Reason for Solar Power Towers on Rooftops of Existing Industrial Buildings 3

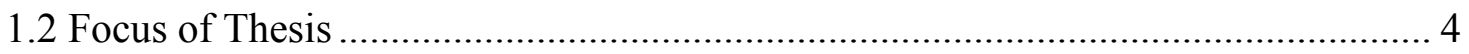

1.2.1 Structural Type for the Roof-Mounted Solar Tower ...................................... 4

1.2.2 Design Considerations of Roof-Mounted Solar Towers.................................. 5

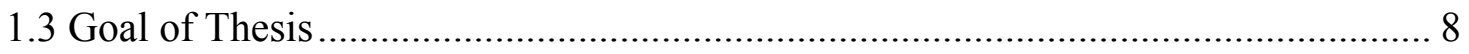

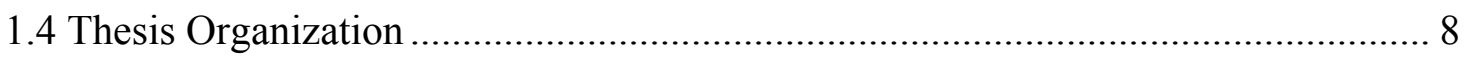

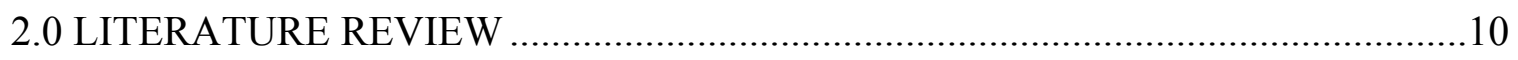

2.1 Floor-Level Amplification Factor................................................................ 10

2.1.1 Assumption \#1: Linear Distribution of Accelerations ................................. 10

2.1.2 Assumption \#2: The Floor-Level Amplification Factor at the Roof .............. 13

2.1.3 Assumption \#3: Mass Interaction between the Tower and the Building ......... 15

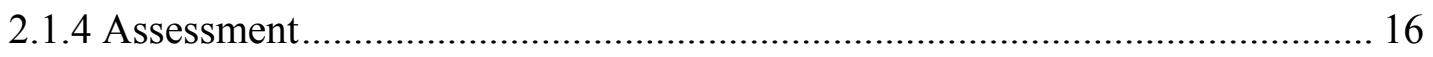

2.2 Component Amplification Factor .................................................................... 17

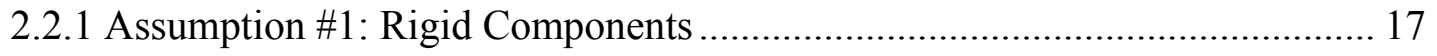

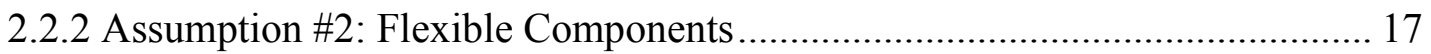

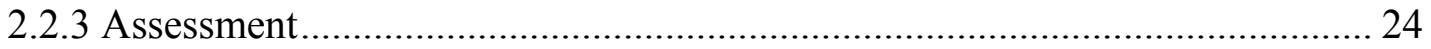

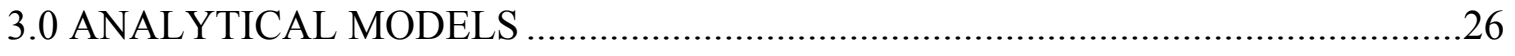

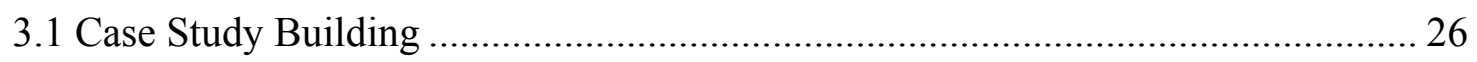

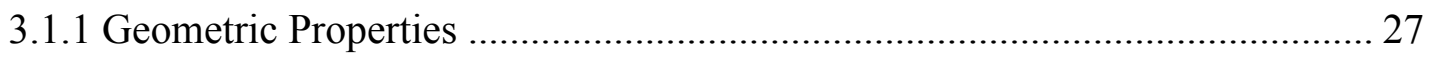

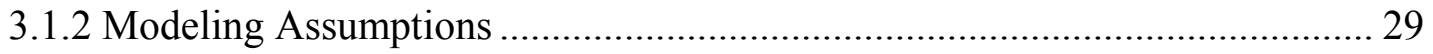

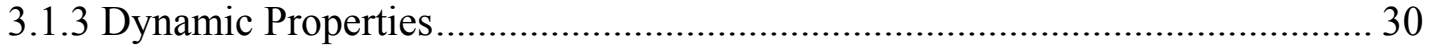

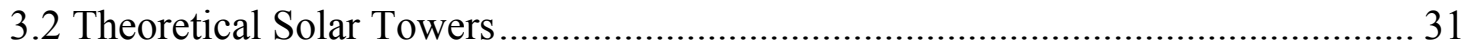




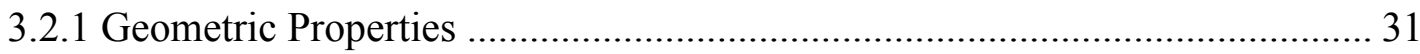

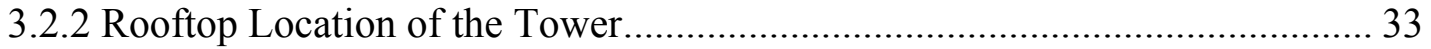

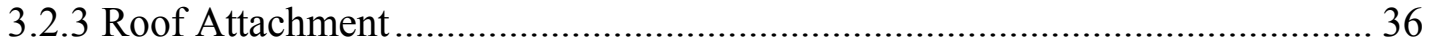

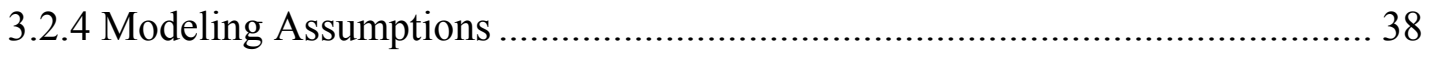

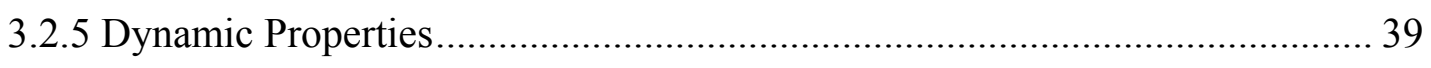

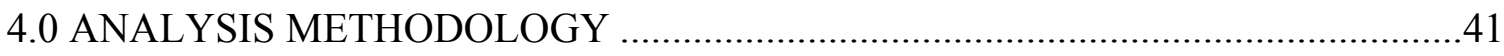

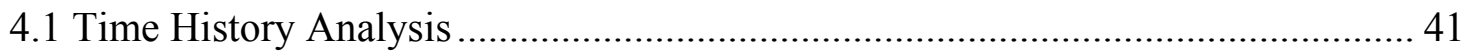

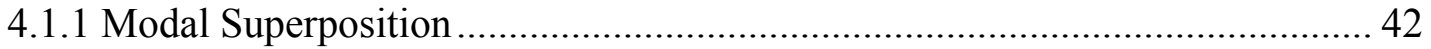

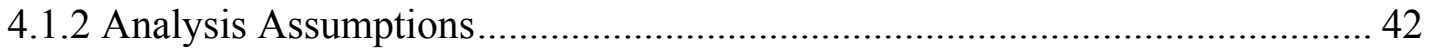

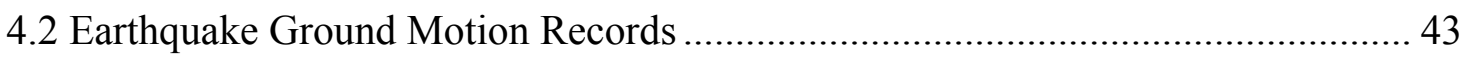

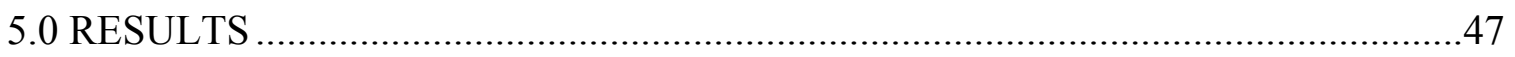

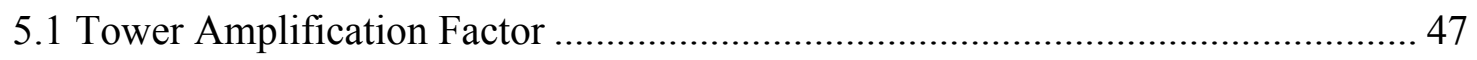

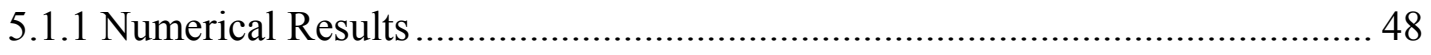

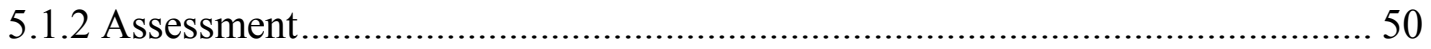

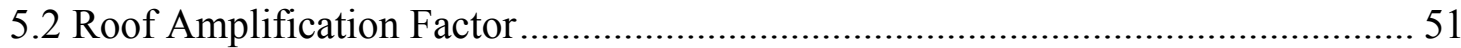

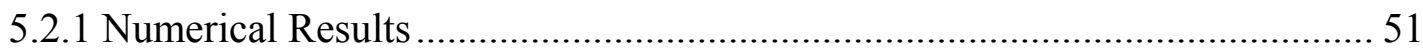

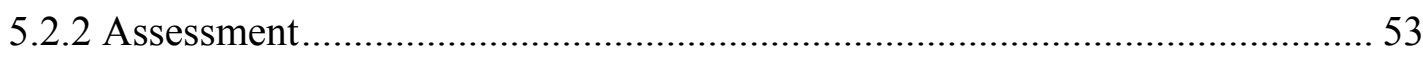

5.3 Proposed Rooftop Solar Tower Amplification Factor .......................................... 54

6.0 CONCLUSIONS AND RECOMMENDED RESEARCH …...............................59

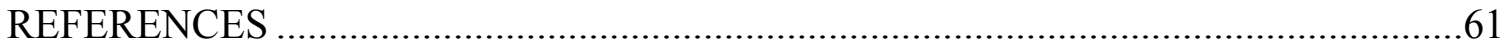

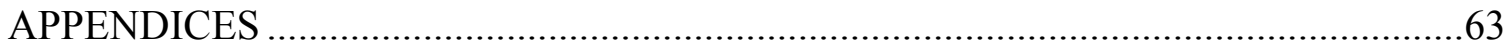

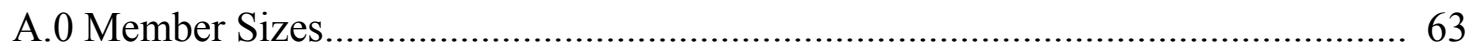

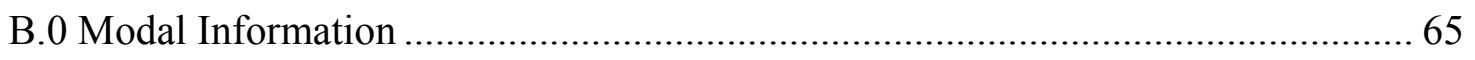

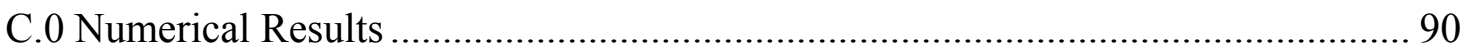




\section{LIST OF TABLES}

Table 1: Values of Approximate Period Parameters $\mathrm{Ct}$ and $\mathrm{x}$...................................... 23

Table 2: Modal Periods and \% Mass Participation of the RECH Building .................... 31

Table 3: Weights of the Three Theoretical Towers ........................................................ 33

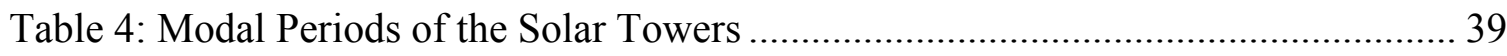

Table 5: Information for Low A/V Ratio Earthquakes Used in the Thesis .................... 45

Table 6: Information for Medium A/V Ratio Earthquakes Used in the Thesis ............... 45

Table 7: Information for High A/V Ratio Earthquakes Used in the Thesis..................... 46

Table 8: Tower Amplification Factor in the U1 Direction .......................................... 48

Table 9: Tower Amplification Factor in the U2 Direction ............................................ 48

Table 10: Roof Amplification Factor in the U1 Direction.......................................... 51

Table 11: Roof Amplification Factor in the U2 Direction........................................... 52 


\section{LIST OF FIGURES}

Page

Figure A: Solar One Project, Mojave Desert, CA …...................................................... 2

Figure B: Example of a Steel Lattice Tower ................................................................. 4

Figure C: Amplification of Accelerations from the Ground Level to the Rooftop .......... 11

Figure D: Typical Mode Shapes for an Idealized Three-Story Building........................ 12

Figure E: Wireframe Model of a Combined Tower/Building Structure......................... 19

Figure F: Alternate Component Amplification Factor for Steel Lattice Towers.............. 22

Figure G: Rosendin Electric Corporate Headquarters, San Jose, California ................... 26

Figure H: Floor and Roof Framing Plans of the RECH Building................................. 27

Figure I: Braced Frame Elevation @ Gridlines A \& D ................................................ 28

Figure J: Braced Frame Elevation @ Gridlines 1, 5, \& 9 ............................................. 28

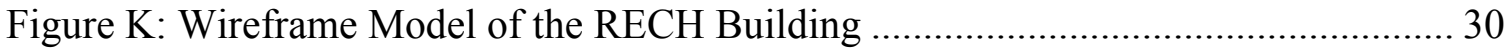

Figure L: Elevation View of Theoretical Solar Towers.............................................. 32

Figure M: Plan Section Cut of Theoretical Solar Towers............................................. 32

Figure N: Tower Location on the Roof of the RECH Building ................................... 33

Figure O: Cosine Effect for Two Heliostats in Opposite Directions from the Tower...... 34

Figure P: Cosine Loss Relative to Heliostat Position ...................................................... 35

Figure Q: The Apparent Path of the Sun across the Sky in the Northern Hemisphere..... 36

Figure R: Plan View of the Platform to Support the Solar Towers ............................... 37

Figure S: Elevation View of the Platform to Support the Solar Towers ......................... 38

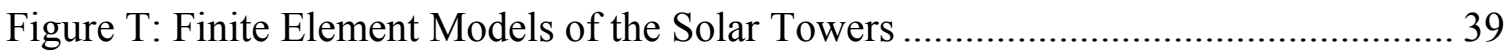

Figure U: Roof Plan View of the RECH Building with the Solar Tower Attached ......... 44

Figure V: Tower Amplification Factor in the U1 Direction ....................................... 49

Figure W: Tower Amplification Factor in the U2 Direction ....................................... 49

Figure X: Roof Amplification Factor in the U1 Direction ........................................... 52

Figure Y: Roof Amplification Factor in the U2 Direction ............................................ 53

Figure Z: Proposed Rooftop Solar Tower Amplification Factor in the U1 Direction ...... 56

Figure AA: Proposed Rooftop Solar Tower Amplification Factor in the U2 Direction... 57 


\section{NOMENCLATURE}

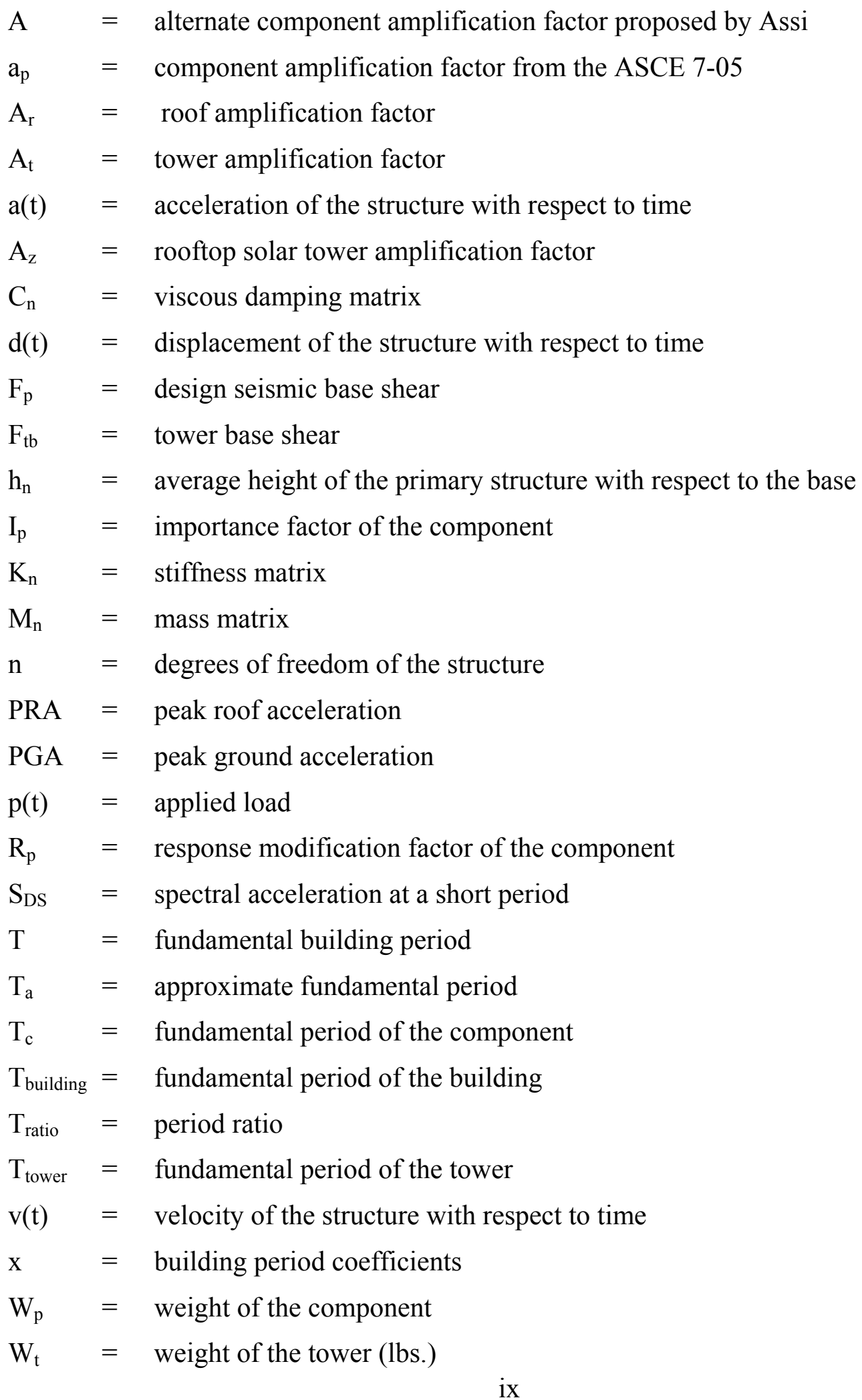


$\mathrm{z}=$ height in the primary structure of the point of attachment of the component with respect to the base

$\mu \quad=$ average

$\sigma=$ standard deviation 


\subsection{INTRODUCTION}

This thesis investigates the seismic amplification effects experienced by a solar tower mounted on the rooftop of an existing low-rise industrial building. Specifically, this investigation uses time history analysis to determine whether amplification factors adopted in current code provisions can adequately approximate these seismic amplification effects.

\subsection{Topic of Thesis}

This investigation provides support for a larger project that explores the implementation of small-scale solar power tower (SPT) facilities in city areas.

\subsubsection{Introduction to Solar Power Tower Systems}

A SPT system, shown in Figure A on page 2, consists of a tall central tower (ranging from 300 feet to 500 feet tall) surrounded by an array of sun-tracking mirrors called heliostats. The heliostats concentrate sunlight to a receiver at the top of the tower. The receiver transfers the thermal energy of the focused sunlight to a heat transfer fluid (HTF). The HTF, either water or molten salt, gets superheated to temperatures between $200^{\circ} \mathrm{C}$ and $1000^{\circ} \mathrm{C}$ (Hicks, 2009). The energy of the superheated HTF is then used to produce steam, which can be utilized directly in steam applications or in turbine engines to produce electricity. 


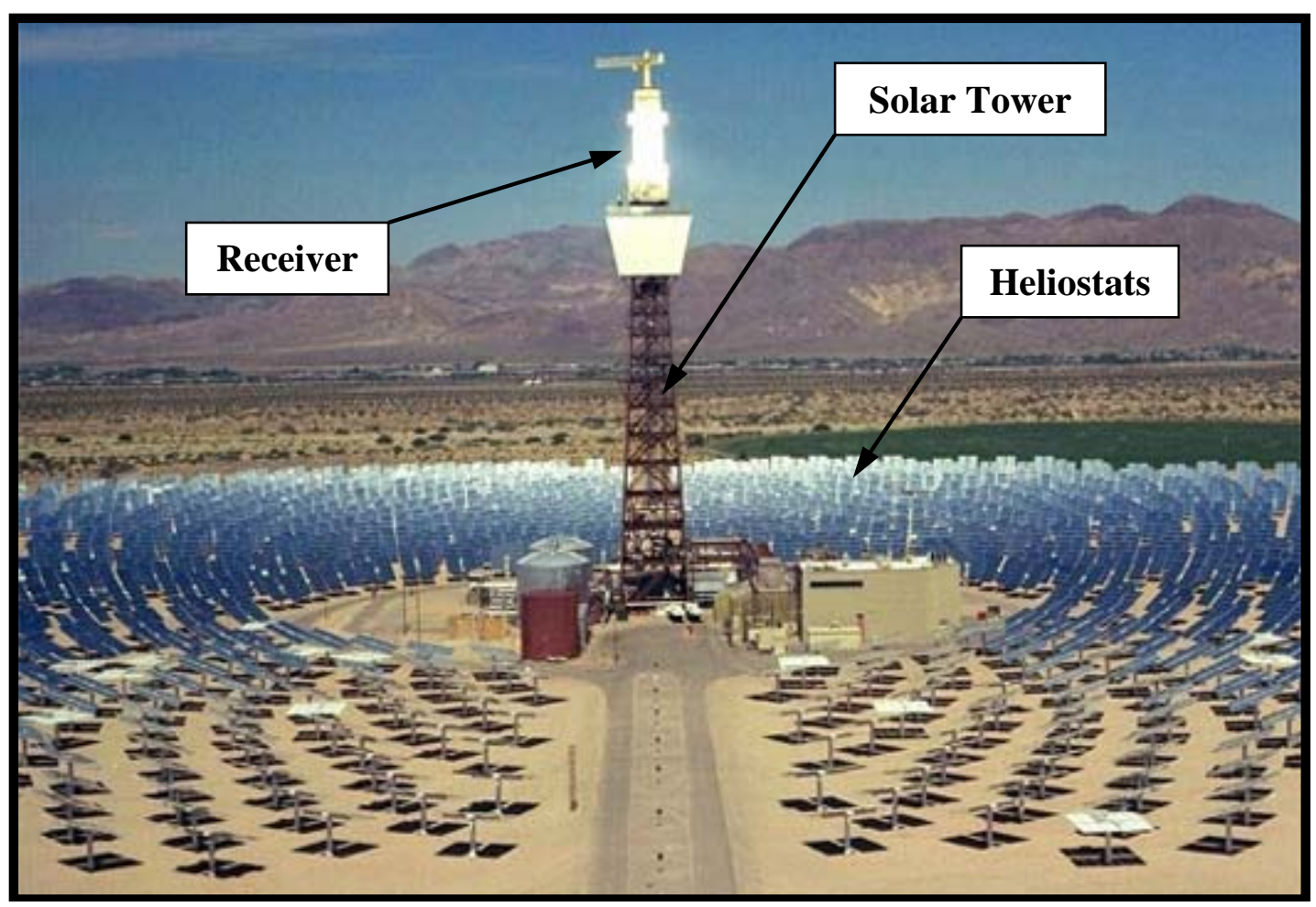

Figure A: Solar One Project, Mojave Desert, CA

(www.greenchipstocks.com, 2013)

\subsubsection{Reason for Solar Power Tower Facilities in City Areas}

Up until now, SPT technology has been developed exclusively in desert areas as large-scale power-plant facilities. Desert areas are favorable locations for SPT facilities because they provide the flat open space with unobstructed sunlight needed for efficient systems. However, developing SPT facilities in desert areas means they are far from consumers in city areas, which leads to several issues. First, any new facility constructed in a desert area requires the construction of miles of new transmission lines in order to distribute the electricity to the existing electrical grids. Second, SPT facilities require large quantities of water for steam production; since water access is limited in dry desert climates, extensive water distribution systems also need to be put into place to sustain facility operations (Solarpaces, 2012). Deploying new SPT facilities in city areas can 
address these issues associated with current SPT locations: electricity can be delivered directly to the existing grid, and water systems already in place are easily accessible. More importantly, bringing SPT facilities closer to buildings allows the steam byproduct to be utilized directly in the buildings for heating and cooling energy demands (Hicks, 2009).

\subsubsection{Reason for Solar Power Towers on Rooftops of Existing Industrial Buildings}

For the implementation of small-scale SPT facilities in city areas, it is advantageous to locate the central tower and heliostat field of the SPT system on the rooftop of an existing industrial building for several reasons (Harding, 2011):

- Attaching the solar tower and heliostat field to the rooftop of an existing building means new property in the city areas doesn't need to be purchased, thus lowering implementation costs.

- The heliostat field can be raised above the shadows of adjacent buildings and trees, allowing more sunlight exposure than if placed on the ground.

- Industrial buildings have large roof surface areas relative to residential housing, allowing a larger heliostat field for more electrical production.

- Industrial buildings, in general, can structurally support the SPT systems without the need for massive upgrades to the existing gravity or lateral loadresisting systems.

- The steam byproduct from the SPT facility can be used for industrial processes such as cleaning, drying, evaporation and distillation, pasteurization, sterilization, and solar absorption cooling (SHC, 2012). 


\subsection{Focus of Thesis}

As a portion of the larger project investigating the implementation of SPT facilities in city areas, this thesis will focus on the seismic design of the central tower of the SPT system. For the purposes of this thesis, the central tower will be referred to as the "solar tower".

\subsubsection{Structural Type for the Roof-Mounted Solar Tower}

The optimal structure type for the roof-mounted solar tower is a four-legged selfsupporting steel lattice tower. Similar to an electrical transmission tower (as shown in Figure B below), a steel lattice tower is a space truss structure made up of individual steel members that are bolted or welded together. The members consist of main legs with horizontal and vertical bracing members typically with tube, circular, or angle cross sections. Steel lattice towers are optimal for roof deployment because they are easy to fabricate and erect. In addition, steel lattice towers are lightweight relative to their height, which minimizes the impact of the additional weight of the tower on the load bearing system of the supporting building.

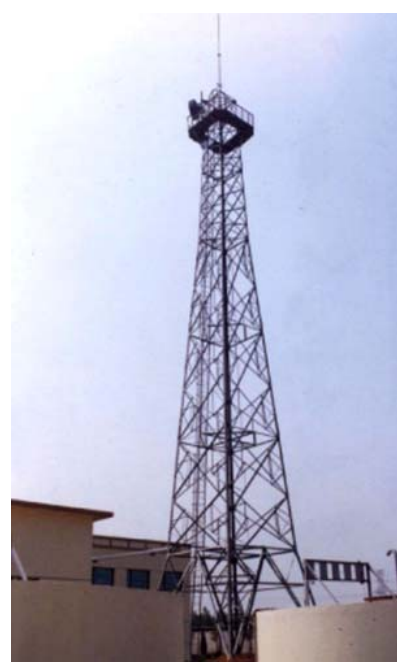

Figure B: Example of a Steel Lattice Tower (www.tradekorea.com, 2013) 


\subsubsection{Design Considerations of Roof-Mounted Solar Towers}

In general, a steel lattice tower is designed to withstand potential earthquake (seismic) and wind forces. For a steel lattice tower attached to the ground, the magnitude of seismic forces experienced by the tower is a function of the tower weight and the acceleration at its base caused by ground shaking during an earthquake; the magnitude of wind force is a function of the wind speed imposed on the vertical surface area along the tower height. Since steel lattice towers are lightweight relative to their height (and have a large vertical surface area), the seismic forces experienced by ground mounted towers tend to be small relative to the wind forces they experience. Therefore, with the exception of towers placed in high seismic hazard areas where large magnitude ground accelerations can occur, the design of steel lattice towers attached to the ground is typically governed by wind forces.

Unlike steel lattice towers attached to the ground, when a roof-mounted tower is exposed to a seismic event, the earthquake accelerations at the ground level are amplified by the dynamic response of the supporting building. In addition, if the fundamental period of the tower closely matches one or more of the periods of the building (a phenomenon called resonance), the dynamic interaction between the tower and building during an earthquake causes further amplification of accelerations at the roof level (at the base of the tower). As a result of these seismic amplification effects, even small magnitude earthquake accelerations at the ground level can lead to large accelerations on the tower at the roof. Therefore, even in low to moderate seismic hazard areas, the seismic forces can exceed those from wind and thus govern tower design. 
The accurate modeling of seismic amplification effects when calculating seismic forces for a roof-mounted tower typically requires a dynamic analysis of the combined tower and building structure to be performed. Dynamic analysis methods such as a modal or time-history analysis, however, can prove to be computationally intensive and time consuming, and often result in high design costs. Since most projects are confined to a tight deadline and cost constraints, simplified methods found in code provisions are employed. However, the simplified code methods available for computing seismic forces for towers are specific to towers attached to the ground and do not address the seismic amplification effects associated with roof attachment (Assi, 2006). Instead, engineers are left to use code provisions devoted to the general category of nonstructural components to determine design-level seismic forces for a roof-mounted tower.

Nonstructural components are defined as "systems and elements housed in or attached to the floors, roofs, and walls of a building but are not part of the main or intended load-bearing structural systems" (Assi, 2006). This definition applies to a number of components attached to buildings, such as mechanical-electrical-plumbing (MEP) equipment (storage tanks, piping, air handlers, pumps, turbines etc.), architectural components (parapets, cladding systems, partitions) and building contents (bookshelves, cabinets, desks, etc.). Other names for nonstructural components include components, secondary systems, building attachments, appendage systems, and non-building components (Villaverde, 1997).

The current code based method for computing design seismic forces for nonstructural components is found in the ASCE 7-05 Minimum Design Loads for Buildings and Other Structures (ASCE 7-05). According to the ASCE 7-05, the design Approximating the Seismic Amplification Effects for Roof-Mounted Solar Towers 
seismic base shear, $\mathrm{F}_{\mathrm{p}}$, for a nonstructural component can be calculated using Equation 1 , below:

$$
\mathrm{F}_{\mathrm{p}}=\frac{0.4 \mathrm{~S}_{\mathrm{DS}} \mathrm{a}_{\mathrm{p}} \mathrm{I}_{\mathrm{P}} \mathrm{W}_{\mathrm{P}}}{\mathrm{R}_{\mathrm{P}}}\left(1+2 \frac{\mathrm{z}}{\mathrm{h}}\right)
$$

where

$$
\begin{aligned}
& \mathrm{S}_{\mathrm{DS}}=\text { spectral acceleration at a short period } \\
& \mathrm{h}=\text { average height of the primary structure with respect to the base } \\
& \mathrm{Z}=\begin{array}{l}
\text { height of component attachment with respect to the base of } \\
\text { the primary structure }
\end{array} \\
& \mathrm{R}_{\mathrm{p}}=\text { response modification factor of the component } \\
& \mathrm{W}_{\mathrm{p}}=\text { weight of the component } \\
& \mathrm{I}_{\mathrm{p}}=\text { importance factor of the component } \\
& \mathrm{a}_{\mathrm{p}}=\text { amplification factor of the component }
\end{aligned}
$$

In Equation 1, the acceleration at the ground level, represented by the quantity $0.4 \mathrm{~S}_{\mathrm{DS}}$, is multiplied by two factors that approximate seismic amplification effects: a floor amplification factor, represented by the quantity $(1+2 \mathrm{z} / \mathrm{h})$, and a component amplification factor, represented by the quantity $\mathrm{a}_{\mathrm{p}}$. To simplify the computation of these amplification factors, several assumptions about the seismic response of the component and building are made (see Section 2.0 Literature Review for a review of the assumptions used to calculate the ASCE 7-05 amplification factors). These assumptions were developed based on empirical research and field observations of the general performance of nonstructural components in past earthquakes. Due to the generalized nature of the assumptions, further analysis is needed to validate the use of these factors in the specific context of steel lattice solar towers mounted on the rooftops of low-rise industrial buildings. 


\subsection{Goal of Thesis}

The goal of this thesis is to assess whether amplification factors adopted by the ASCE 7-05 provide adequate estimates of the seismic amplification effects experienced by roof-mounted steel lattice solar towers mounted on the rooftops of existing low-rise industrial buildings. In addition, alternate amplification factors proposed by Assi in the paper, "Seismic Analysis of Telecommunication Towers Mounted on Building Rooftops," will be investigated. The alternate amplification factors were developed based on the results of time history analyses of electrical transmission towers mounted to the rooftops of buildings in Taiwan (see Section 2.1.2 and Section 2.2.2 for a review of the factors proposed by Assi). This thesis looks to determine whether these alternate amplification factors are more appropriate to use in the context of roof-mounted solar towers than the ASCE 7-05 amplification factors.

As a basis of comparison of those amplification factors, this thesis conducts timehistory analyses of three theoretical solar towers mounted on the roof of a case study building. The time history analyses are conducted in the finite element computer modeling program SAP 2000 v15.1.0 (SAP). In SAP, each combined tower/building structure is modeled and subjected to 30 earthquake ground motion records of varying frequency.

\subsection{Thesis Organization}

This thesis is organized into the following sections:

- Section 2.0 Literature Review reviews the assumptions used to develop the amplification factors adopted by the ASCE 7-05. In addition, the alternate amplification factors proposed by Assi are presented. 
- Section 3.0 Analytical Models presents the geometric and dynamic properties of the three theoretical solar towers and the case study building investigated in this thesis. The assumptions used to generate the finite element models of the tower and building models in SAP are also presented.

- Section 4.0 Analysis discusses the time history analysis assumptions and earthquake records used in this thesis.

- Section 5.0 Results presents results from the time history analyses of the three tower/building models and provides a comparison of the results with the amplification factors adopted by the ASCE 7-05. In addition, modifications to the amplification factors are proposed based on the time history analyses results.

- Section 6.0 Conclusion highlights the conclusions of the thesis research and provides recommendations for areas of future research.

- Section 7.0 References presents the references cited throughout the thesis. 


\subsection{LITERATURE REVIEW}

The current code based method for computing design level seismic forces for nonstructural components is found in the ASCE 7-05 Minimum Design Loads for Buildings and Other Structures (ASCE 7-05). To calculate the design-level seismic forces, the ASCE 7-05 adopts two factors, a floor-level amplification factor and a component amplification factor, to approximate seismic amplification effects associated with building attachment. To simplify the calculation of these factors, the ASCE 7-05 incorporates several assumptions about the seismic response of the component and building. The following sections take a closer look these assumptions and review research relevant to steel lattice solar towers mounted on low rise industrial buildings that investigate these assumptions. In addition, the alternate amplification factors proposed by Assi are presented.

\subsection{Floor-Level Amplification Factor}

The purpose of the floor-level amplification factor adopted by the ASCE 7-05 is to approximate the amplification of seismic accelerations caused by the dynamic response of the building during an earthquake. For simplification, several assumptions about the response of the tower and building are incorporated in the computation of the floor-level amplification factor.

\subsubsection{Assumption \#1: Linear Distribution of Accelerations}

The ASCE 7-05 assumes that seismic accelerations at the ground level are amplified linearly along the height of the building; that is, there is a linear relationship between the peak ground acceleration (PGA) and peak floor amplification (PFA) at the level of component attachment. Figure $\mathrm{C}$ on the next page illustrates the linear relationship between the peak roof acceleration (PRA), PFA, and PGA. The concept of a Approximating the Seismic Amplification Effects for Roof-Mounted Solar Towers 
linear variation of accelerations is primarily associated with the assumptions that (a) the building responds linear-elastically to the earthquake (does not experience inelastic deformations) and (b) the building motion during the earthquake is dominated by its first fundamental mode of vibration. If (a) and (b) are satisfied, the distribution of accelerations will match the first fundamental mode shape of the building. The typical first, second, and third mode shapes of an idealized three-story building are shown on the next page in Figure D. As shown in Figure D, the first fundamental mode shape is approximately linear. The first mode shape is linear because it takes the least energy to force the floors to deflect in the same direction than to force the floors in opposite directions, as is the case for the second and third mode shapes.

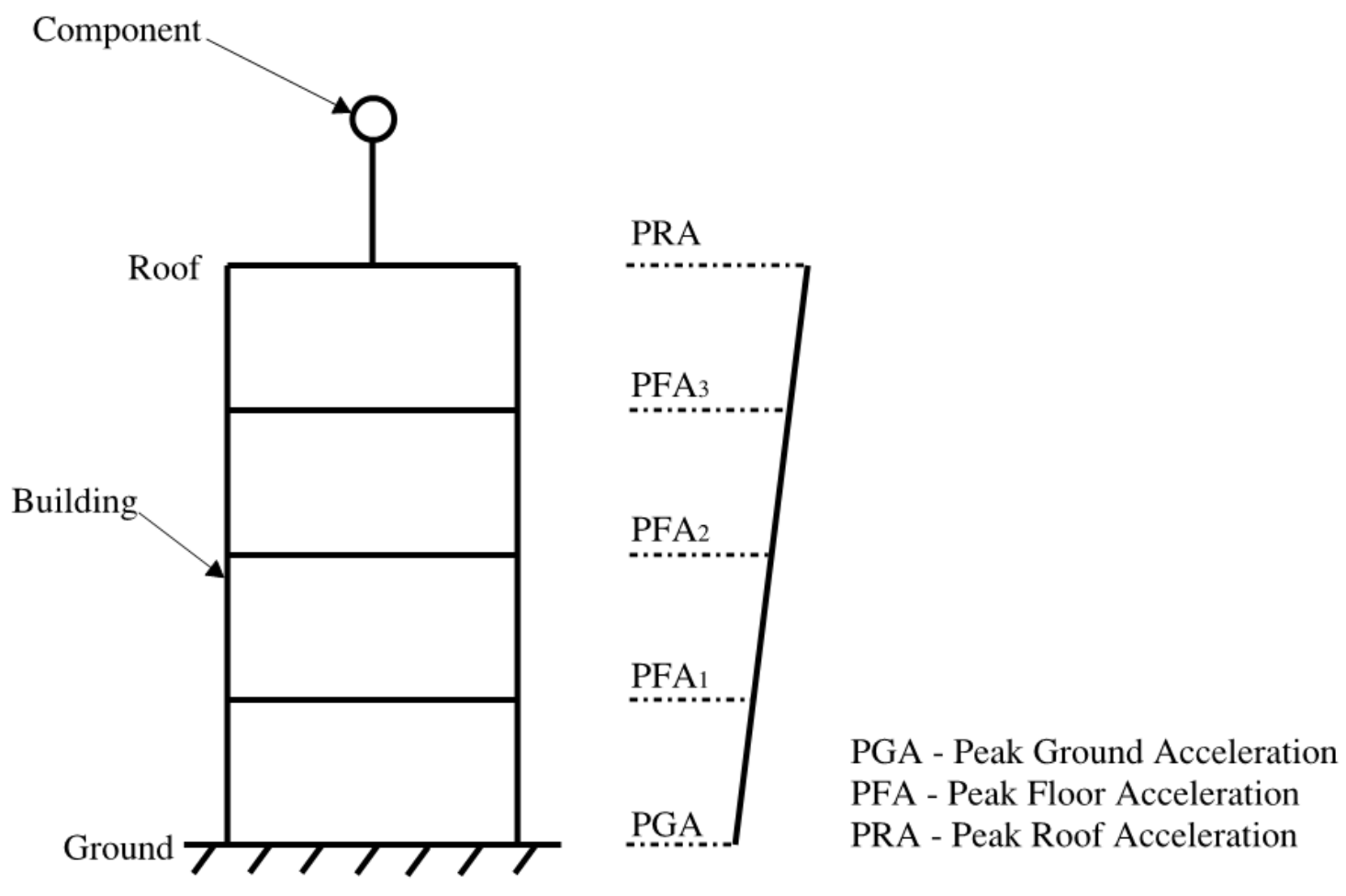

Figure C: Amplification of Accelerations from the Ground Level to the Rooftop 


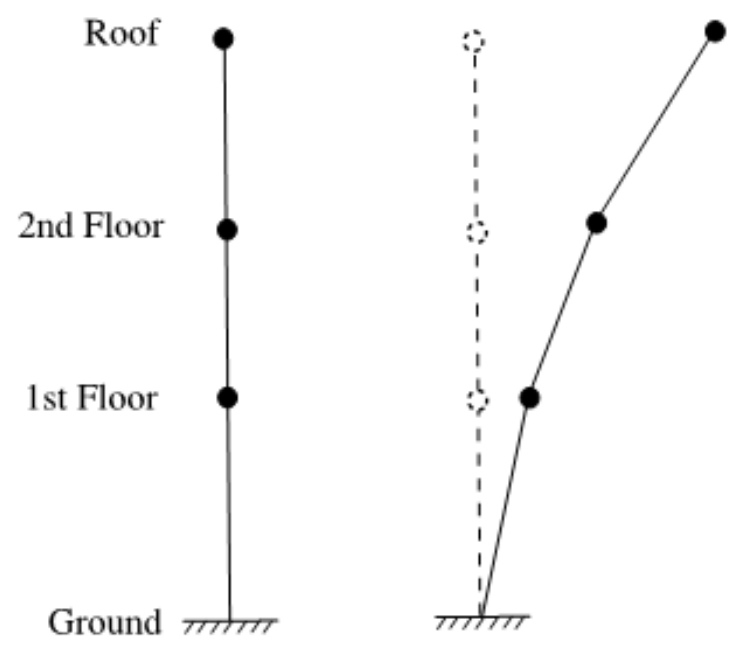

1st Mode Shape

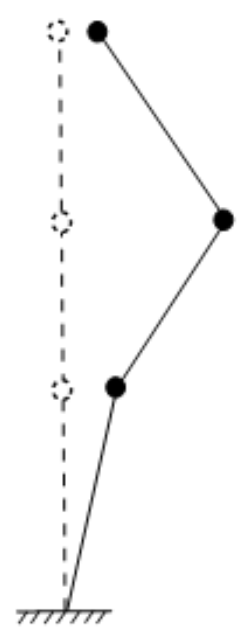

2nd Mode Shape

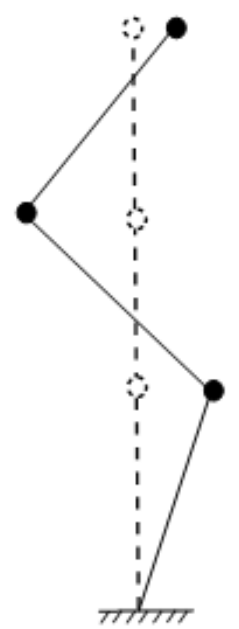

3rd Mode Shape

\section{Figure D: Typical Mode Shapes for an Idealized Three-Story Building}

Several researchers have investigated the acceleration demands in buildings to determine the validity of the linear distribution assumption adopted by the ASCE 7-05. In 2006, Singh used time-history analyses to investigate the distribution of accelerations for buildings of varying heights. In the study, Singh found that while buildings of eight stories or less exhibit a linear variation of accelerations, the same was not true for taller buildings. For buildings taller than eight stories, the acceleration profile was found to be linear for the lower floors, constant for the middle floors, and sharply increased at the top. The sharp increase was attributed to a whiplash effect from higher modes of vibration. The whiplash effect was especially large for irregular buildings (Singh et al., 2006).

A 2011 study by Fathali and Lizundia investigated floor acceleration records from 37 sets of earthquake records obtained from 16 fixed-base buildings; the 37 sets of records were taken from 17 earthquakes that occurred between the 1987 Whittier Earthquake to 2009 Inglewood Earthquake. In the study, Fathali and Lizundia found the 
acceleration distribution assumed by the ASCE 7-05 to be a good fit for the distribution of accelerations in stiff buildings with short periods (fundamental period less than 0.5 seconds). For medium range period buildings (period between 0.5 seconds and 1.5 seconds), however, the acceleration distribution assumed by the ASCE 7-05 was found to be significantly conservative (up to 100\%) for medium-range period buildings (period between $0.5 \mathrm{~s}$ and $1.5 \mathrm{~s}$ ), long-period buildings (period over $1.5 \mathrm{~s}$ ) and tall buildings (Fathali and Lizundia, 2011).

\subsubsection{Assumption \#2: The Floor-Level Amplification Factor at the Roof}

In addition to a linear variation of accelerations assumption, the ASCE 7-05 assumes a floor-level amplification factor of 3.0 for components attached at the roof level; that is, the acceleration at the roof level is assumed to be three times larger than the peak ground acceleration. The floor-level amplification factor of 3.0 for roof-mounted components is illustrated in Equation 1 on page 7 when $\mathrm{z}$ equals $\mathrm{h}$.

The floor-level amplification factor value of 3.0 at the roof level was first introduced into code based on an investigation by Bachman and Drake of over 400 acceleration data sets of buildings in Southern California subject to the 1971 San Fernando earthquake and the 1994 Northridge earthquake. While Bachman and Drake observed floor-level amplification factors at the roof level to be as high as 4.0 in the study, a value of 3.0 was found to represent well the majority of buildings investigated (Bachman and Drake, 1995, 1996).

In 2005, Assi examined roof acceleration records from 11 buildings in Taiwan during the 1999 Chi Chi earthquake to determine the effect that building period had on the expected floor-level amplification factor at the roof level. Upon examination of the 
accelerations records, Assi determined that buildings with fundamental periods less than 0.7 seconds experienced a floor-level amplification factor bounded by a value of 3 . For buildings with fundamental periods between 0.7 seconds and 1.7 seconds, the floor-level amplification factor at the roof was found to fall between the values of 3 and 4 . For buildings with periods larger than 1.7 seconds, the floor-level amplification factor was found to be less than 3 (Assi et al., 2005).

In a follow up study in 2006, Assi used time history analysis to investigate floorlevel amplification factor for the same 11 buildings used in the 2005 study. In the new study, Assi investigated the effects of earthquake frequency on the magnitude of the floor-level amplification factor at the roof level. To investigate the effects of earthquake frequency, Assi selected ground motion records based on their $a / v$ ratio; the $\mathrm{a} / \mathrm{v}$ ratio is defined as the ratio of the peak ground acceleration (PGA) to the peak ground velocity (PGV) of the ground motion record. The correlation between the ground motion a/v ratio and ground motion frequency was introduced in a 1992 paper by Tso titled, "Engineering Implication of Ground Motion A/V Ratio.” According to Tso, earthquake records with high a/v ratios are usually of short duration with seismic energy in the high frequency range; earthquakes with high $\mathrm{a} / \mathrm{v}$ ratios correlated to ground motions close in vicinity to a small or moderate earthquake. Conversely, earthquakes with low a/v ratios usually have long duration with energy in the low frequency range; earthquakes with low a/v ratios correlate with ground motions distant from large earthquakes (Tso et al., 1992). To quantify the effects of frequency content on the amplification factors experienced by the roof-mounted solar tower, Assi used 45 ground motions classified into three categories (15 each category) based on their $\mathrm{a} / \mathrm{v}$ ratio: 
- Low a/v: $\mathrm{a} / \mathrm{v} \leq 0.8 \mathrm{~g} / \mathrm{m} / \mathrm{s}$

- Medium a/v: $0.8 \mathrm{~g} / \mathrm{m} / \mathrm{s}<\mathrm{a} / \mathrm{v}<1.2 \mathrm{~g} / \mathrm{m} / \mathrm{s}$

- High $\mathrm{a} / \mathrm{v}: \mathrm{a} / \mathrm{v} \geq 1.2 \mathrm{~g} / \mathrm{m} / \mathrm{s}$

As a result of the study, Assi found that buildings subjected to high a/v ratio ground motions experienced a floor-level amplification factor bounded by a value of 3.0. For buildings subjected to low or medium $\mathrm{a} / \mathrm{v}$ ratio ground motions, the floor-level amplification factor was instead bounded by a value of 4.0. Due to the difficulty of incorporating the effects of $\mathrm{a} / \mathrm{v}$ ratio into simplified code procedures, Assi suggests that the floor-level amplification factor be increased to a value of 4.0.

\subsubsection{Assumption \#3: Mass Interaction between the Tower and the Building}

According to the ASCE 7-05, the magnitude of acceleration amplification is constant regardless of the weight of the component. In reality, acceleration amplification varies based on the ratio of the weight of the component to the weight of the building, or the mass ratio. The effect of component mass on the magnitude of acceleration amplification is illustrated in a study by Yong and Lin in 1987. Using time history analysis with deterministic and stochastic input earthquake ground motions, Yong and Lin investigated the acceleration amplification experienced by single-degree-of-freedom components mounted on multi-degree of freedom structures. In the study, Yong and Lin found that when the natural period of the component matched the natural period of the building, the magnitude of acceleration amplification decreased as the mass ratio increased; that is, heavier components at resonance with the supporting building experienced smaller acceleration amplification than lighter components. The effect of mass ratio was found to be insignificant, however, when the component period did not 
match the building period; acceleration amplification was equal for all components not at resonance, regardless of the component mass (Yong and Lin, 1987). Results similar to those of Yong and Lin were found by Der Kiureghian (1983), Igusa and Kiureghian (1985), and Newmark (1972) among others.

Despite the results determined by Yong and Lin and others, the computation of the ASCE7-05 floor-level amplification factor doesn't include provisions for a decrease in magnitude resulting from mass interaction between the component and building. Ignoring mass interaction, however, leads to an overestimation of acceleration amplification and thus produces conservative values for the floor-level amplification factor.

\subsubsection{Assessment}

While the studies by Singh and Fathali and Lizundia found the assumption of a linear distribution of acceleration to be conservative for tall and longer period buildings, only solar towers attached to low-industrial buildings are being investigated in this thesis; low-rise industrial buildings, which tend to be stiff with low fundamental periods, were found to exhibit acceleration distributions that were approximated well by a linear approximation. The studies by Bachman and Drake and Assi, however, found floor-level amplification factors at the roof level to be as large as 4.0 , greater than the 3.0 value assumed by the ASCE 7-05. In addition, the study by Yong and Lin found the mass interaction between the tower and building to have a significant effect on acceleration amplification for heavier components when at resonance. Therefore, in Section 5.0 Results, this thesis will take a closer look at the expected floor-level amplification factor 
at the roof level for industrial buildings and will investigate the effect of mass interaction on the acceleration amplification experienced by the solar tower.

\subsection{Component Amplification Factor}

The purpose of the component amplification factor adopted by the ASCE 7-05 is to approximate the amplification of seismic accelerations caused by dynamic interaction between a component and its supporting building. For simplification, the ASCE 7-05 assigns different values of component amplification factor for rigid and flexible components.

\subsubsection{Assumption \#1: Rigid Components}

In general, rigid components experience relatively small deflections along their height during an earthquake and are thus subject to accelerations equal in magnitude to the accelerations at the floor-level of attachment; therefore, rigid components are assigned a component amplification factor of 1.0. Examples of components designated as rigid by the ASCE 7-05 include electrical generators, lighting fixtures, and plumbing, among others (ASCE 7-05); steel lattice towers, however, are not considered rigid components.

\subsubsection{Assumption \#2: Flexible Components}

According to the ASCE 7-05, roof-mounted towers are grouped into the category of flexible components. Unlike rigid components, flexible components experience deflections along their height relative to their base and are thus susceptible to dynamic interaction with their supporting building. Therefore, the ASCE 7-05 assigns a larger component amplification factor of 2.5 for flexible components.

One of the first investigations of roof-mounted transmission towers was conducted by Kimura and Konno in 1973. In their paper titled, "Earthquake Effects on 
Steel Tower Structures Atop Building," investigated the dynamic properties and seismic response 7 electrical transmission towers atop buildings in Japan. First, Kimura and Konno used the results of full-scale measurements in conjunction with forced-vibration and shake table tests of scaled models to determine the natural periods, damping coefficients, and mode shapes of the towers. In addition, Kimura and Konno used time history analysis to determine the magnitude of base shear amplification associated with roof attachment. For the time history analyses, the towers were analyzed as lumped mass single-degree-of-freedom (SDOF) systems attached to the ground and as SDOF systems attached to SDOF building systems. As a result of the time history analysis, Kimura and Konno found that when tower fundamental period matched the building fundamental period, the towers experienced a base shear at the roof level that was 3.5 to 7.0 times larger than the base shear of the tower attached to the ground. This peak amplification 7.0 is comparable to the product of the ASCE 7-05 amplification factors; the product of the ASCE 7-05 floor-level amplification factor (3.0) and component amplification factor (2.5) is 7.5. However, when the tower fundamental period was twice as large as the building fundamental period, the tower acceleration was found to be 1.3 to 2.0 times larger than ground base shear, a value significantly less than the 7.5 factor assumed by the ASCE 7-05 (Konno and Kimura, 1973).

In 2004, McClure used computer modeling in the computer analysis program SAP to perform time history analyses of four tower/building structures subjected to 30 ground motions of varying frequency content. Figure $\mathrm{E}$ on page 19 shows the computer model of a 27 -story concrete frame building supporting a 100 -foot steel lattice tower that was used by McClure. The intent of McClure's study was to explore the correlation between the Approximating the Seismic Amplification Effects for Roof-Mounted Solar Towers 
building accelerations and the maximum seismic base shear on the tower. Similar to the study by Kimura and Konno,, McClure found tower seismic base shear to be greater when its fundamental period was similar to the fundamental period of the supporting building. In addition, McClure found towers with periods that closely matched the building period experienced a larger base shear when the building period also matched the dominant period of the ground motion (McClure et al., 2004). This variation of tower base shear with the matching of tower period, building period, and ground motion period, however, is not reflected in the ASCE 7-05.

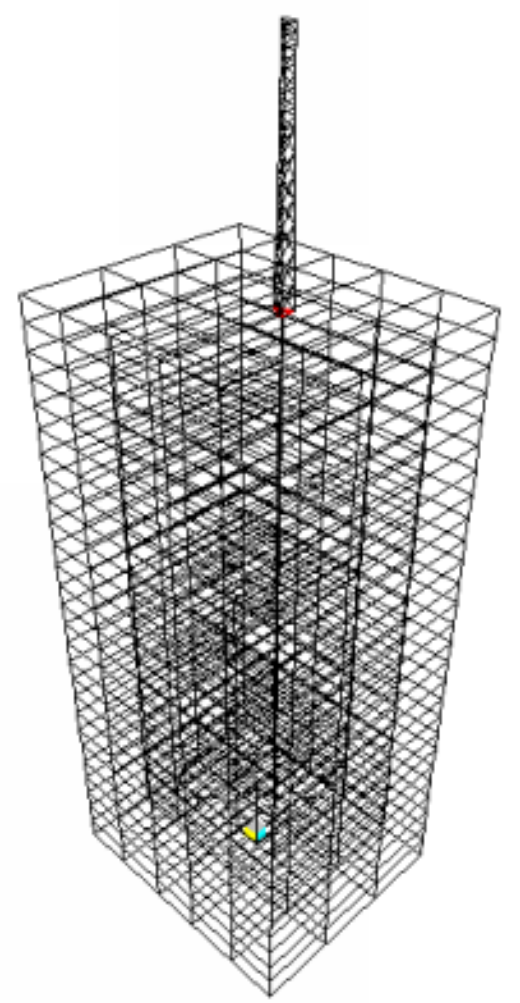

Figure E: Wireframe Model of a Combined Tower/Building Structure (McClure, 2004)

In a follow up to McClure's study, Assi conducted a similar study in 2006 on 16 tower/building combinations ( 4 towers, 4 buildings) subject to 59 ground motions to Approximating the Seismic Amplification Effects for Roof-Mounted Solar Towers 
quantify the amplification factor for electrical transmission towers mounted on buildings located in Taiwan. In the study, Assi calculated pseudo component amplification factor, referred to as the tower amplification factor, for each tower using simple force equal mass time acceleration methodology; the tower amplification factor was determined as the ratio of the total force at the base of the tower, $\mathrm{F}_{\mathrm{bt}}$, to the peak roof acceleration, PRA, and the tower weight, $\mathrm{W}_{\mathrm{t}}$. The calculation of the tower amplification factor is summarized in Equation 2 below:

$$
\mathrm{A}_{\mathrm{t}}=\frac{\mathrm{F}_{\mathrm{tb}}}{\mathrm{W}_{\mathrm{t}} \mathrm{PRA}}
$$

where

$$
\begin{aligned}
& \mathrm{A}_{\mathrm{t}}=\text { tower amplification factor } \\
& \mathrm{F}_{\mathrm{tb}}=\text { tower base shear } \\
& \mathrm{W}_{\mathrm{t}}=\text { weight of the tower } \\
& \text { PRA }=\text { acceleration at the base of the tower }
\end{aligned}
$$

As a result of the investigation, Assi found the towers to experience a component amplification factor bounded by a value of 4.0 when the tower period matched the fundamental building period; when the periods did not match, the component amplification factor was bounded by a value of 1.0 (Assi, 2006). Based on these results, Assi developed an alternate set of equations specific to the context of roof-mounted steel lattice towers to replace the component amplificaiton factor adopted by ASCE 7-05. According to Assi, the alternate component amplification factor, A, for a steel lattice tower attached to the roof of a building can be calculated using Equations 3 through 7 on the next page (Assi, 2006): 


$$
\begin{array}{clc}
\mathrm{A}=1 & \text { for } \mathrm{T}_{\text {ratio }}<0.6 & \text { Eq. } 3 \\
\mathrm{~A}=1+10\left(\mathrm{~T}_{\text {ratio }}-0.6\right) & \text { for } 0.6<\mathrm{T}_{\text {ratio }} \leq 0.9 & \text { Eq. } 4 \\
\mathrm{~A}=4 & \text { for } 0.9<\mathrm{T}_{\text {ratio }} \leq 1.1 & \text { Eq. } 5 \\
\mathrm{~A}=4-30\left(\mathrm{~T}_{\text {ratio }}-1.1\right) & \text { for } 1.1<\mathrm{T}_{\text {ratio }} \leq 1.2 & \text { Eq. } 6 \\
\mathrm{~A}=1 & \text { for } 1.2<\mathrm{T}_{\text {ratio }} & \text { Eq. } 7
\end{array}
$$

where

A $=$ alternate component amplification factor proposed by Assi

$\mathrm{T}_{\text {ratio }}=$ period ratio

$\mathrm{T}_{\text {tower }}=$ fundamental period of the tower

$\mathrm{T}_{\text {building }}=$ fundamental period of the building

Unlike the component amplification factor adopted by the ASCE 7-05, A varies depending on the ratio of the fundamental period of the tower to the fundamental period of the building, or the period ratio, $\mathrm{T}_{\text {ratio. }}$ The variation of $\mathrm{A}$ with respect to $\mathrm{T}_{\text {ratio }}$ is illustrated graphically in Figure $\mathrm{F}$ below. Observing Figure $\mathrm{F}$, when $\mathrm{T}_{\text {ratio }}$ is less than or equal to 0.6 , the tower is assigned an A value of 1.0. Similarly, when $\mathrm{T}_{\text {ratio }}$ is larger than 1.2, $\mathrm{A}$ is also limited to a value of 1.0. When $\mathrm{T}_{\text {ratio }}$ is between a value of 0.9 and $1.1, \mathrm{~A}$ is assigned a maximum value of 4.0. The plateau region where $\mathrm{A}$ is at a maximum (between $\mathrm{T}_{\text {ratio }}$ values of 0.9 and 1.1) is to account for any error associated with calculating the fundamental periods of the tower or building. 


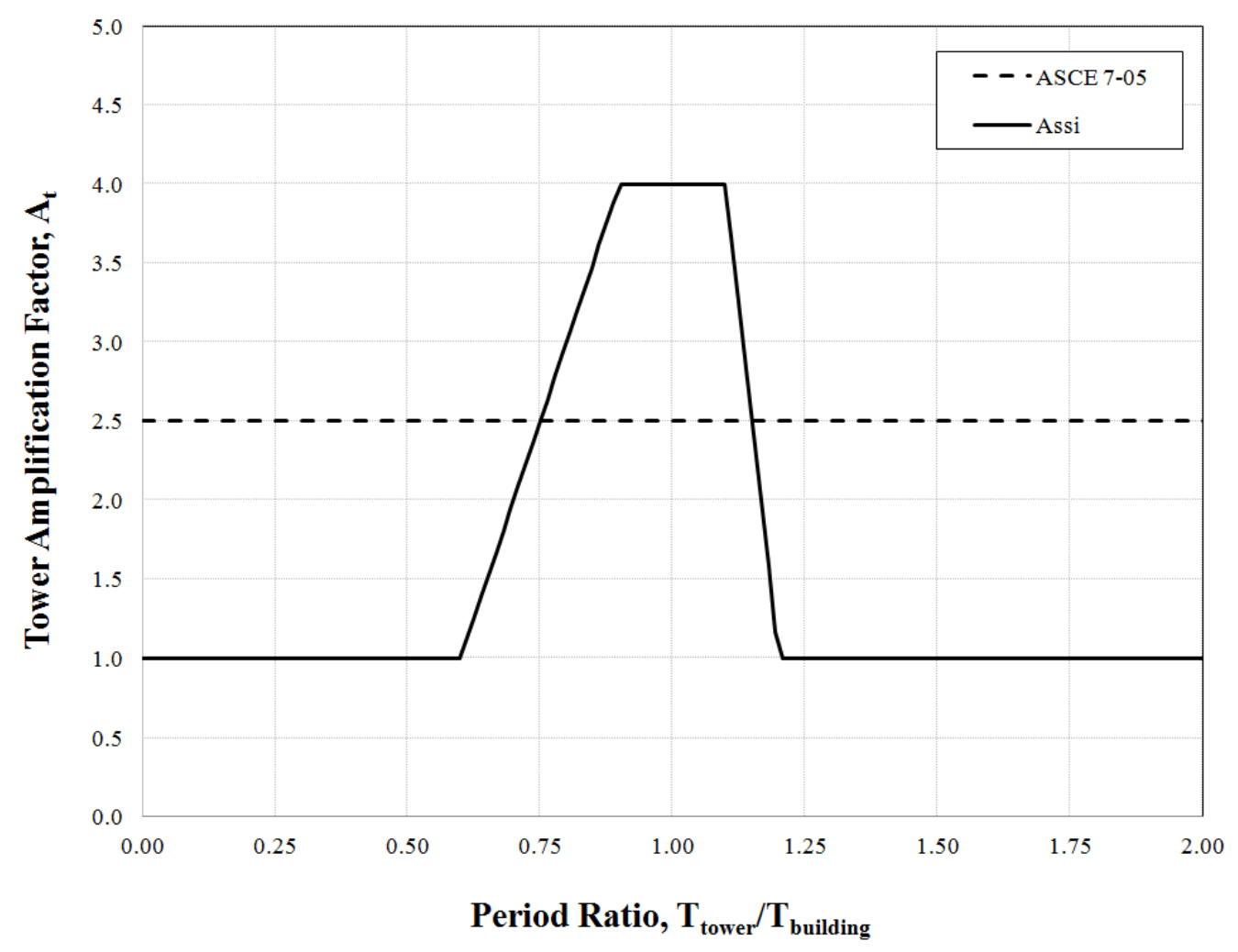

Figure F: Alternate Component Amplification Factor for Steel Lattice Towers (Assi, 2006)

The calculation of A using Equation 3 through 7 depends in large part on the ability to accurately calculate the fundamental period of the building and the tower. For low-rise industrial buildings with regular floor plans, the fundamental period can be approximated using equations within the ASCE 7-05. According to the ASCE 7-05, the approximate fundamental period, $\mathrm{T}_{\mathrm{a}}$, can be calculated using Equation 8 on the next page:

$$
\mathrm{T}_{\mathrm{a}}=\mathrm{C}_{\mathrm{t}} \mathrm{h}_{\mathrm{n}}^{\mathrm{x}}
$$

where

$$
\begin{aligned}
& \mathrm{Ta} \quad=\text { approximate fundamental period } \\
& \mathrm{hn} \quad=\text { height above the base to the highest level of the structure } \\
& \mathrm{Ct} \quad=\text { building period coefficient (found in Table } 1) \\
& \mathrm{x} \quad=\text { building period coefficient (found in Table } 1)
\end{aligned}
$$




\begin{tabular}{|l|c|c|}
\hline Structural Type & Ct & $\mathbf{X}$ \\
\hline $\begin{array}{l}\text { Moment-resisting frame systems in which the } \\
\text { frames resist } 100 \% \text { of the required seismic force } \\
\text { and are not enclosed or adjoined by components } \\
\text { that are more rigid and will prevent the frames } \\
\text { from deflecting where subjected to seismic forces: }\end{array}$ & & \\
\hline Steel Moment Resisting Frames & 0.028 & \\
& $(0.0724)^{\mathrm{a}}$ & 0.8 \\
\hline Concrete moment-resisting frames & 0.016 & 0.9 \\
& $(0.0466)^{\mathrm{a}}$ & \\
\hline Eccentrically braced steel frames & 0.03 & 0.75 \\
& $(0.0731)^{\mathrm{a}}$ & \\
\hline All other structural systems & 0.02 & 0.75 \\
& $(0.0488)^{\mathrm{a}}$ & \\
\hline
\end{tabular}

${ }^{\mathrm{a}}$ Metric equivalents are shown in parentheses.

Table 1: Values of Approximate Period Parameters Ct and $x$ (ASCE 7-05)

For more complex buildings that are non-regular (asymmetric geometries, asymmetric lateral force resisting systems) and/or taller (above 8 stories), however, the formula in Equation 8 become less accurate. Therefore, a more detail analysis approach, such as a modal analysis, is necessary to calculate the fundamental period for complex buildings.

In addition to the fundamental period of the building, the fundamental period of the tower is also required to calculate A. Several researchers have proposed simplified formulas for calculating the fundamental period for steel lattice towers. In a paper titled, “Seismic Response of 4 Supporting Telecommunication Towers," Amiri developed empirical formulas that calculated the first three modal periods for steel lattice transmission towers based on the overall height of the tower (Amiri et al., 2007). More advanced formulas were proposed by Sackmann in a paper titled, "Prediction of natural frequencies and mode shapes of self-supporting lattice telecommunication towers." The Approximating the Seismic Amplification Effects for Roof-Mounted Solar Towers 
formulas proposed by Sackmann incorporated additional tower properties such as bracing type, module height, and base width (Sackmann, 1996).

The formulas developed by Amiri and Sackmann, however, are specific to transmission tower attached to rigid ground. Unlike transmission towers attached to the ground, roof mounted solar towers experience period lengthening due to added flexibility at its base provided by the roof members supporting the tower. In addition, solar towers experience additional period lengthening due to added weight on the tower, such as a 4000 pound receiver at the top of the tower. Since the methods proposed by both Amiri and Sackmann do not account for these period lengthening effects, they can underestimate the fundamental period of a roof mounted solar tower. Therefore, determining an accurate solar tower period requires a more detail analysis approach, such as modal analysis using a computer software program, where additional weight and roof framing members can be modeled. To avoid calculating the fundamental periods of the building and tower altogether, the tower can be assumed to be at resonance with the building (assume a period ratio of 1.0) and the maximum value 4.0 can be used in the computation of tower earthquake forces.

\subsubsection{Assessment}

The studies by Kimura and Konno, McClure, and Assi, illustrate the fundamental issues with using the ASCE 7-05 component amplification factor to approximate dynamic interaction for a roof-mounted steel lattice tower. First, the aforementioned studies show that the magnitude of amplification is not constant for all towers; rather, it varies depending on the fundamental periods of the tower and building. In addition, the study by Assi shows that the component amplification factor for a roof-mounted tower 
can reach magnitudes larger than the 2.5 value assumed by the ASCE 7-05. Due to the discrepancies in amplification factor between the ASCE 7-05 and the analytical studies of rooftop steel lattice towers, a more accurate definition of component amplification factor is needed. A new factor proposed by Assi could provide a viable alternative to the ASCE 7-05 factor. Section 5.0 Results of this thesis will investigate the validity of both the component amplification factor adopted by the ASCE 7-05 and the alternate component amplification factor proposed by Assi through a comparison with numerical results from the time history analysis. 


\subsection{ANALYTICAL MODELS}

As a basis of comparison, this thesis investigates three theoretical solar towers attached to the rooftop of a case study building. Detailed 3D computer models of the three solar towers and the building were generated in the computer analysis program SAP 2000 version 15.1.0 (SAP). The following sections present the geometric and dynamic properties of the case study building and solar towers as well as the assumptions used to generate their computer models.

\subsection{Case Study Building}

The case study building used for this thesis investigation is the Rosendin Electric Corporate Headquarters (RECH) building located in San Jose, California. The RECH building is shown below in Figure G.

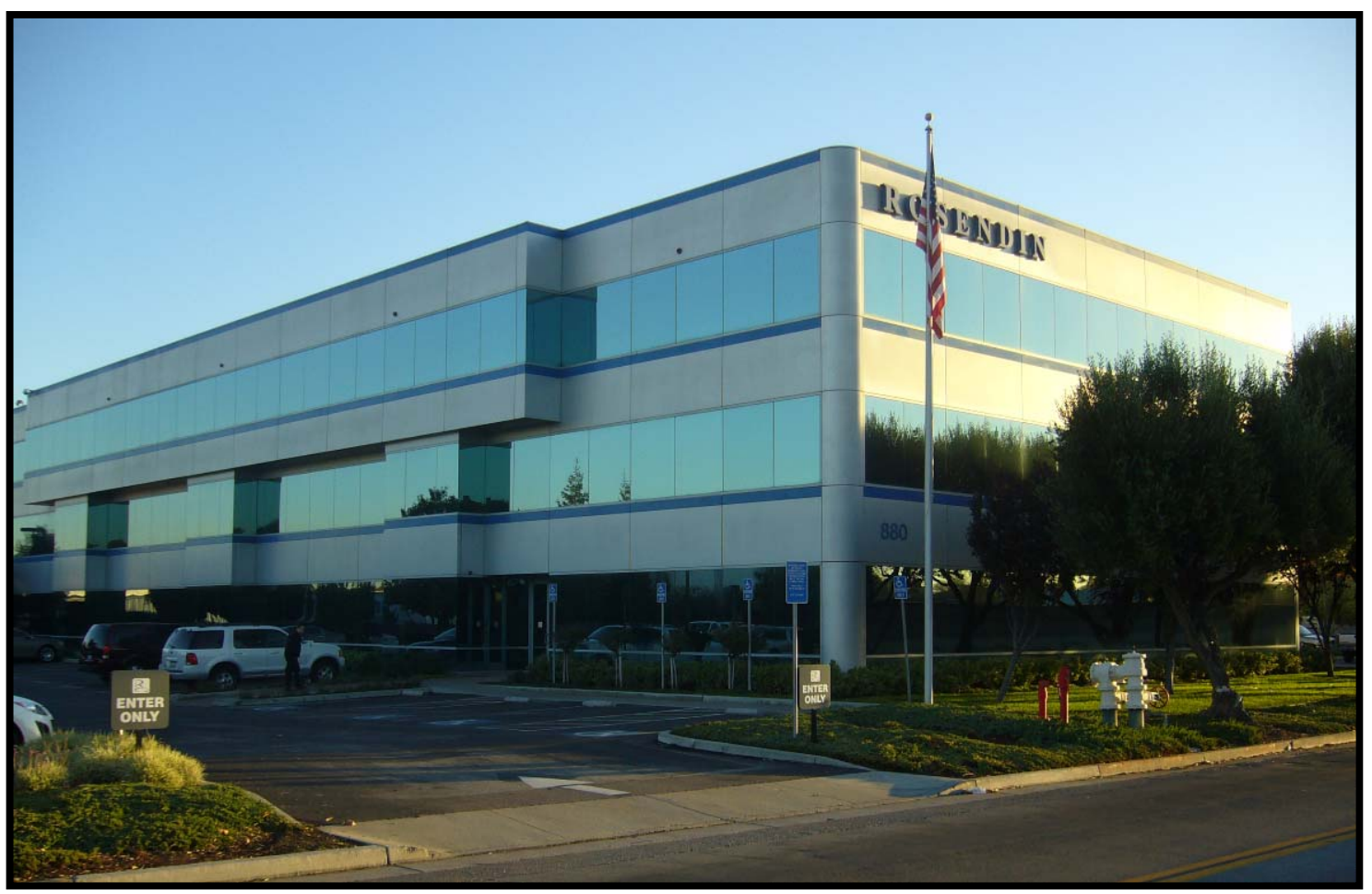

Figure G: Rosendin Electric Corporate Headquarters, San Jose, California 


\subsubsection{Geometric Properties}

The RECH building is a 40,000 square-foot rectangular steel building. The building consists of three stories with heights of $12^{\prime}-6^{\prime \prime}$ each. Each floor of the building is 184 feet by 74 feet in plan and consists of a $4 \frac{1 / 2}{2}$ normal weight concrete topping over a W3 metal deck supported by W-flange beams and girders. The main lateral force resisting systems (LFRS) in both orthogonal directions consist of steel braced frames. The foundation system of the RECH building consists of individual spread footings for the gravity columns and spread footing connected by grade beams at the base of the braced frame columns. A framing plan and elevations of the building are shown in Figures $\mathrm{H}$ below and Figure I and J on page 27. In Figure H through Figure J, gravity members are represented by thin black lines and braced frame members are represented by thick black lines (see section A.0 of the Appendix for gravity and braced frame member sizes).

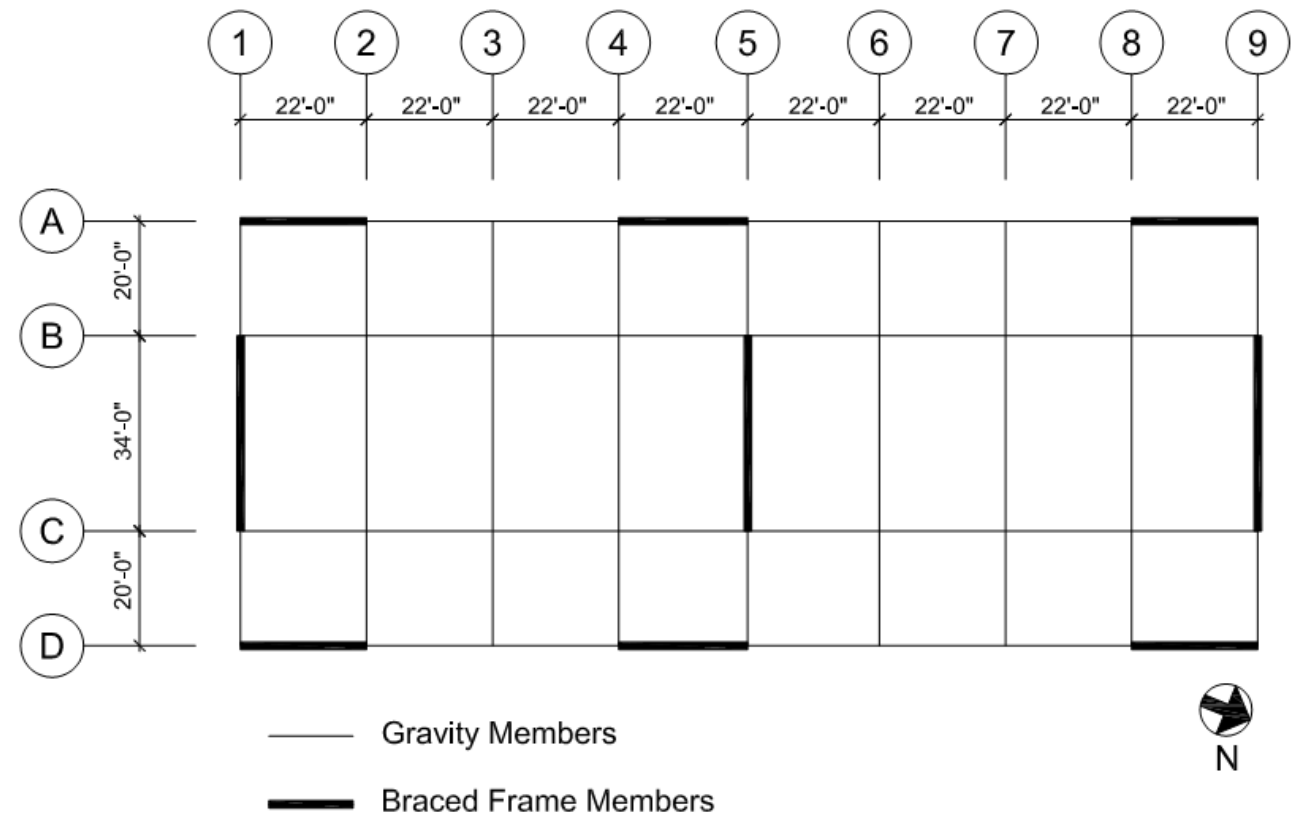

Figure H: Floor and Roof Framing Plans of the RECH Building 


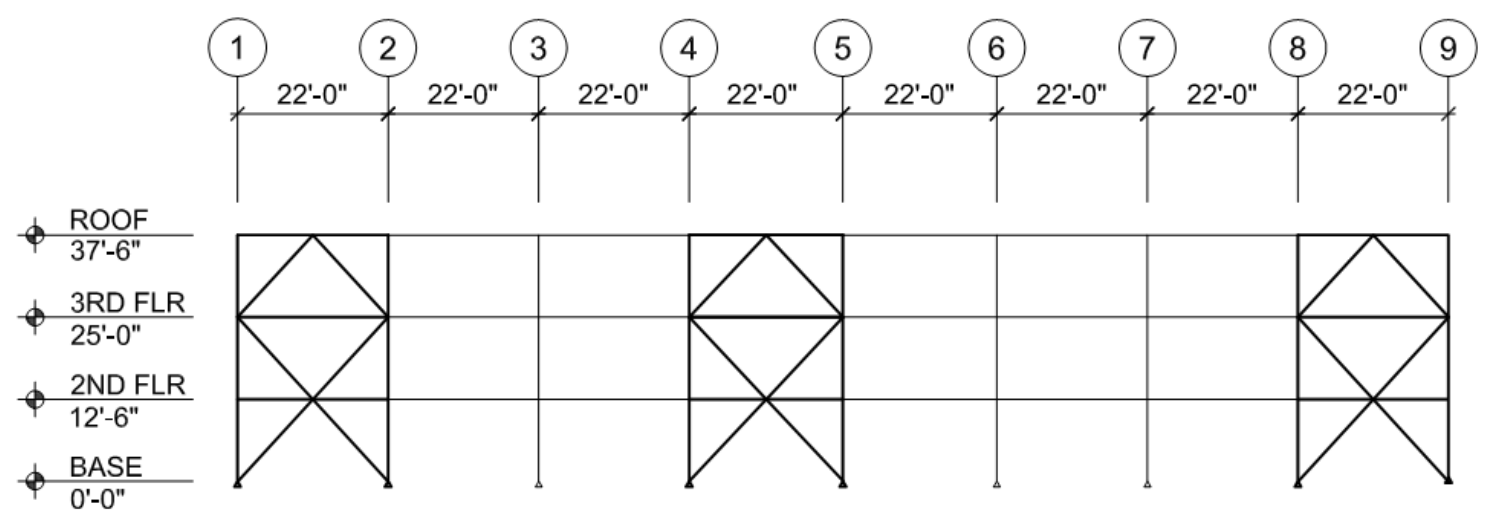

Figure I: Braced Frame Elevation @ Gridlines A \& D

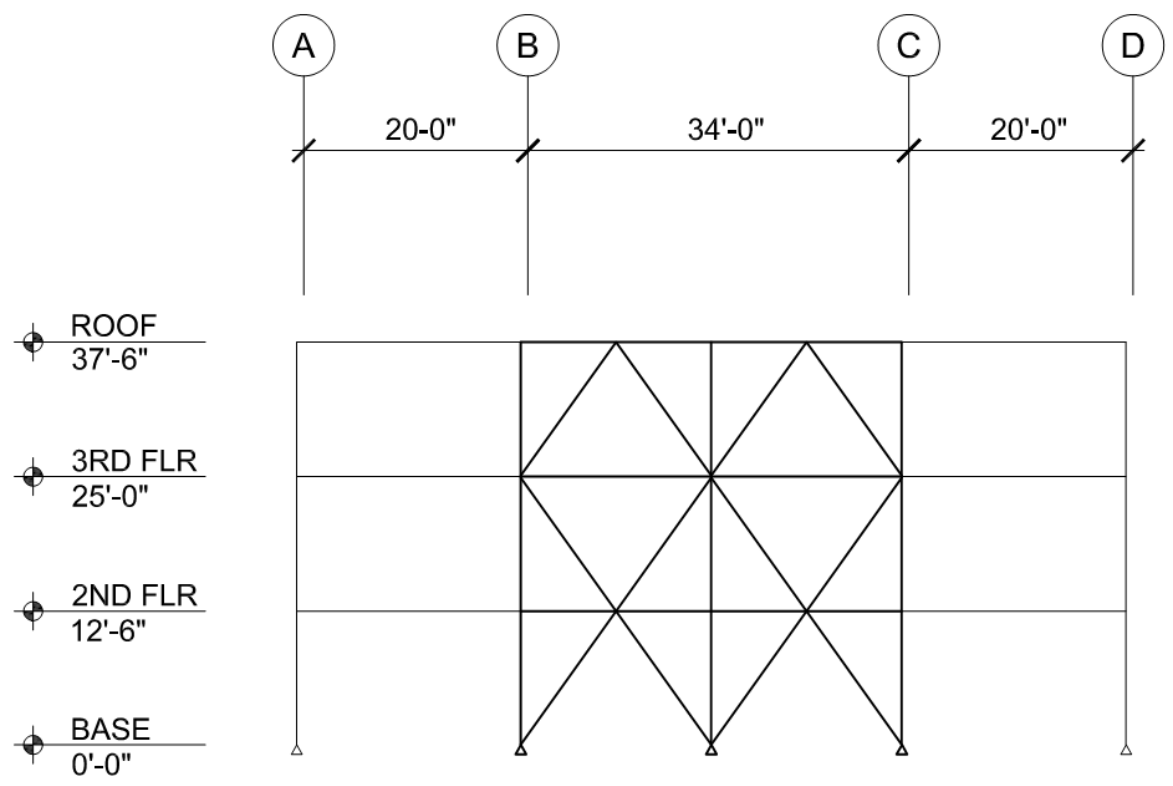

Figure J: Braced Frame Elevation @ Gridlines 1, 5, \& 9

Observing Figure I and Figure J, a chevron brace type is used at the first and third floors while a "V" brace type is used at the second floor. This combined chevron and "V" brace configuration allows for a continuous load path of the lateral seismic force from upper-floor brace directly to the brace on the floor below it, instead of through the floor beam; the floor beam can then be assigned a lighter member size since it is not counted on to transfer the entire load from the floor above it to the brace. The chevron and "V" 
brace configuration is also advantageous because it allows for doorways and corridors through the exterior bracing lines at the first floor and through the interior brace line (along gridline 5) at all floors. This additional interior bracing line along gridline 5 is incorporated in the design of the LRFS to cut down on the diaphragm aspect ratio in the long direction of the building.

Although the RECH building is an office building, it has geometric properties similar to those of typical industrial buildings, including

- a large roof surface-area (13,500 square-feet) capable of supporting a small-scale heliostat field,

- regular and symmetric floor and roof plans,

- symmetric LFRS layouts,

- less than five building stories.

\subsubsection{Modeling Assumptions}

To begin the study, a three-dimensional computer model of the RECH building was generated in SAP without the towers attached to the roof. Figure $\mathrm{K}$ on page 30 shows a wireframe model of the RECH building. The floors and roof of the building were modeled as rigid diaphragms. A uniform surface pressure of 60 pounds-per-square-foot (psf) was applied at each level to account for the seismic weights of the decks, beams, columns, walls, floor finishes, and MEP (mechanical, electrical, and plumbing) equipment; the $60 \mathrm{psf}$ surface pressure at the roof level includes a $5 \mathrm{psf}$ surface pressure for additional weights of the heliostat field. At the ground level, the column supports were modeled as pinned and the foundations were assumed to be rigid enough such that the soil-structure interaction was neglected. 


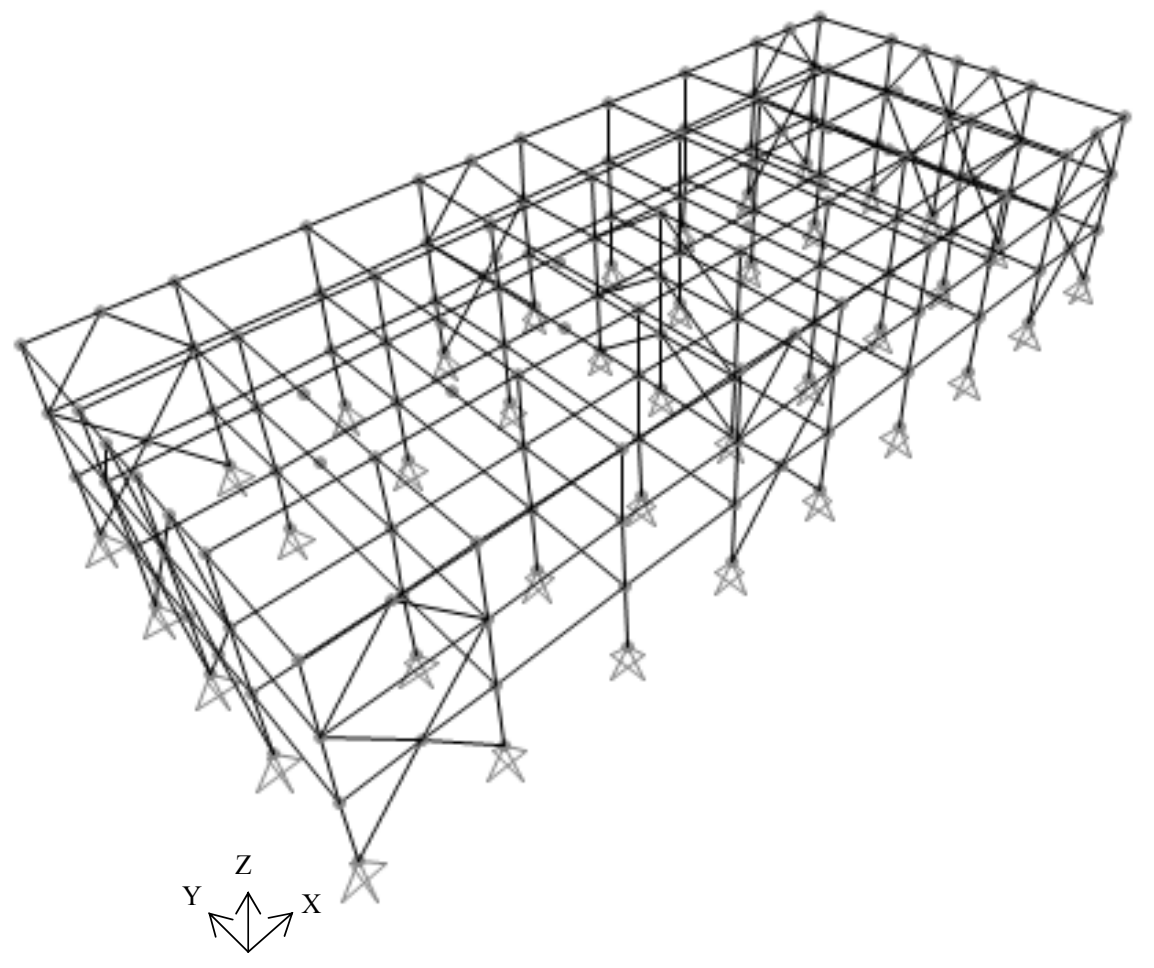

Figure K: Wireframe Model of the RECH Building

\subsubsection{Dynamic Properties}

Next, a dynamic analysis using modal superposition was performed in SAP to determine the dynamic properties of the RECH building. Table 2, on the next page, lists the modal periods and mass participation resulting from the dynamic analysis (see section B.0 of the Appendix for mode shapes of the RECH building). In Table 2, modes 1, 4, and 7 represent the first, second, and third sway (translational) modes in the Y direction; modes 2,5 , and 8 represent the first, second, and third sway modes in the X direction; and modes 3, 6, and 9 represent the first, second, and third rotational modes about the $\mathrm{Z}$ (vertical) axis. The values in Table 2 show the periods and mass participation of the RECH building are consistent with values expected for low-rise industrial buildings. As is typical for most industrial buildings, the first sway modes of the RECH building are 
found at low periods in both orthogonal directions: 0.36 seconds in the UY direction and 0.33 seconds in the UX direction. In addition, the modal response of the RECH building is dominated by its fundamental modes of vibration, with over $80 \%$ mass participation accounted for in the first fundamental modes in the UX, UY, and RZ directions.

\begin{tabular}{|c|c|c|c|c|}
\hline \multirow{2}{*}{} & \multirow{2}{*}{ Period (s) } & \multicolumn{3}{|c|}{ \% Mass Participation } \\
\cline { 3 - 5 } & & UX & UY & RZ \\
\hline \hline Mode 1 & 0.36 & - & 88.4 & - \\
\hline Mode 2 & 0.33 & 81.2 & - & - \\
\hline Mode 3 & 0.25 & - & - & 85.5 \\
\hline Mode 4 & 0.14 & - & 9.8 & - \\
\hline Mode 5 & 0.13 & 15.0 & - & - \\
\hline Mode 6 & 0.10 & - & - & 11.8 \\
\hline Mode 7 & 0.09 & - & 1.8 & - \\
\hline Mode 8 & 0.08 & 3.8 & - & - \\
\hline Mode 9 & 0.06 & - & - & 2.6 \\
\hline \hline$\Sigma$ & - & 100.0 & 100.0 & 100.0 \\
\hline
\end{tabular}

Table 2: Modal Periods and \% Mass Participation of the RECH Building

\subsection{Theoretical Solar Towers}

The theoretical solar towers used for this thesis investigation are four-legged steel lattice towers of heights 42,60 , and 78 feet. These solar towers are significantly smaller in scale than the solar towers found in typical solar power tower facilities, which range from 300 to 500 feet tall.

\subsubsection{Geometric Properties}

Each tower has an $8^{\prime}-0^{\prime \prime}$ by $8^{\prime}-0^{\prime \prime}$ square base and a $6^{\prime}-0^{\prime \prime}$ module height. For simplicity, L4x4x1/2 steel angles are used for all tower members (main legs, horizontal braces, vertical braces). At the top of each tower is a 4000-pound central receiver. Plan and elevation views of the towers are shown in Figures $\mathrm{L}$ and $\mathrm{M}$ on page 31. Table 3 on 
page 32 summarizes the weights of the towers. The listed weights of each tower combine the weight of the tower itself plus an additional $5 \%$ for member connections.

4000 lb. Central Receiver (typical all towers)

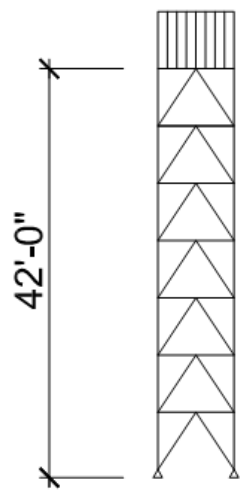

Tower 1

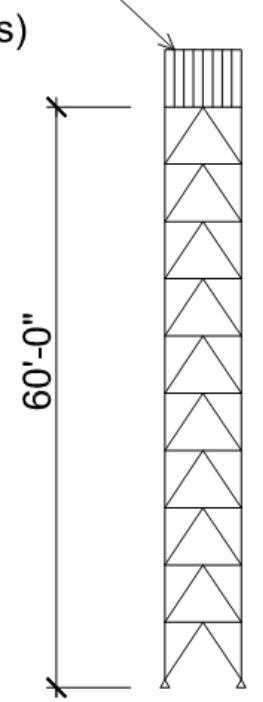

Tower 2

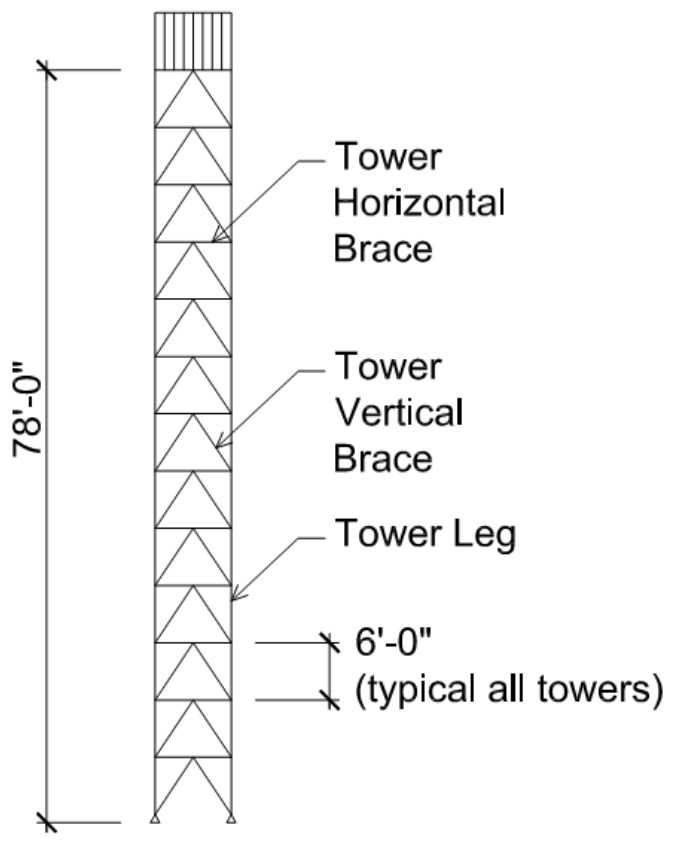

Tower 3

Figure L: Elevation View of Theoretical Solar Towers

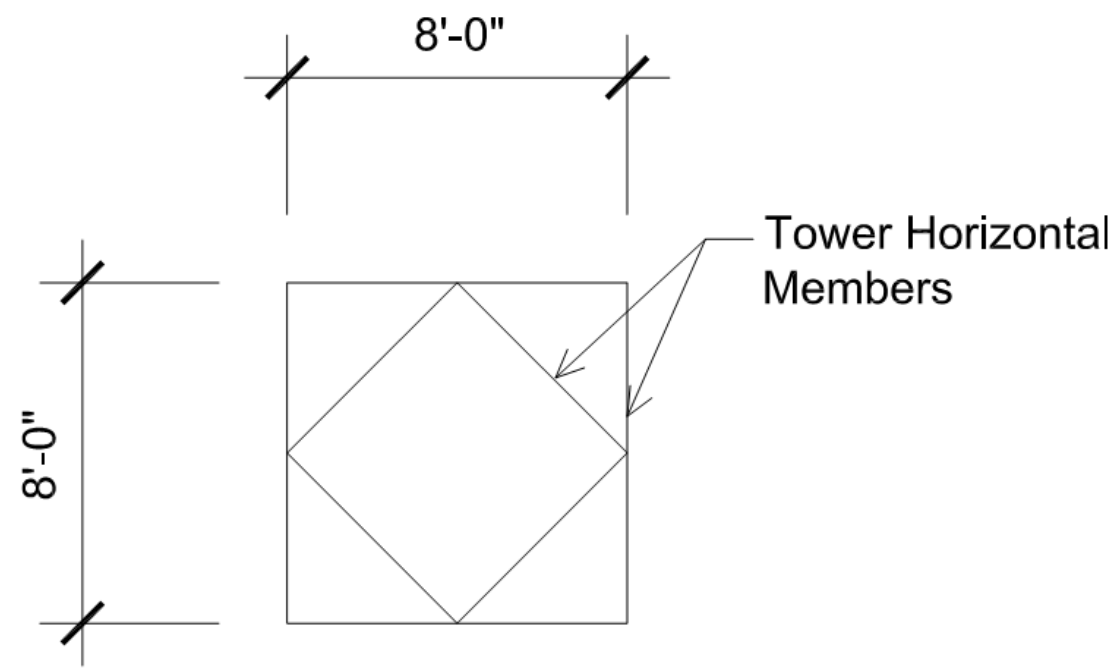

Figure M: Plan Section Cut of Theoretical Solar Towers 


\begin{tabular}{|c|c|c|}
\hline Tower ID & $\begin{array}{c}\text { Weight w/out } \\
\text { Receiver } \\
{[\mathrm{lbs}]}\end{array}$ & $\begin{array}{c}\text { Weight w/ } \\
\text { Receiver } \\
{[\mathrm{lbs}]}\end{array}$ \\
\hline \hline Tower 1 & 14,200 & 18,200 \\
\hline Tower 2 & 20,300 & 24,300 \\
\hline Tower 3 & 26,400 & 30,400 \\
\hline \hline
\end{tabular}

Table 3: Weights of the Three Theoretical Towers

\subsubsection{Rooftop Location of the Tower}

The solar towers are located in the south portion of the RECH building rooftop, between gridlines $1 \& 2$ and A \& B (Figure $\mathrm{N}$ below).

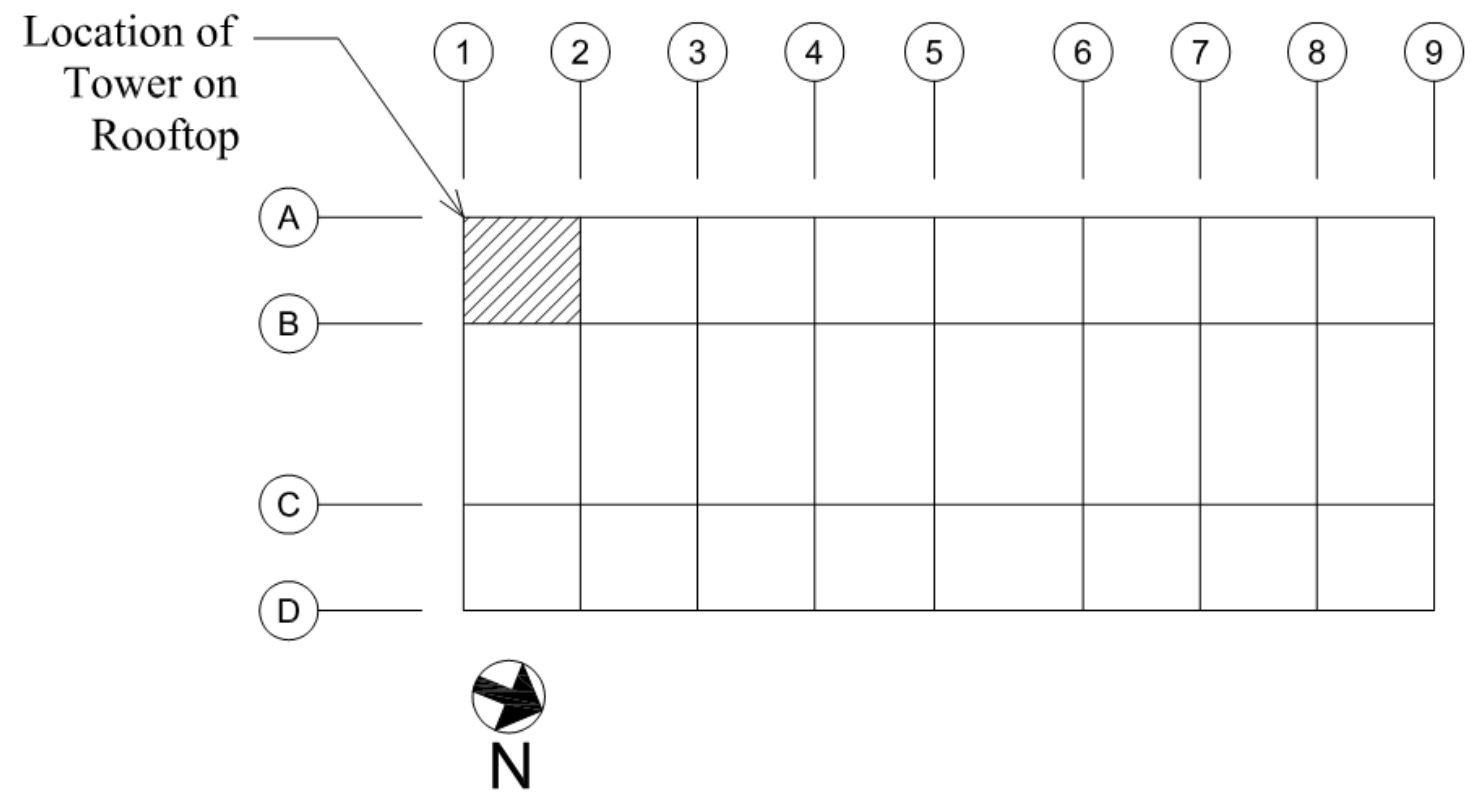

Figure N: Tower Location on the Roof of the RECH Building 
The towers are located in the south portion of the RECH roof in order to achieve maximum heliostat efficiency. The efficiency of a heliostat depends on its ability to reflect sunlight to the central receiver at the top of the solar tower; the more sunlight reflected to the receiver, the more electricity produced by the solar tower facility. The amount of sunlight reflected to the central receiver depends on both the sun path through the day and the location of the individual heliostats relative to the tower. The tilt of the heliostat is positioned and controlled by a tracking mechanism that maintains surface normal of the heliostat in a position that bisects the angle between the sun's rays and a line from the heliostat to the tower. The effective reflection area of the heliostat is reduced by the cosine of one-half of this angle. This effect can be visualized by considering two heliostats at two positions in a field, as shown in Figure $\mathrm{O}$ below, and Figure $\mathrm{P}$ on the next page.

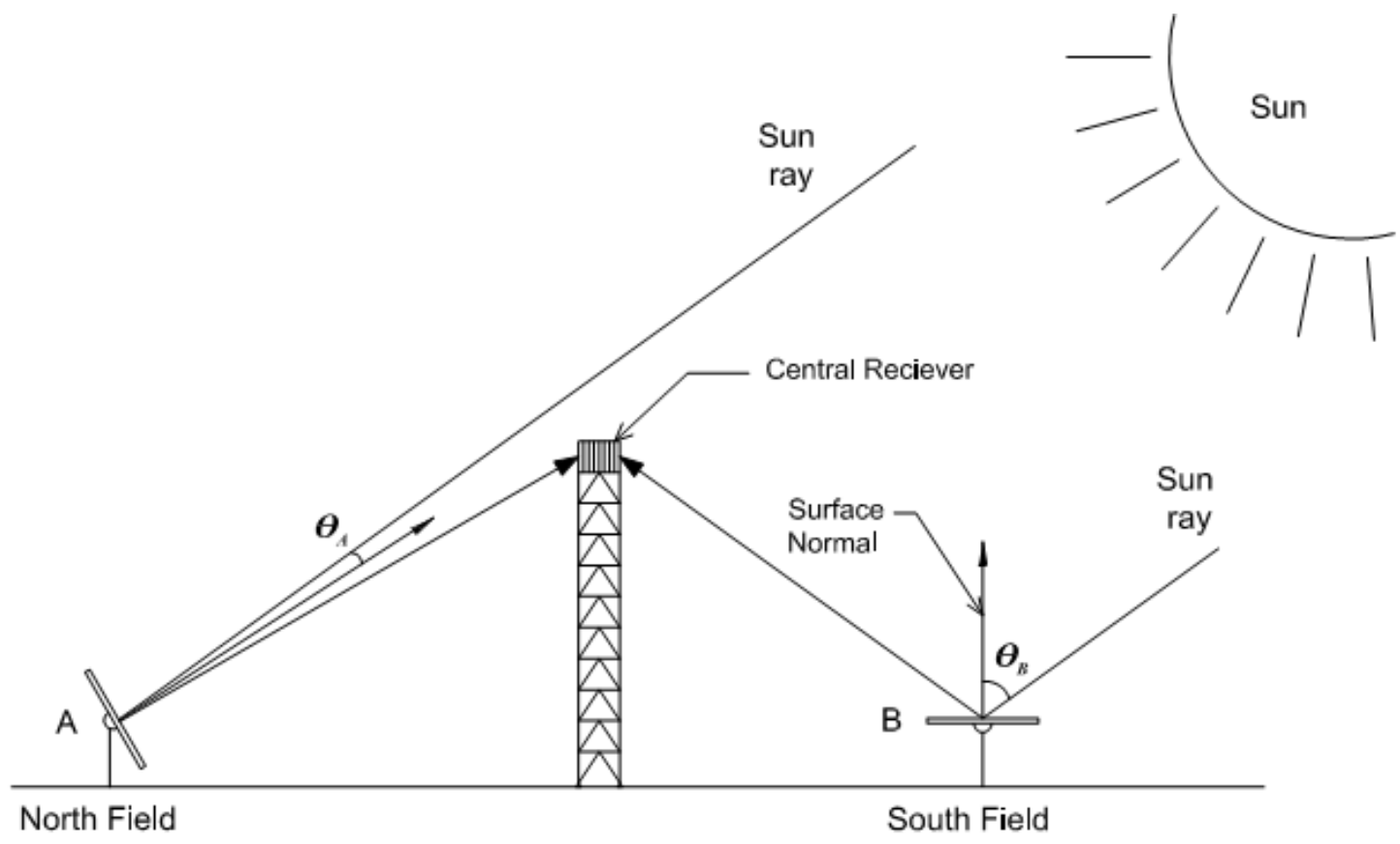

Figure O: Cosine Effect for Two Heliostats in Opposite Directions from the Tower (Stine and Geyer, 2001) 


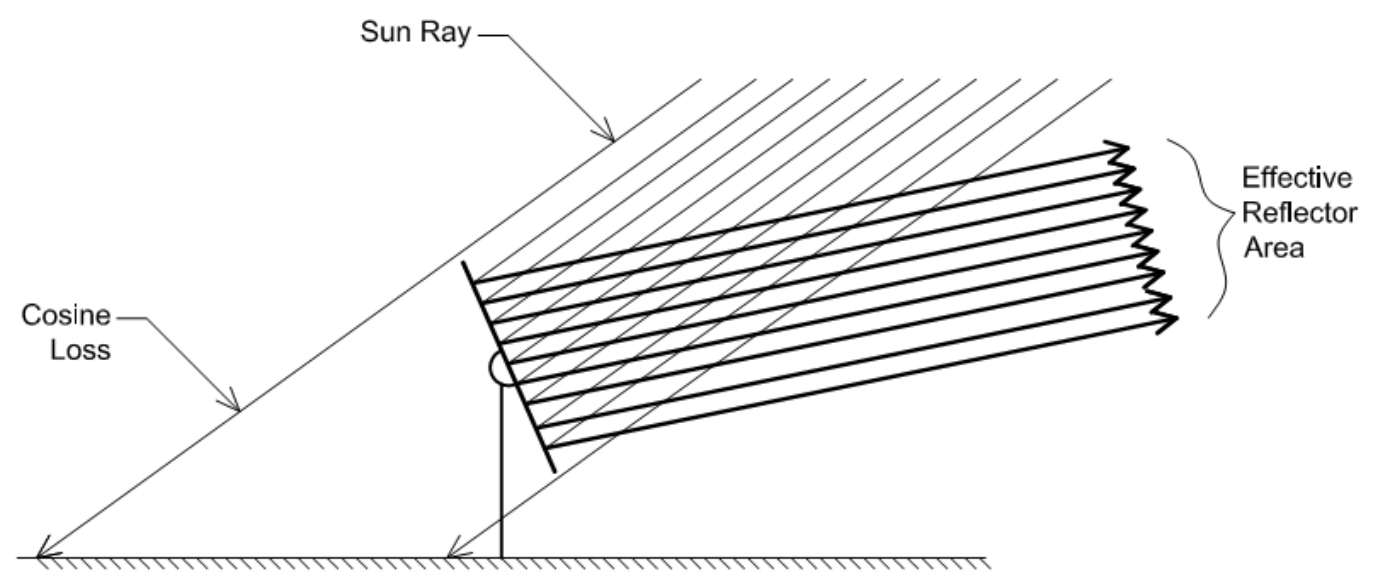

Heliostat A

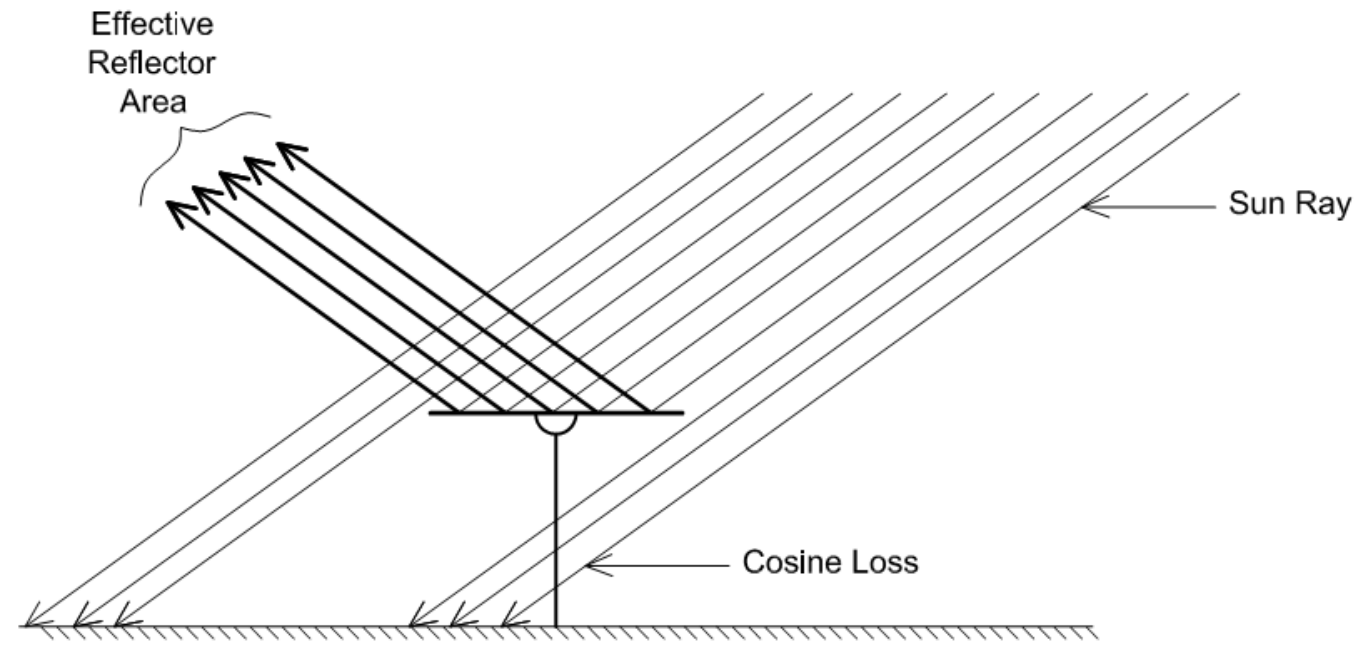

\section{Heliostat B}

\section{Figure P: Cosine Loss Relative to Heliostat Position \\ (Stine and Geyer, 2001)}

As illustrated in Figure $\mathrm{O}$ and Figure $\mathrm{P}$, Heliostat $\mathrm{A}$ has a small cosine loss since its surface normal is almost pointing towards the receiver. Heliostat B, on the other hand, has a larger cosine loss because of the position it must assume in order to reflect the sun's rays onto the receiver. Therefore, a heliostat field placed between the tower and the sun, 
similar to Heliostat B, reflects less sunlight and is less efficient than a heliostat field placed opposite the sun and tower, similar to Heliostat A. Since the sun path leans to the south for a building located in the northern hemisphere (see Figure Q below), the heliostat field is most efficient when located to the north of the tower; in other words, when the solar tower is placed to the south of the heliostat field (Stine and Geyer, 2001).

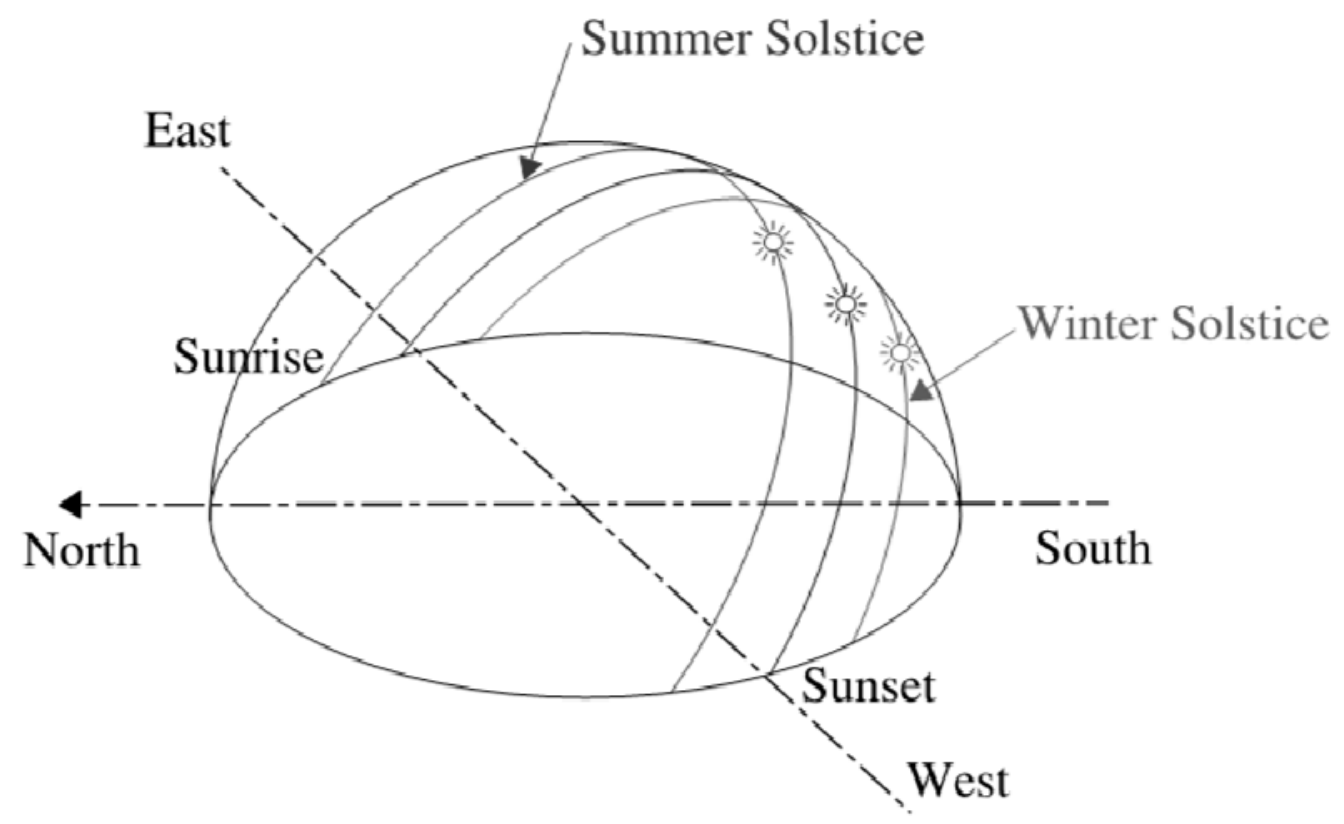

Figure Q: The Apparent Path of the Sun across the Sky in the Northern Hemisphere www-spof.gsfc.nasa.gov/

\subsubsection{Roof Attachment}

Deployment of a solar tower on the roof of an existing building presents challenges associated with attachment to existing roof members. Typically, roof members are designed for relatively light loads and do not have sufficient capacity to support the additional weight of the individual tower. In addition, the roof members are not usually designed to transfer seismic loads from the tower to the main lateral force resisting system (LRFS) of the building. Therefore, most industrial buildings require at least a 
local retrofit of the existing roof members supporting the tower to provide an adequate load path of tower forces to the main gravity and lateral-resisting systems of the building.

To avoid the need for retrofit of roof members on the RECH building, the towers are instead attached to a platform that spans between the columns and supports the tower three feet above the existing roof level. Plan and elevation views of the platform can be found in Figures R below and Figure $\mathrm{S}$ on the next page. The platform consists of moment connected members with posts at each corner. The posts connect directly to the columns at the roof level and match the column sizes. Each post has braces in each orthogonal direction to help lower the horizontal deflection of the platform.

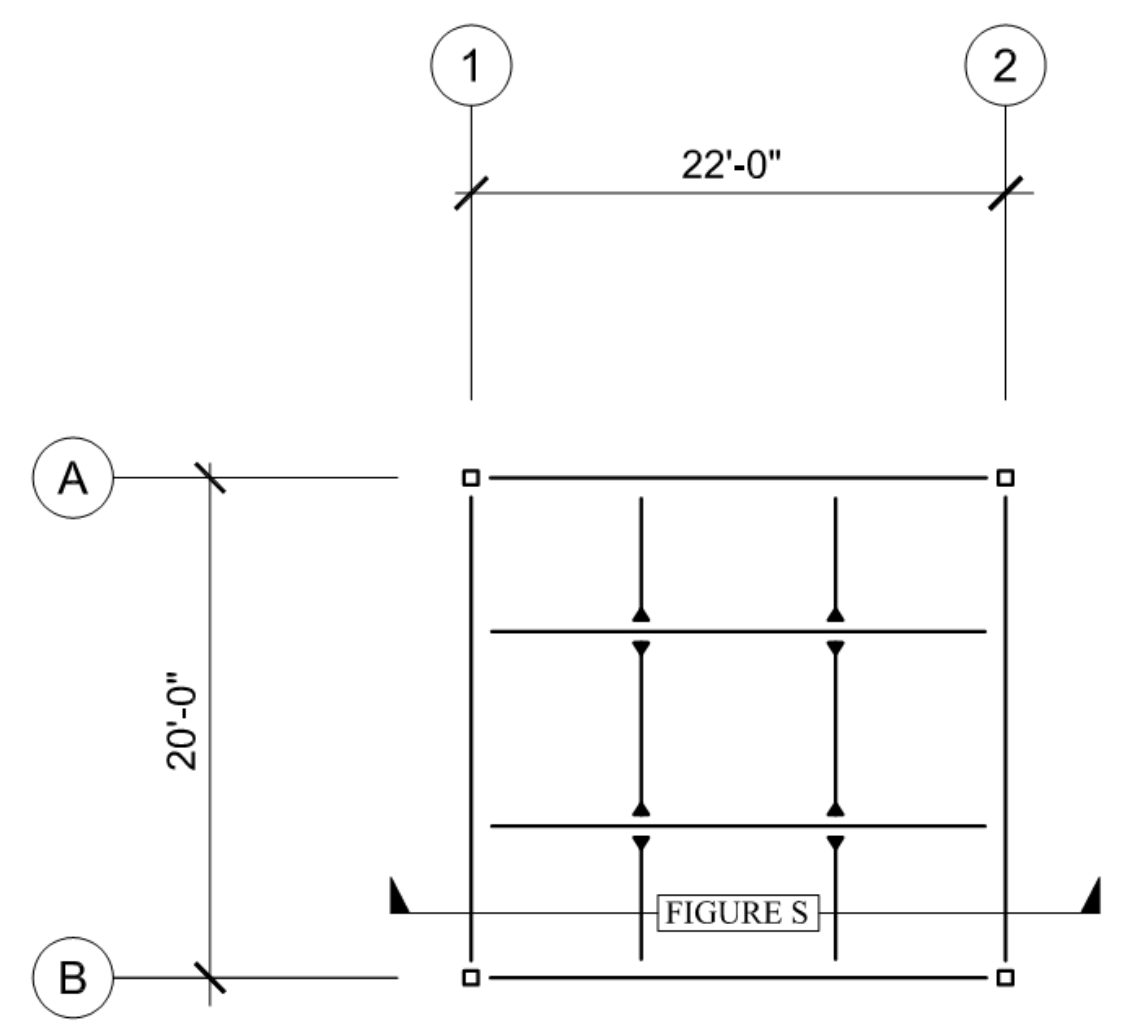

Figure R: Plan View of the Platform to Support the Solar Towers 


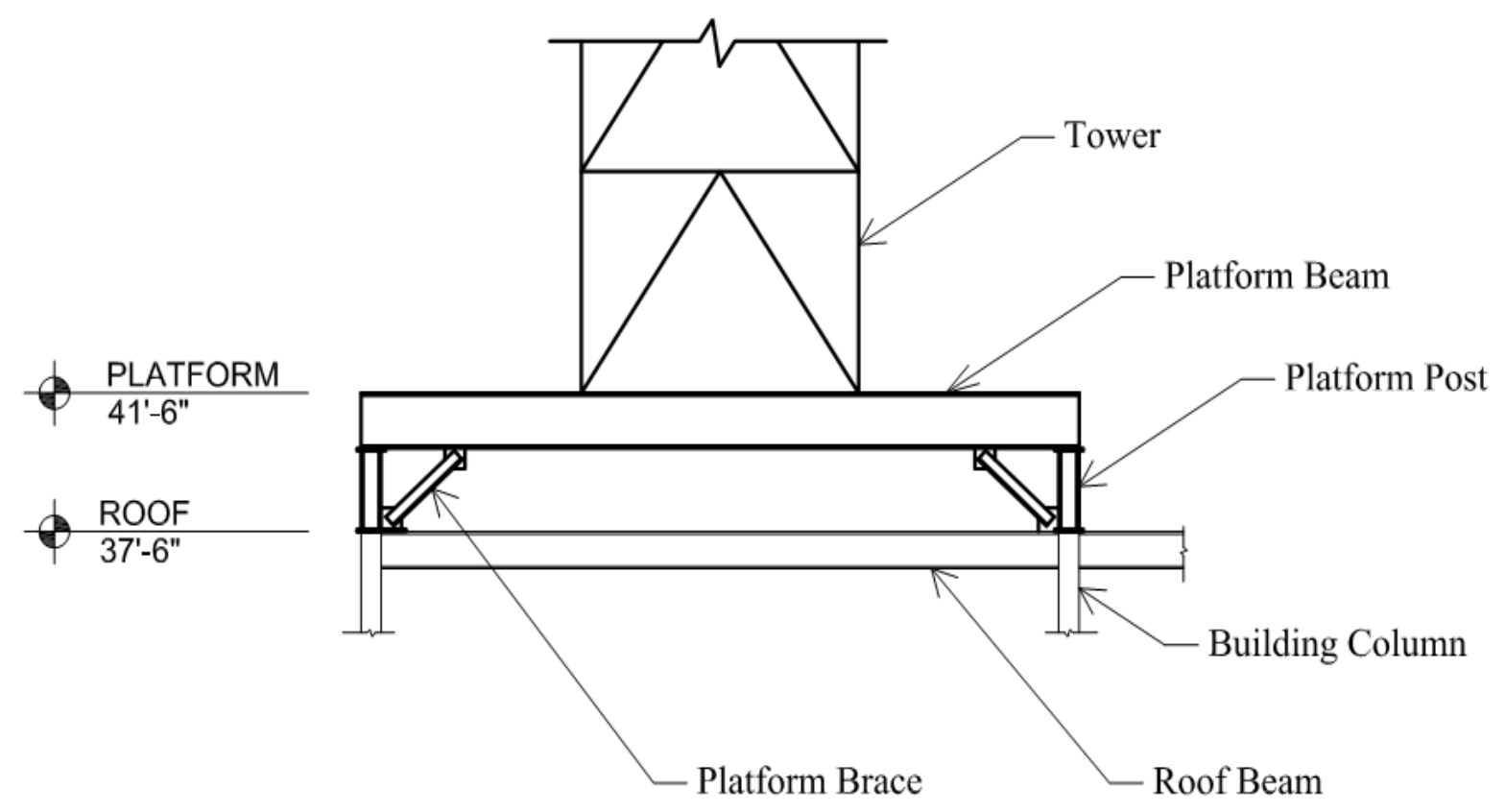

Figure S: Elevation View of the Platform to Support the Solar Towers

\subsubsection{Modeling Assumptions}

The three solar towers were modeled in SAP with beam elements for the main legs and truss elements for diagonal and horizontal members. The weight of the tower members (braces, horizontal members, legs) was lumped at leg joints such that the members themselves were considered weightless; weight lumping avoids local spurious modes of vibration from occurring. Then a 4000-pound force was applied at the top of the tower to represent the weight of the receiver. Each tower was assumed to be rigidly attached to the platform and the platform was assumed to be rigidly attached to the columns at the roof level of the RECH building. The platform members were modeled as beam elements. Figure $\mathrm{T}$ on the next page shows wireframe models of the three tower structures in SAP. 


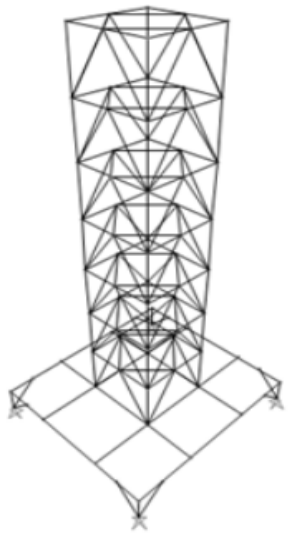

(a) Tower 1

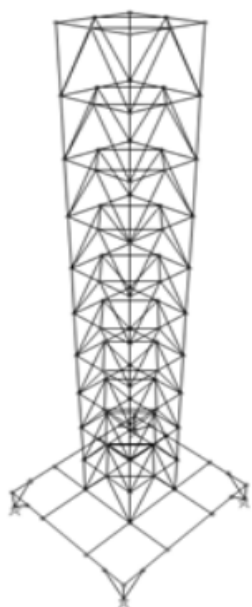

(b) Tower 2

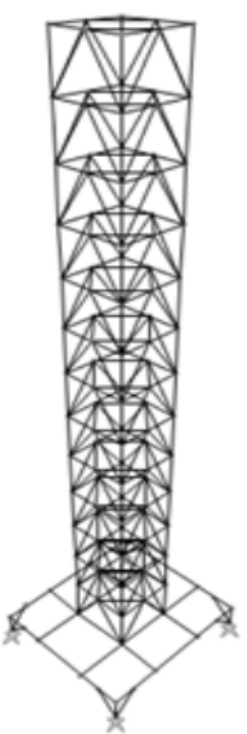

(c) Tower 3

Figure T: Finite Element Models of the Solar Towers

\subsubsection{Dynamic Properties}

A dynamic analysis using modal superposition was performed in SAP to determine the dynamic properties of the three solar towers. Table 4 below summarizes the first fundamental periods for each tower (see Section B.0 of the Appendix for a full list of modal periods as well as mode shapes).

\begin{tabular}{|c|c|c|c|}
\hline Tower ID & $1^{\text {st }}$ Period (sec) & $2^{\text {nd }}$ Period (sec) & $3^{\text {rd }}$ Period (sec) \\
\hline \hline Tower 1 & $\begin{array}{c}0.24 \\
\text { (sway in UY) }\end{array}$ & $\begin{array}{c}0.24 \\
\text { (sway in UX) }\end{array}$ & $\begin{array}{c}0.07 \\
\text { (rotation in RZ) }\end{array}$ \\
\hline Tower 2 & $\begin{array}{c}0.37 \\
\text { (sway in UY) }\end{array}$ & $\begin{array}{c}0.37 \\
\text { (sway in UX) }\end{array}$ & $\begin{array}{c}0.11 \\
\text { (rotation in RZ) }\end{array}$ \\
\hline Tower 3 & $\begin{array}{c}0.42 \\
\text { (sway in UY) }\end{array}$ & $\begin{array}{c}0.42 \\
\text { (sway in UX) }\end{array}$ & $\begin{array}{c}0.11 \\
\text { (rotation in RZ) }\end{array}$ \\
\hline \hline
\end{tabular}

Table 4: Modal Periods of the Solar Towers 
Because the platform provides a flexible base for the tower and thus affects its dynamic response, the values listed in Table 4 include the platform framing in the computation of tower periods. As shown in Table 4, the period increases as the tower height and weight increase; Tower 1, the lightest and shortest tower has the lowest natural period at 0.17 seconds; Tower 2 has a natural period of 0.27 seconds; and Tower 3 , the tallest and heaviest tower, has a natural period of 0.40 seconds. Each tower has a matching fundamental sway mode in orthogonal directions due to the symmetric nature of the towers. 


\subsection{ANALYSIS METHODOLOGY}

To investigate the amplification factors, this thesis conducts time history analyses in the computer analysis program SAP 2000 (SAP) of the three tower/building structures described in Section 3.0.

\subsection{Time History Analysis}

A time history analysis is a step-by-step analysis of the dynamic response of a structure subject to a loading that varies with time. For the purposes of this thesis, the loading on the structures is applied as earthquake ground acceleration records taken from historical earthquakes (see Section 4.2 for a description of the earthquake ground motion records used). To determine the dynamic response of a tower/building structure to a given ground motion record, the dynamic equilibrium equation of the structure must be solved for each time step of the ground motion record using the solution of the previous time step as the initial conditions. Equation 9 below shows the dynamic equilibrium equation in its most general form:

$$
\mathrm{p}(\mathrm{t})=K_{\mathrm{n}} \mathrm{d}(\mathrm{t})+C_{\mathrm{n}} \mathrm{v}(\mathrm{t})+M_{\mathrm{n}} \mathrm{a}(\mathrm{t})
$$

where

$$
\begin{array}{ll}
\mathrm{K}_{\mathrm{n}} & =\text { stiffness matrix } \\
\mathrm{C}_{\mathrm{n}} & =\text { viscous damping matrix } \\
\mathrm{M}_{\mathrm{n}} & =\text { mass matrix } \\
\mathrm{d}(\mathrm{t}) & =\text { displacement of the structure } \\
\mathrm{v}(\mathrm{t}) & =\text { velocity of the structure } \\
\mathrm{a}(\mathrm{t}) & =\text { acceleration of the structure } \\
\mathrm{p}(\mathrm{t}) & =\text { applied load } \\
\mathrm{n} & =\text { degrees of freedom of the structure }
\end{array}
$$


For a tower/building structure with $\boldsymbol{n}$ degrees of freedom, the dynamic equilibrium equation in Equation 9 is made up of a set of $\boldsymbol{n}$ coupled differential equations of second order. For a structure with a large number of degrees of freedom, the dynamic equilibrium equation can become complex, resulting in long run times in SAP. To cut down on run time, modal superposition embedded within SAP was used to simplify the computation of the dynamic equilibrium equation.

\subsubsection{Modal Superposition}

The concept of modal superposition derives from the idea that each natural mode of vibration of the structure, of which there are exactly $\boldsymbol{n}$, can be treated as an independent linear single-degree-of-freedom (SDOF) system; each modal SDOF system has its own pattern of deformation, its own natural period, and its own viscous damping. As a result, the dynamic equilibrium equation can be solved independently for each mode and combined to determine the total response. Since modes with the lowest natural frequencies contribute more significantly to the total response of the structure, higher modes with low mass participation can be ignored. For this thesis, the number of modes included in the analysis was selected to yield a mass participation ratio of at least $90 \%$.

\subsubsection{Analysis Assumptions}

In order to use modal superposition to simplify the computation of the time history analysis, several assumptions about the tower/building structure must be made. First, the tower/building structure must be assumed to be classically damped; that is, the viscous damping ratio must be the same for all modes. For this thesis, a viscous damping ratio of $3 \%$ of the critical damping was used for each mode of the combined structure. 
In addition to a classical damping assumption, modal superposition requires that the tower/building structure responds linear-elastically to the applied loading. For the solar tower, a linear-elastic assumption is considered appropriate since the design intent of the tower is to have continuous serviceability after the earthquake; continuous serviceability implies that the solar tower does not experience any damage or only minor damage during an earthquake. For the building, while some of the earthquake ground motion records chosen may be strong enough to cause inelastic deformations in the lateral force resisting system of the building, any structural yielding absorbs seismic energy. As a result, the energy transferred onto the tower is reduced. Therefore, assuming a linear-elastic response will ensure the maximum amount of energy is transferred to the tower, thus producing upper bound limits for the expected seismic amplification effects on the tower (Soong, 1993).

\subsection{Earthquake Ground Motion Records}

In SAP, each combined solar tower/building structure was subjected to 30 earthquake ground motion records of varying frequency. The earthquake records were applied to each structure in the transverse direction, U1, and the longitudinal direction, $\mathrm{U} 2$, independently. Figure $\mathrm{U}$ on the next page shows the relationship of the U1 and U2 directions to the RECH building. 


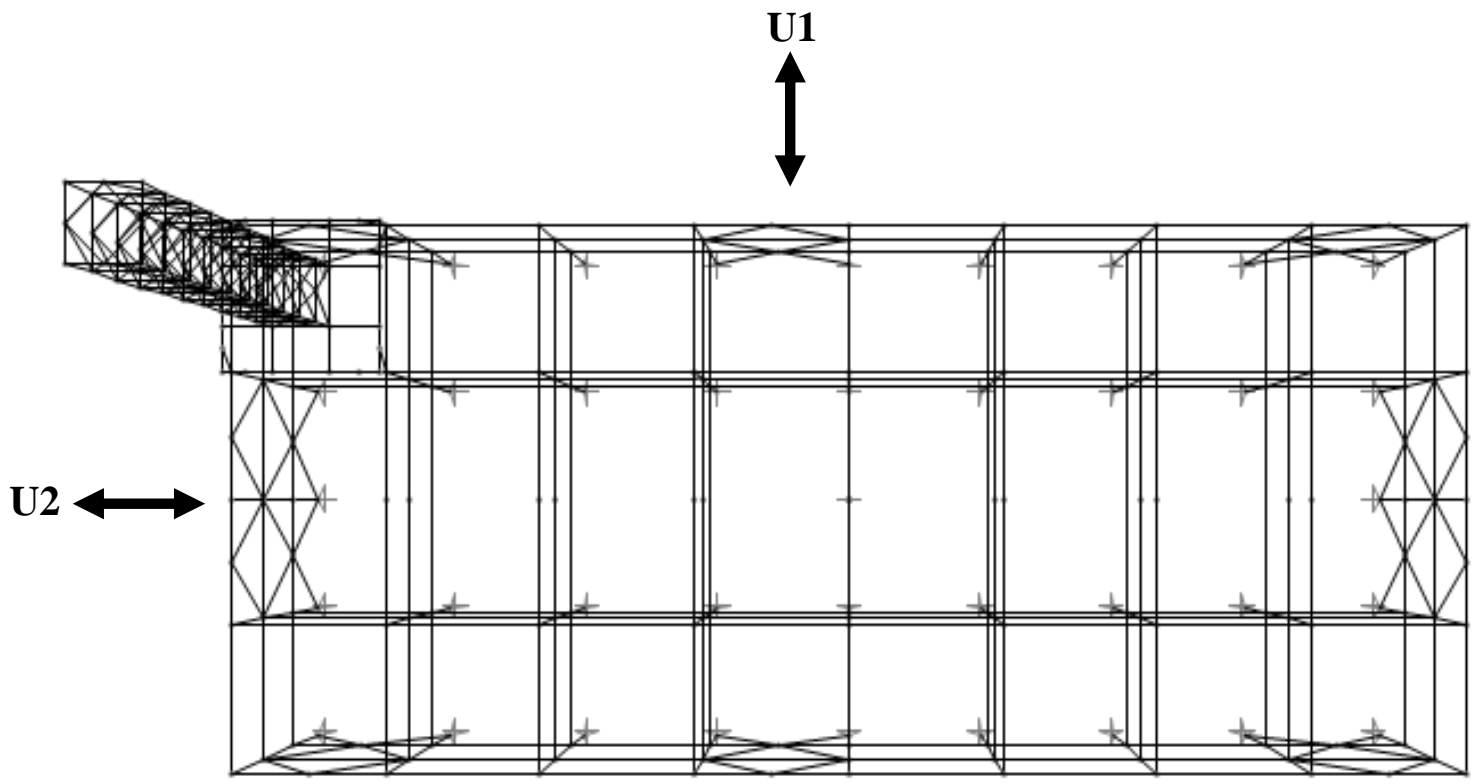

Figure U: Roof Plan View of the RECH Building with the Solar Tower Attached

The earthquake records used were taken from sites with hard rock ground conditions as the effects of soil conditions on amplification factors is outside the scope of this project. Different sets of earthquake records were used to investigate the effects of frequency content of ground motion on the amplification factor experienced by the tower. As in the study by Assi (Assi, 2006), the earthquake ground motion records were chosen based on the ratio of the peak ground acceleration to the peak ground velocity, or the $a / v$ ratio. As discussed previously in Section 2.1.2, there is a strong correlation between the $\mathrm{a} / \mathrm{v}$ ratio and the frequency of the ground motion; earthquakes with low a/v ratios tend to be low frequency, while earthquakes with high a/v ratios tend to be high frequency. For the purposes of this thesis, the ground motion records used have been classified into three categories based on their a/v ratio: 
- Low a/v: a/v $\leq 0.8 \mathrm{~g} / \mathrm{m} / \mathrm{s}$

- Medium a/v: $0.8 \mathrm{~g} / \mathrm{m} / \mathrm{s}<\mathrm{a} / \mathrm{v}<1.2 \mathrm{~g} / \mathrm{m} / \mathrm{s}$

- High $\mathrm{a} / \mathrm{v}: \mathrm{a} / \mathrm{v} \geq 1.2 \mathrm{~g} / \mathrm{m} / \mathrm{s}$

Tables 5 through 7 list the name, year, and station of the ground motion records used along with their corresponding peak ground acceleration (PGA), peak ground velocity (PGV), and a/v ratio.

\begin{tabular}{|c|c|c|c|c|c|}
\hline Earthquake & Year & Station & $\begin{array}{c}\text { PGA } \\
{[\mathrm{g}]}\end{array}$ & $\begin{array}{c}\text { PGV } \\
{[\mathrm{m} / \mathrm{s}]}\end{array}$ & $\begin{array}{c}\mathrm{a} / \mathrm{v} \text { ratio } \\
{[\mathrm{g} / \mathrm{m} / \mathrm{s}]}\end{array}$ \\
\hline Landers & 1992 & 90019 San Gabriel - E Grand Ave. & 0.041 & 0.141 & 0.29 \\
\hline Duzce, Turkey & 1999 & Mudurnu & 0.056 & 0.163 & 0.34 \\
Loma Prieta & 1989 & 58373 APEEL 10 - Skyline & 0.088 & 0.240 & 0.37 \\
San Fernando & 1971 & 1035 Isabella Dam & 0.006 & 0.014 & 0.43 \\
Loma Prieta & 1989 & 58131 SF - Pacific Heights & 0.061 & 0.128 & 0.48 \\
\hline Loma Prieta & 1989 & 58222 SF - Presidio & 0.058 & 0.117 & 0.50 \\
\hline Loma Prieta & 1989 & 1601 Palo Alto - SLAC Lab & 0.194 & 0.375 & 0.52 \\
\hline Northridge & 1994 & 23590 Wrightwood - Jackson Flat & 0.056 & 0.100 & 0.56 \\
Chalfant Valley & 1986 & 54101 Tinemaha Res. Free Field & 0.037 & 0.063 & 0.59 \\
\hline Loma Prieta & 1989 & 58471 Berkeley LBL & 0.057 & 0.092 & 0.62 \\
\hline
\end{tabular}

Table 5: Information for Low A/V Ratio Earthquakes Used in the Thesis

\begin{tabular}{|c|c|c|c|c|c|}
\hline Earthquake & Year & Station & $\begin{array}{c}\text { PGA } \\
{[\mathrm{g}]}\end{array}$ & $\begin{array}{c}\text { PGV } \\
{[\mathrm{m} / \mathrm{s}]}\end{array}$ & $\begin{array}{c}\mathrm{a} / \mathrm{v} \text { ratio } \\
{[\mathrm{g} / \mathrm{m} / \mathrm{s}]}\end{array}$ \\
\hline Imperial Valley & 1979 & 6604 Cerro Prieto & 0.157 & 0.186 & 0.84 \\
\hline Chalfant Valley & 1986 & 54214 Long Valley Dam & 0.056 & 0.064 & 0.88 \\
Gazli, USSR & 1976 & 9201 Karakyr & 0.608 & 0.654 & 0.93 \\
Northridge & 1994 & 23595 Littlerock - Brainard Can. & 0.06 & 0.063 & 0.95 \\
\hline Nahanni, Canada & 1985 & 6098 Site 2 & 0.323 & 0.331 & 0.98 \\
\hline San Fernando & 1971 & 111 Cedar Springs, Allen Ranch & 0.009 & 0.009 & 1.00 \\
\hline Coalinga & 1983 & 36176 Parkfield & 0.137 & 0.135 & 1.01 \\
\hline Helena, Montana & 1935 & 2022 Carroll College & 0.173 & 0.165 & 1.05 \\
San Fernando & 1971 & 121 Fairmont Dam & 0.039 & 0.035 & 1.11 \\
Santa Barbara & 1978 & 106 Cachuma Dam Toe & 0.072 & 0.063 & 1.14 \\
\hline
\end{tabular}

Table 6: Information for Medium A/V Ratio Earthquakes Used in the Thesis 
4.0 Analysis Methodology 46

\begin{tabular}{|c|c|c|c|c|c|}
\hline Earthquake & Year & Station & $\begin{array}{c}\text { PGA } \\
{[\mathrm{g}]}\end{array}$ & $\begin{array}{c}\text { PGV } \\
{[\mathrm{m} / \mathrm{s}]}\end{array}$ & $\begin{array}{c}\mathrm{a} / \mathrm{v} \text { ratio } \\
{[\mathrm{g} / \mathrm{m} / \mathrm{s}]}\end{array}$ \\
\hline Victoria, Mexico & 1980 & 6604 Cerro Prieto & 0.621 & 0.316 & 1.97 \\
\hline San Fernando & 1971 & 266 Pasadena - Old Seismo Lab & 0.09 & 0.044 & 2.05 \\
\hline Westmorland & 1981 & 286 Superstition Mtn. Camera & 0.116 & 0.05 & 2.32 \\
\hline Anza & 1980 & 5044 Anza - Pinyon Flat & 0.131 & 0.051 & 2.57 \\
Coyote Lake & 1979 & 47379 Gilroy Array \#1 & 0.072 & 0.025 & 2.88 \\
\hline Coalinga & 1983 & 1608 Oil Fields Fire Station & 0.062 & 0.020 & 3.10 \\
\hline $\begin{array}{c}\text { Northern } \\
\text { California }\end{array}$ & 1975 & 1249 Cape Mendocino, Petrolia & 0.026 & 0.008 & 3.25 \\
\hline San Fernando & 1971 & 104 Santa Anita Dam & 0.212 & 0.061 & 3.48 \\
Whittier Narrows & 1987 & 24436 Tarzana, Cedar Hill & 0.248 & 0.059 & 4.20 \\
\hline Mammoth Lakes & 1980 & 52 USC McGee Creek & 0.078 & 0.016 & 4.88 \\
\hline
\end{tabular}

Table 7: Information for High A/V Ratio Earthquakes Used in the Thesis 


\subsection{RESULTS}

The following section presents the numerical results from the time history analyses of the three tower/building structures. In addition, this section provides a comparison of the amplification factors generated from numerical results with the amplification factors adopted by the ASCE 7-05 as well as the component amplification factor proposed by Assi. Modifications to the component amplification factor proposed by Assi are also presented.

\subsection{Tower Amplification Factor}

In SAP, the total horizontal force at the base of the tower, $\mathrm{F}_{\mathrm{bt}}$, and the peak roof acceleration, PRA, was determined for each tower/building structure in the direction of the applied earthquake record (U1 or U2 direction). Using simple force equal mass time acceleration $(\mathrm{f}=\mathrm{ma})$ methodology, the tower amplification factor, $\mathrm{A}_{\mathrm{t}}$, was then computed using Equation 10 below:

$$
\mathrm{A}_{\mathrm{t}}=\frac{\mathrm{F}_{\mathrm{tb}}}{\mathrm{W}_{\mathrm{t}} \mathrm{PRA}}
$$

where

$$
\begin{aligned}
& \mathrm{A}_{\mathrm{t}} \quad=\text { tower amplification factor } \\
& \mathrm{F}_{\mathrm{tb}} \quad=\text { tower base shear } \\
& \mathrm{W}_{\mathrm{t}} \quad=\text { weight of the tower } \\
& \text { PRA } \quad=\text { acceleration at the base of the tower }
\end{aligned}
$$

The value $A_{t}$ in Equation 10 was calculated in a similar manner to the tower amplification factor calculated by Assi (see Equation 2 on page 19). The average values $(\mu)$ and standard deviations $(\sigma)$ of $A_{t}$ for each building configuration are presented in Table 8 and 9 on page 47. The graphs in Figures $\mathrm{V}$ and $\mathrm{W}$ on page 48 illustrate the average of $A_{t}$ plotted against the period ratio. The period ratio, $T_{\text {ratio }}$, is defined as the Approximating the Seismic Amplification Effects for Roof-Mounted Solar Towers 
ratio of the fundamental period of the tower, $T_{\text {tower }}$, to the fundamental period of the building, $\mathrm{T}_{\text {building, }}$ in the direction of the applied ground motion record. Also shown on the graphs are the component amplification factor adopted by the ASCE 7-05 and the component amplification factor proposed by Assi.

\subsubsection{Numerical Results}

\begin{tabular}{|c|c|c|c|c|c|c|}
\hline \multirow{3}{*}{ a/v Category } & \multicolumn{6}{|c|}{ Tower Amplification Factor, $A_{t}$} \\
\hline & \multicolumn{2}{|c|}{$\begin{array}{c}\text { Tower } 1 \text { Attached } \\
\text { to RECH Building } \\
\left(\mathrm{T}_{\text {ratio }}=0.67\right)\end{array}$} & \multicolumn{2}{|c|}{$\begin{array}{c}\text { Tower } 2 \text { Attached } \\
\text { to RECH Building } \\
\quad\left(\mathrm{T}_{\text {ratio }}=0.98\right)\end{array}$} & \multicolumn{2}{|c|}{$\begin{array}{c}\text { Tower } 3 \text { Attached } \\
\text { to RECH Building } \\
\quad\left(\mathrm{T}_{\text {ratio }}=1.26\right)\end{array}$} \\
\hline & $\mu$ & $\sigma$ & $\mu$ & $\sigma$ & $\mu$ & $\sigma$ \\
\hline Low & 2.22 & 0.20 & 3.45 & 0.90 & 1.16 & 0.47 \\
\hline Medium & 2.45 & 1.05 & 3.28 & 0.89 & 1.06 & 0.25 \\
\hline High & 2.28 & 0.53 & 2.48 & 0.68 & 0.72 & 0.26 \\
\hline ASCE 7-05 & 2.50 & - & 2.50 & - & 2.50 & - \\
\hline Assi & 1.70 & - & 4.00 & - & 1.00 & - \\
\hline
\end{tabular}

Table 8: Tower Amplification Factor in the U1 Direction

\begin{tabular}{|c|c|c|c|c|c|c|}
\hline \multirow{3}{*}{ a/v Category } & \multicolumn{6}{|c|}{ Tower Amplification Factor, $\mathrm{A}_{\mathrm{t}}$} \\
\cline { 2 - 7 } & $\begin{array}{c}\text { Tower 1 Attached } \\
\text { to RECH Building } \\
\left(\mathrm{T}_{\text {ratio }}=0.73\right)\end{array}$ & \multicolumn{2}{c|}{$\begin{array}{c}\text { Tower 2 Attached } \\
\text { to RECH Building } \\
\left(\mathrm{T}_{\text {ratio }}=1.06\right)\end{array}$} & $\begin{array}{c}\text { Tower 3 Attached } \\
\text { to RECH Building } \\
\left(\mathrm{T}_{\text {ratio }}=1.36\right)\end{array}$ \\
\cline { 2 - 8 } & $\mu$ & $\sigma$ & $\mu$ & $\sigma$ & $\mu$ & $\sigma$ \\
\hline \hline Low & 1.40 & 0.09 & 3.91 & 0.64 & 1.14 & 0.32 \\
\hline Medium & 1.63 & 0.45 & 3.81 & 0.63 & 1.18 & 0.31 \\
\hline High & 1.46 & 0.23 & 3.15 & 0.83 & 0.84 & 0.28 \\
\hline ASCE 7-05 & 2.50 & - & 2.50 & - & 2.50 & - \\
\hline Assi & 2.30 & - & 4.00 & - & 1.00 & - \\
\hline \hline
\end{tabular}

Table 9: Tower Amplification Factor in the U2 Direction 


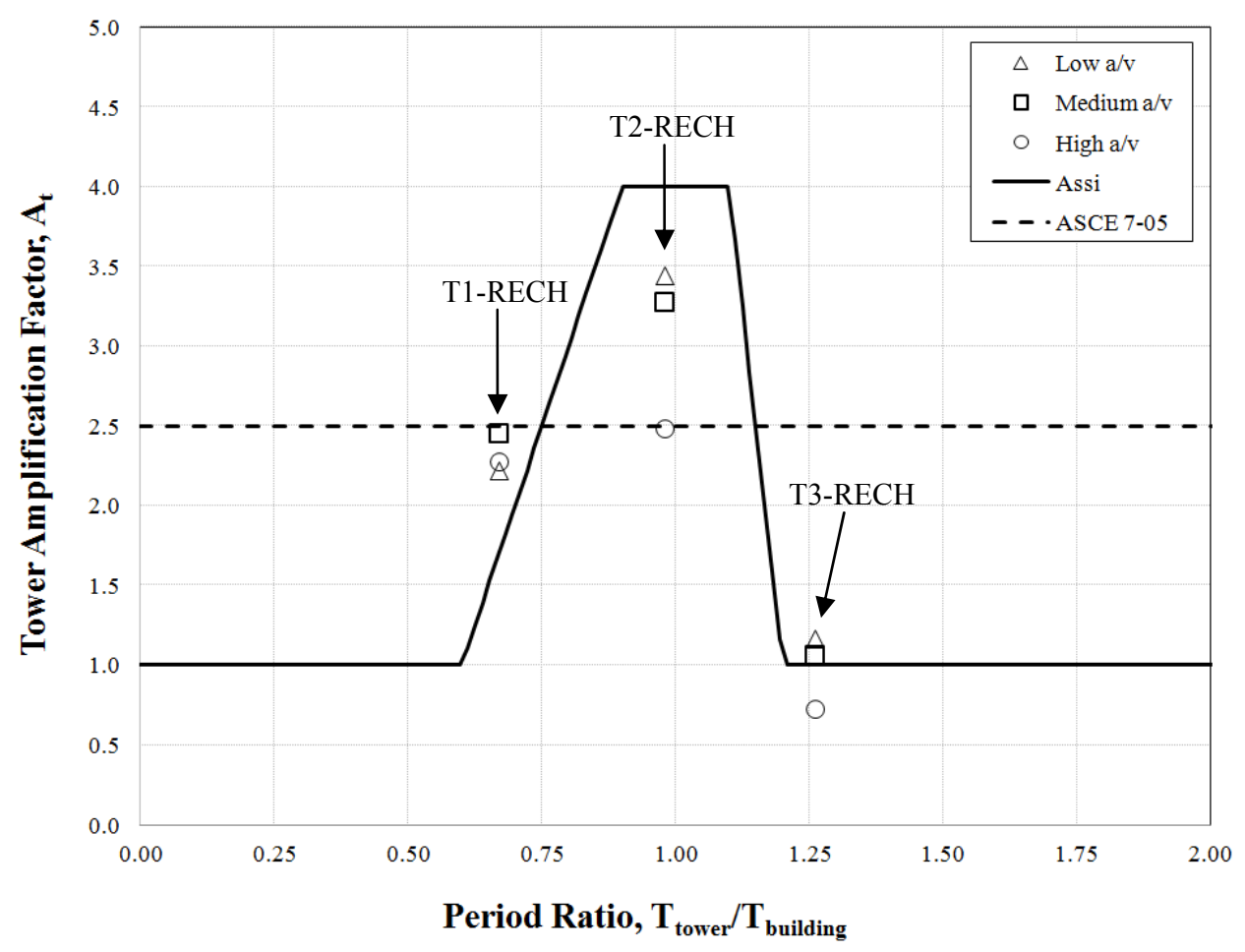

Figure V: Tower Amplification Factor in the U1 Direction

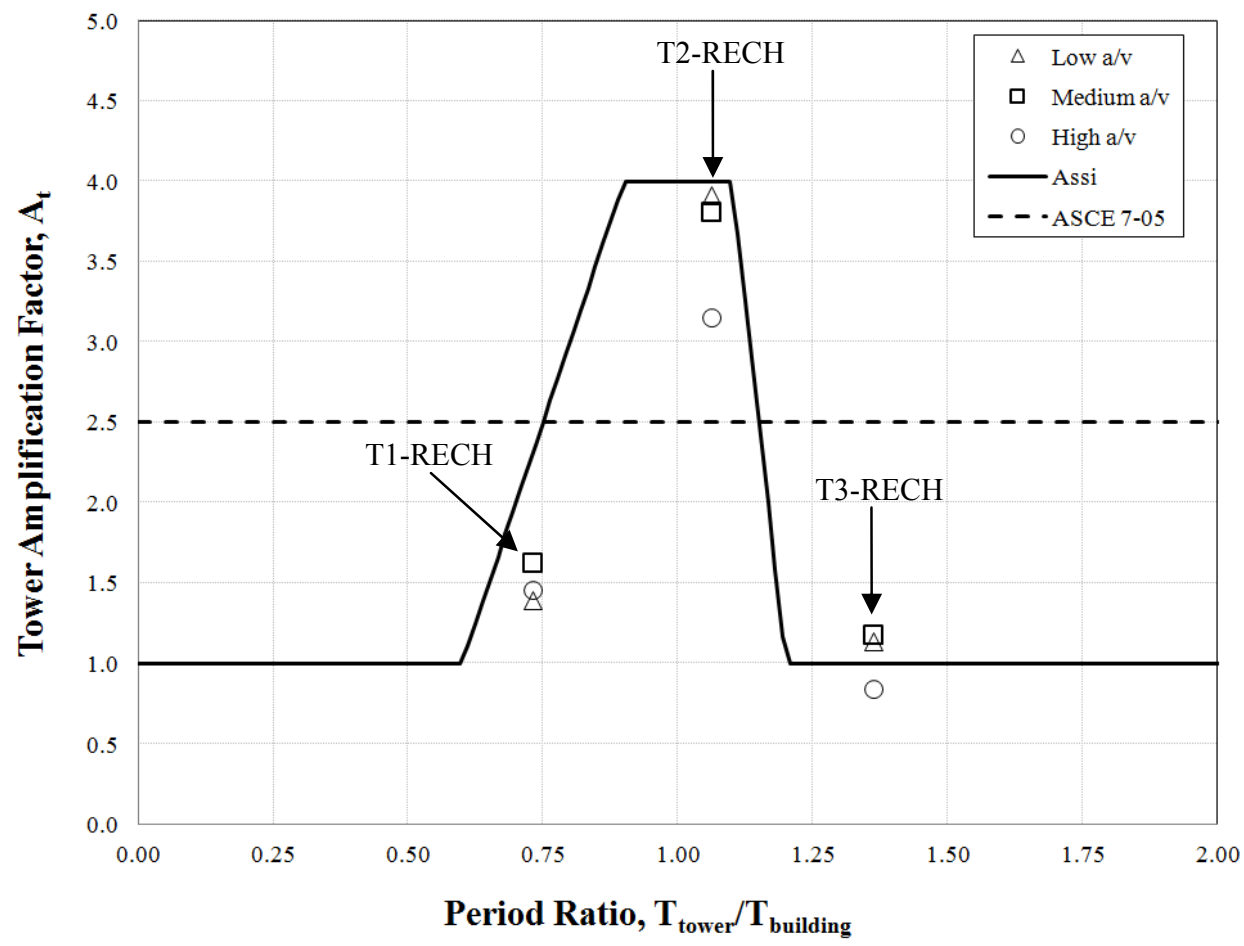

Figure W: Tower Amplification Factor in the U2 Direction 


\subsubsection{Assessment}

The results shown in Table 8 and Table 9 indicate that the ASCE 7-05 component amplification factor of 2.5 for flexible components is a conservative approximation for $A_{t}$ for tower/building structures with period ratios less than 0.9 and greater than 1.1 . For period ratios less than 0.9 , as seen in $\mathrm{T} 1-\mathrm{RECH}$, the numerical results produce values of $\mathrm{A}_{\mathrm{t}}$ bounded by 2.5 . When the period ratio is greater than 1.1, as is the case for T3-RECH, the numerical results produce values of $\mathrm{A}_{\mathrm{t}}$ bounded by 1.2. For period ratios between 0.9 and 1.1, however, the ASCE 7-05 component amplification factor was found to underestimate At; for period ratios between 0.9 and 1.1, as seen in T2-RECH, the numerical results produced a value of $A_{t}$ bounded by 4.0.

The results shown in Figure V and Figure W also show that the component amplification factor proposed by Assi provides a good match for the overall trend of $A_{t}$. However, while the maximum value of 4.0 proposed by Assi provides a good upper limit for period ratios between 0.8 and 1.1 , the factor can underestimate the results for period ratios between 0.6 and 0.9 and between 1.1 and 1.2. Looking at Table 8 , the numerical results for T1-RECH and T3-RECH in the U1 direction produced maximum tower amplification factors of 2.28 and 1.16, respectively; Assi's factor, on the other hand, estimates values of 1.70 and 1.00, respectively. In Table 9, the numerical results for T1$\mathrm{RECH}$ in the U2 direction produced a maximum tower amplification factor of 1.18, while Assi factor estimated a value of 1.0.

Also illustrated in Figure $\mathrm{V}$ and $\mathrm{W}$ is the effect the $\mathrm{a} / \mathrm{v}$ ratio of the ground motion record has on the value of $A_{t}$. As shown, the $a / v$ ratio only has a significant effect on $A_{t}$ for period ratios between 0.9 and 1.1 . For these period ratios, high a/v records were found 
to produce $A_{t}$ values $20 \%$ to $30 \%$ smaller than those produced by low or medium a/v records.

\subsection{Roof Amplification Factor}

For each tower/building structure modeled in SAP, the roof amplification factor, $A_{r}$, was calculated as the ratio of the peak roof acceleration (PRA) to the peak ground acceleration (PGA). Equation 11 summarizes the calculation of $\mathrm{A}_{\mathrm{r}}$ :

$$
A_{r}=\frac{P R A}{P G A}
$$

where

$$
\begin{aligned}
& \mathrm{A}_{\mathrm{r}}=\text { average roof amplification factor } \\
& \text { PRA }=\text { peak roof acceleration } \\
& \text { PGA }=\text { peak ground acceleration }
\end{aligned}
$$

The average values $(\mu)$ and standard deviations $(\sigma)$ of $A_{r}$ are presented in Table 10 below and Table 11 on page 51. Figure $X$ on page 51 and Figure $Y$ on page 52 show the averages of $\mathrm{A}_{\mathrm{r}}$ plotted against the period ratio of the tower/building structures. Also shown on the plots in Figure $\mathrm{X}$ and $\mathrm{Y}$ is the floor amplification factor adopted by the ASCE 7-05 for a component attached to the roof level of a building

\subsubsection{Numerical Results}

\begin{tabular}{|c|c|c|c|c|c|c|c|c|}
\hline \multicolumn{3}{|c|}{ a/v Category } & \multicolumn{2}{c|}{$\begin{array}{c}\text { RECH } \\
\text { Building } \\
\text { Only }\end{array}$} & \multicolumn{2}{c|}{$\begin{array}{c}\text { RECH Building w/ } \\
\text { Tower 1 Attached } \\
\left(\mathrm{T}_{\text {ratio }}=0.67\right)\end{array}$} & $\begin{array}{c}\text { RECH Building w/ } \\
\text { Tower 2 Attached } \\
\left(\mathrm{T}_{\text {ratio }}=0.98\right)\end{array}$ & $\begin{array}{c}\text { RECH Building w/ } \\
\text { Tower 3 Attached } \\
\left(\mathrm{T}_{\text {ratio }}=1.26\right)\end{array}$ \\
\cline { 2 - 10 } & $\mu$ & $\sigma$ & $\mu$ & $\sigma$ & $\mu$ & $\sigma$ & $\mu$ & $\sigma$ \\
\hline \hline Low & 3.63 & 1.02 & 3.81 & 0.80 & 3.38 & 1.10 & 3.75 & 1.07 \\
\hline Medium & 2.69 & 1.03 & 2.64 & 0.99 & 2.31 & 0.71 & 2.62 & 0.98 \\
\hline High & 2.23 & 0.60 & 2.43 & 0.46 & 2.03 & 0.57 & 2.39 & 0.61 \\
\hline ASCE 7-05 & 3.00 & - & 3.00 & - & 3.00 & - & 3.00 & - \\
\hline \hline
\end{tabular}

Table 10: Roof Amplification Factor in the U1 Direction 


\begin{tabular}{|c|c|c|c|c|c|c|c|c|}
\hline \multicolumn{3}{|c|}{ a/v Category } & $\begin{array}{c}\text { RECH } \\
\text { Building } \\
\text { Only }\end{array}$ & \multicolumn{2}{c|}{$\begin{array}{c}\text { RECH Building w/ } \\
\text { Tower 1 Attached } \\
\left(\mathrm{T}_{\text {ratio }}=0.73\right)\end{array}$} & $\begin{array}{c}\text { RECH Building w/ } \\
\text { Tower 2 Attached } \\
\left(\mathrm{T}_{\text {ratio }}=1.06\right)\end{array}$ & $\begin{array}{c}\text { RECH Building w/ } \\
\text { Tower 3 Attached } \\
\left(\mathrm{T}_{\text {ratio }}=1.36\right)\end{array}$ \\
\cline { 2 - 9 } & $\mu$ & $\sigma$ & $\mu$ & $\sigma$ & & $\mu$ & $\sigma$ & $\mu$ \\
\hline \hline Low & 3.86 & 0.98 & 3.82 & 0.97 & 3.09 & 0.66 & 3.77 & 0.95 \\
\hline Medium & 2.66 & 1.20 & 2.64 & 1.18 & 2.24 & 0.81 & 2.61 & 1.14 \\
\hline High & 1.84 & 0.61 & 1.84 & 0.62 & 1.72 & 0.51 & 1.79 & 0.59 \\
\hline ASCE 7-05 & 3.00 & - & 3.00 & - & 3.00 & - & 3.00 & - \\
\hline \hline
\end{tabular}

Table 11: Roof Amplification Factor in the U2 Direction

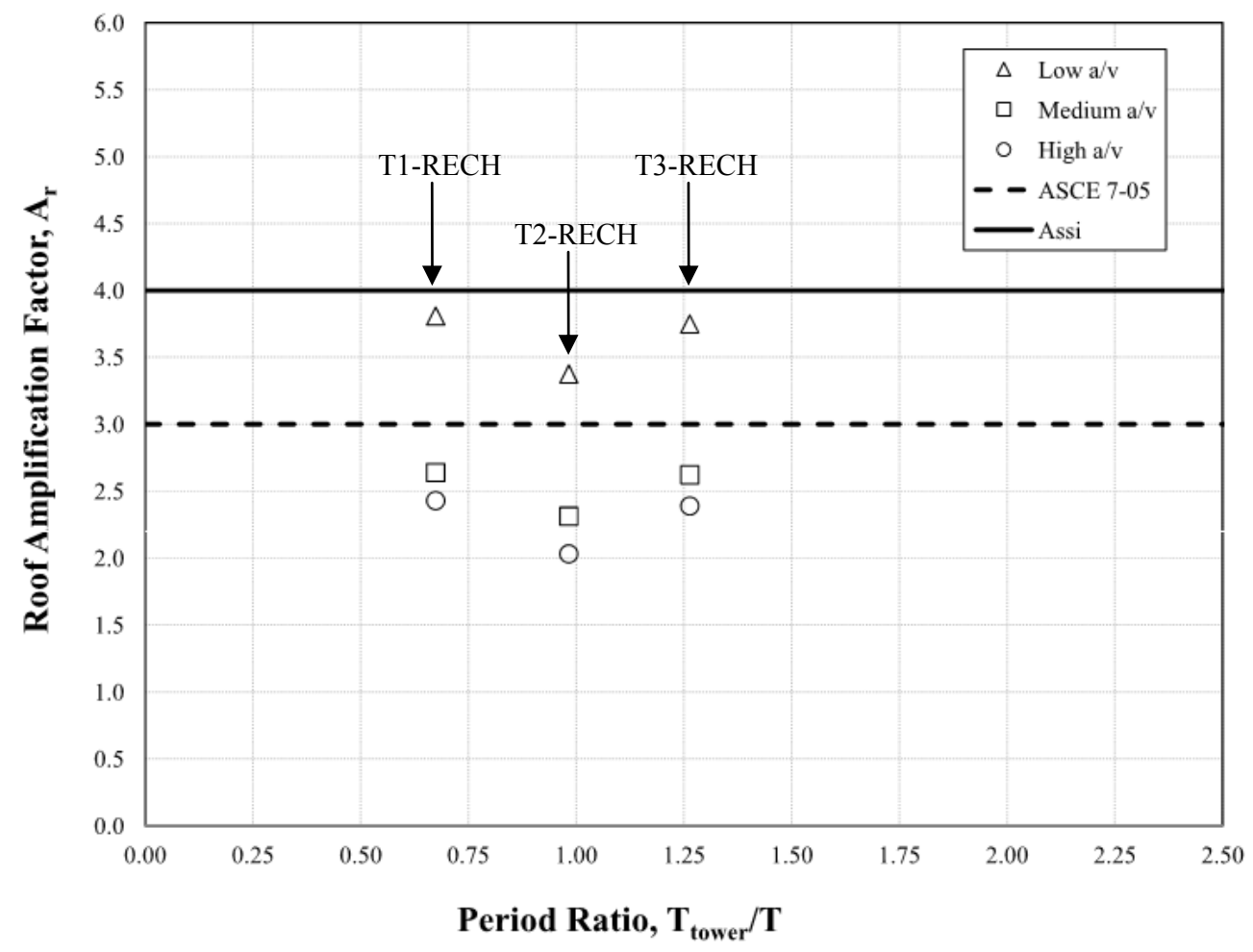

Figure X: Roof Amplification Factor in the U1 Direction 


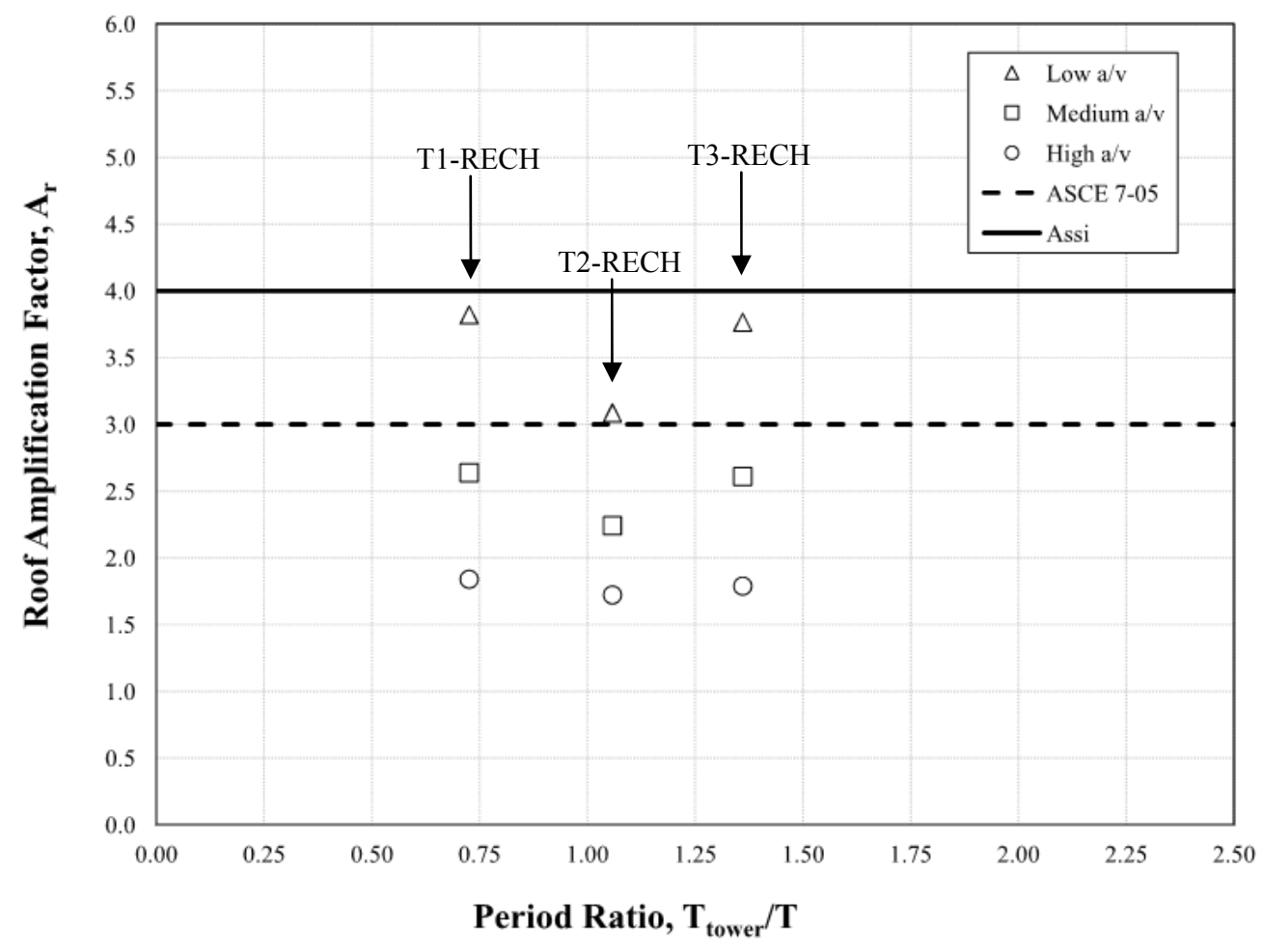

Figure Y: Roof Amplification Factor in the U2 Direction

\subsubsection{Assessment}

The results presented in Table 10 and Table 11 indicate that the ASCE 7-05 floor amplification factor of 3.0 at the roof level provides a conservative approximation of $\mathrm{A}_{\mathrm{r}}$ for tower/building structures subject to medium and high a/v records. Medium and high $\mathrm{a} / \mathrm{v}$ records produced $\mathrm{A}_{\mathrm{r}}$ values bounded by 2.7 and 2.5 , respectively. For low a/v records, however, the ASCE 7-05 floor amplification factor of 3.0 was found to underestimate roof acceleration amplification, where $A_{r}$ values as large as 3.86 were determined. The floor amplification factor value of 4.0 proposed by Assi provides a good upper limit for the numerical results of $A_{r}$.

The results also indicate that $A_{r}$ is not constant for all period ratios, as assumed by the ASCE 7-05 and Assi. Instead, the results show a decrease in $A_{r}$ as the period ratio 
approaches unity at a value of 1.0. The decrease in $A_{r}$ for period ratios close to 1.0 can be seen in Table 11 for low a/v records. Table 11 shows that when the RECH building is analyzed without a tower attached, the magnitude of $\mathrm{A}_{\mathrm{r}}$ is 3.86. When T1-RECH and T3$\mathrm{RECH}$ which have period ratios 0.73 and 1.36 in the $\mathrm{U} 1$ direction respectively, are analyzed, similar values of $A_{r}$ are produced. The magnitudes for $A_{r}$ are 3.82 and 3.77 for T1-RECH and T3-RECH, respectively. When T2-RECH which has a period ratio of 0.97 in the $\mathrm{U} 1$ direction, is analyzed, the magnitude of $\mathrm{A}_{\mathrm{r}}$ is significantly less at a value of 3.09. Figure $X$ and Figure $Y$ illustrate this similar trend of decreasing $A_{r}$ for all $a / v$ record categories for period ratios between 0.9 and 1.1; however, the decrease in $\mathrm{A}_{\mathrm{r}}$ was found to be more significant for low a/v records. The floor-level amplification factor proposed by Assi does not account for this decrease in magnitude of $A_{r}$ at period ratios between 0.9 and 1.1. The decrease in $\mathrm{A}_{\mathrm{r}}$ is a result of mass interaction between the tower and the building. As illustrated in the result for $A_{t}$ in Table 9 and Table 10 in Section 6.1.2, when the tower and building are at resonance at a period ratio between 0.9 and 1.1 , the response of the tower is magnified. The magnified response of the tower then acts as a damper on the building and lowers its response, thus producing lower values of $A_{r}$.

\subsection{Proposed Rooftop Solar Tower Amplification Factor}

Based on the observations of $\mathrm{A}_{\mathrm{r}}$ and $\mathrm{A}_{t}$ for the tower/building structures investigated in this thesis, a new formula for calculating the design seismic base shear, $\mathrm{F}_{\mathrm{p}}$, for a roof-mounted solar tower is proposed in Equation 12 below:

$$
\mathrm{F}_{\mathrm{p}}=\frac{0.4 \mathrm{~S}_{\mathrm{DS}} \mathrm{A}_{\mathrm{z}} \mathrm{I}_{\mathrm{p}} \mathrm{W}_{\mathrm{p}}}{\mathrm{R}_{\mathrm{p}}}
$$


where

$\mathrm{F}_{\mathrm{p}} \quad=\quad$ design seismic base shear

$\mathrm{S}_{\mathrm{DS}}=$ spectral acceleration at a short period

$\mathrm{R}_{\mathrm{p}}=$ response modification factor of the tower

$\mathrm{W}_{\mathrm{p}} \quad=\quad$ weight of the tower

$\mathrm{I}_{\mathrm{p}} \quad=\quad$ importance factor of the tower

$\mathrm{A}_{\mathrm{z}}=$ rooftop solar tower amplification factor

Equation 11 uses the same simple format as the formulas adopted by the ASCE 705 for nonstructural components. However, Equation 12 combines the component amplification factor and floor amplification factor into a single factor. The new factor, referred to as the rooftop tower amplification factor, $\mathrm{A}_{\mathrm{z}}$, can be calculated using Equation 13 through 17 below:

$$
\begin{array}{clc}
\mathrm{A}_{\mathrm{z}}=4 & \text { for } \mathrm{T}_{\text {ratio }}<0.6 & \text { Eq. } 13 \\
\mathrm{~A}_{\mathrm{z}}=4+40\left(\mathrm{~T}_{\text {ratio }}-0.6\right) & \text { for } 0.6<\mathrm{T}_{\text {ratio }} \leq 0.8 & \text { Eq. } 14 \\
\mathrm{~A}_{\mathrm{z}}=12 & \text { for } 0.8<\mathrm{T}_{\text {ratio }} \leq 1.2 & \text { Eq. } 15 \\
\mathrm{~A}_{\mathrm{z}}=12-40\left(\mathrm{~T}_{\text {ratio }}-1.2\right) & \text { for } 1.2<\mathrm{T}_{\text {ratio }} \leq 1.4 & \text { Eq. } 16 \\
\mathrm{~A}_{\mathrm{z}}=4 & \text { for } 1.4<\mathrm{T}_{\text {ratio }} & \text { Eq. } 17
\end{array}
$$

where

$$
\begin{aligned}
& \mathrm{A}_{\mathrm{z}}=\text { rooftop solar tower amplification factor } \\
& \mathrm{T}_{\text {ratio }}=\text { period ratio } \\
& \mathrm{T}_{\text {tower }}=\text { fundamental period of the tower } \\
& \mathrm{T}_{\text {building }}=\text { fundamental period of the building }
\end{aligned}
$$

The graphs in Figure $\mathrm{Z}$ and AA show comparisons of the new formulas in Equations 13 through 17 with the product of the floor amplification factor and the 
component amplification factor adopted by the ASCE 7-05 and proposed by Assi. The product of $A_{r}$ and $A_{t}$ from the time history analyses are also shown on the graphs.

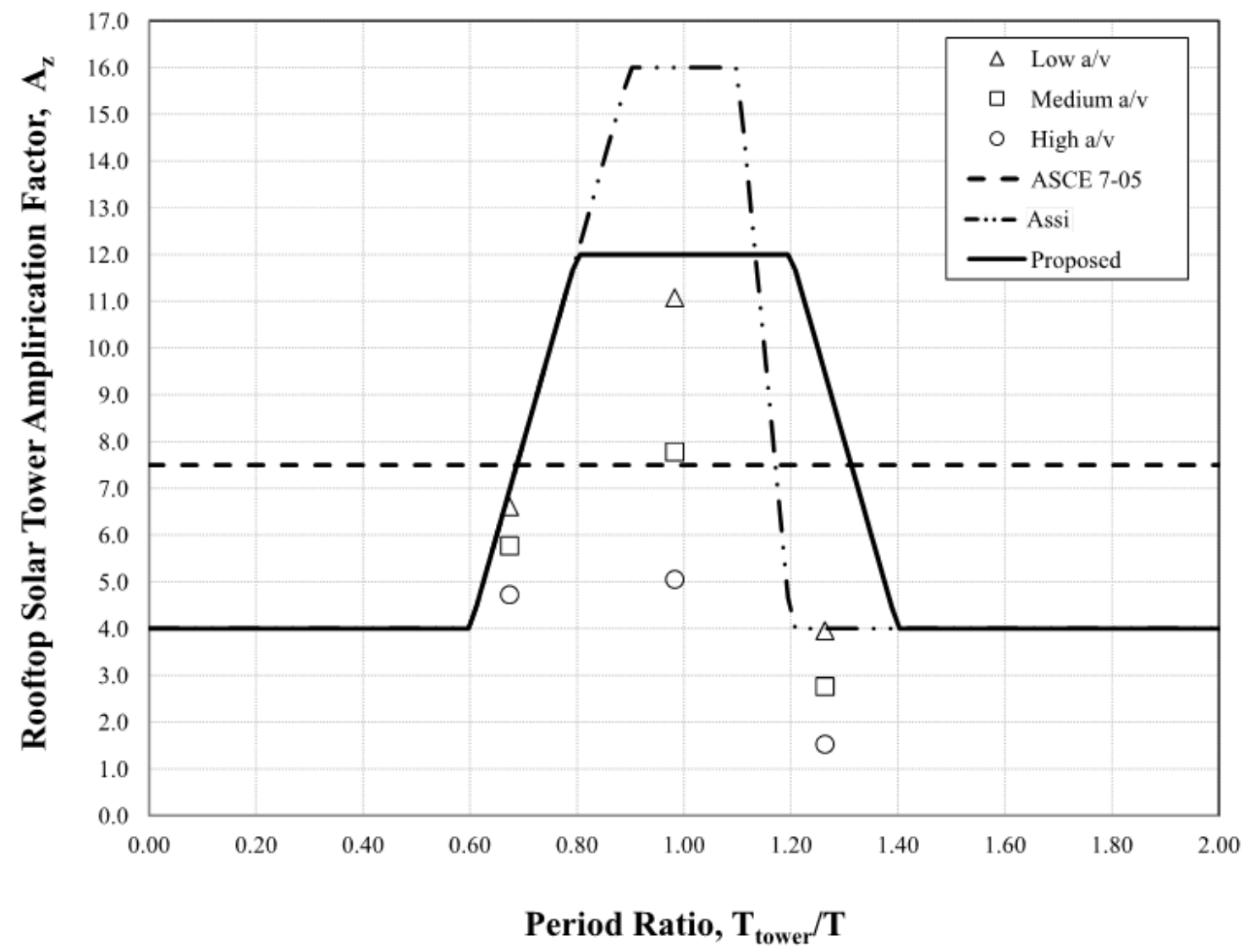

Figure Z: Proposed Rooftop Solar Tower Amplification Factor in the U1 Direction 


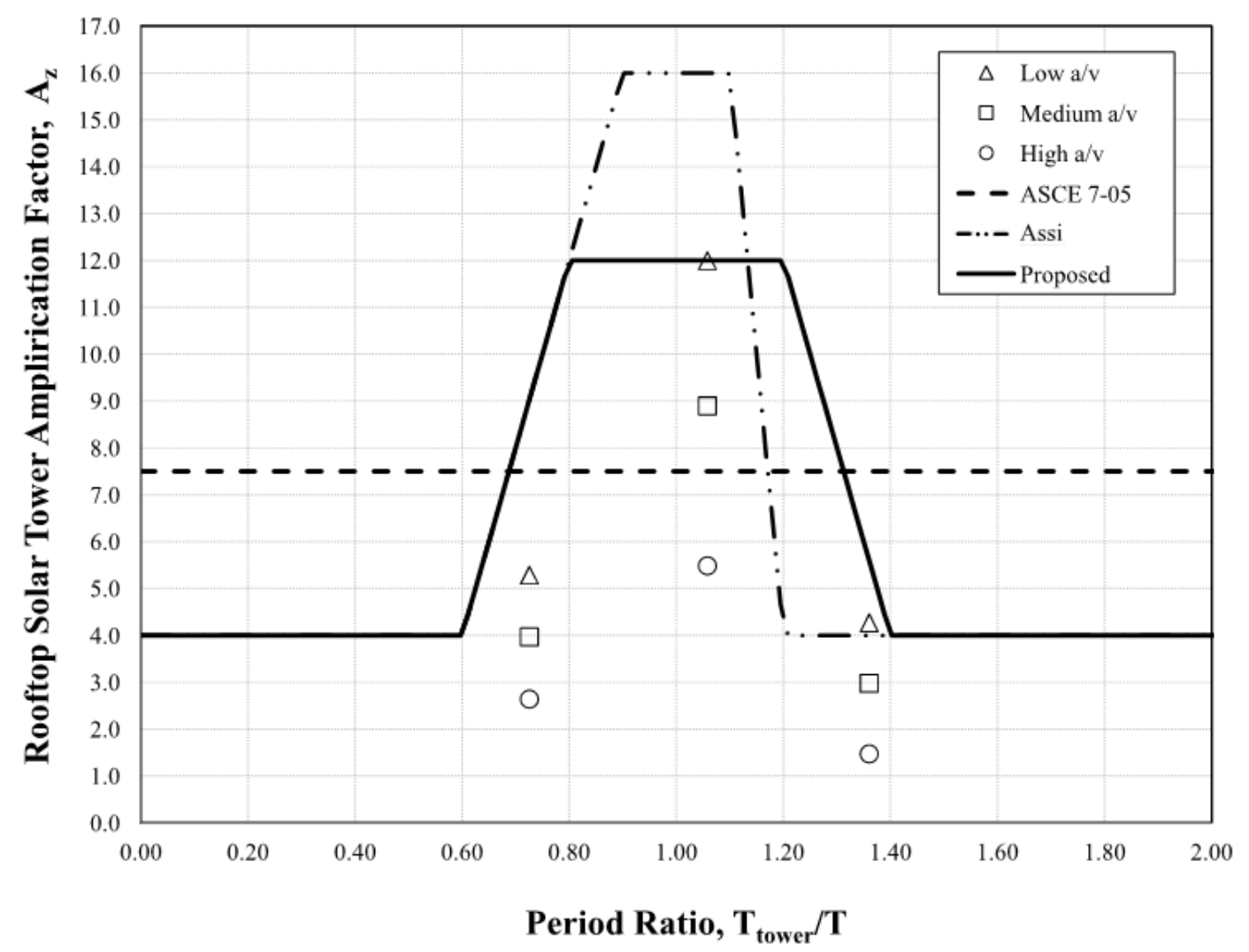

Figure AA: Proposed Rooftop Solar Tower Amplification Factor in the U2 Direction

Observing Figures $\mathrm{Z}$ and $\mathrm{AA}$, the proposed factor $\mathrm{A}_{\mathrm{z}}$ provides a good estimate for the total acceleration amplification experienced by the towers investigated in this thesis. When the period ratio is between 0.8 and 1.2, the maximum $\mathrm{A}_{\mathrm{z}}$ value of 12.0 gives a more accurate upper bound estimate of the numerical results than the 7.5 factor adopted by the ASCE 7-05 or the 16.0 factor proposed by Assi. In addition, when the period ratio is less than 0.6 or greater than 1.4 , the minimum $A_{z}$ value of 4.0 gives a more accurate lower bound estimate of the numerical results than the 7.5 factor adopted by ASCE 7-05.

While the proposed $\mathrm{A}_{\mathrm{z}}$ factor may provide a good estimate of the acceleration amplification experienced by a rooftop solar tower, the calculation of $\mathrm{A}_{\mathrm{z}}$ relies heavily on the ability to determine the fundamental periods of the tower and building. As discussed 
in Section 2.2.2, an approximate method for calculating the fundamental period of the low-rise industrial buildings is available in the ASCE 7-05 (see Equation 8 on page 22). The simplified methods available for calculating the fundamental period for a steel lattice tower, however, are specific to towers attached to the ground and do not account for period lengthening caused by the flexible base provided by the roof members supporting the tower or by the additional weight of the receiver at the top of the solar tower. As a result, determining an accurate value for the fundamental period of the rooftop solar tower requires a dynamic analysis of the tower modeled with the roof members and the additional receiver weight to be performed.

To avoid the need to determine the fundamental period of the solar tower and simplify the calculation of $A_{z}$, the same approach as that adopted by ASCE 7-05 can be utilized: the ASCE 7-05 assumes a component and its supporting building are at resonance (the period ratio is 1.0) and assigns the maximum value for the component amplification factor. Similarly, a period ratio of 1.0 can be assumed for the solar tower and the maximum $\mathrm{A}_{\mathrm{z}}$ value of 12.0 can be used. 


\subsection{CONCLUSIONS AND RECOMMENDED RESEARCH}

For this thesis, a time history analysis was performed for three theoretical solar towers attached to the roof of a case study industrial building. The time history analyses were conducted using finite-element modeling in the computer software program SAP 2000 v15.1.0. In SAP, computer models of each solar tower/building structure were generated and subjected to 30 ground motions of varying frequency. The goal of the time history analysis was to determine whether the amplification factors adopted by the ASCE 7-05 provide adequate approximations of the seismic amplification effects experienced by roof-mounted solar towers during a seismic event. Based on the results of time history analyses of the three tower/building structures, the ASCE 7-05 amplification factors were found to underestimate the seismic amplification effects experienced by the three solar towers when at resonance with their supporting building. In addition, the ASCE 7-05 factors do not take advantage of a decrease in amplification for tower/building structures not at resonance. Therefore, it is recommended that new approximation factors proposed in Section 5.3 be used in lieu of the ASCE 7-05 factors.

To further explore the validity of the formulas proposed by this thesis, recommendations for areas of future research include the following:

- study of solar towers attached to industrial buildings larger than three stories,

- study of solar towers attached to industrial buildings with irregular floor plans and/or asymmetric lateral resisting system layouts,

- study of solar towers with different geometries, heights, and weights,

- study of different tower attachment conditions at the roof level, 
- study of solar towers attached to industrial buildings constructed on different soil types,

- study of the solar towers attached to buildings undergoing nonlinear deformations. 


\section{REFERENCES}

(Amiri et al., 2007) Amiri, G. Ghodrati, S. R. Massah, and A. Boostan. "Seismic response of 4-legged self-supporting telecommunication towers." International Journal of Engineering Transactions B: Applications 20.2 (2007): 107-126. Print.

(ASCE 7-05) American Society of Civil Engineers (ASCE), and Structural Engineering Institute (SEI). Minimum Design Loads for Buildings and Other Structures. Reston, VA: American Society of Civil Engineers/Structural Engineering Institute, 2006. Print.

(Assi, 2006) Assi, Rola. "Seismic analysis of telecommunication towers mounted on building rooftops.” Dissertation Abstracts International 68.3 (2006). Print.

(Assi et al., 2005) Assi, Rola, Ghyslaine McClure, and George C. Yao. "Floor acceleration demands for 11 instrumented buildings in Taiwan during the 1999 Chi Chi earthquake." Proceedings of the Structures Congress. 2005. Print.

(Bachman and Drake, 1995) Bachman, R. E., and R. M. Drake. "A Study to Empirically Validate the In-Structure Response Accelerations in the 1994 NEHRP Provisions Design Force Equations for Architectural, Mechanical, and Electrical Components." Letter report submitted to the National Center for Earthquake Engineering Research per NSF Grant No. CMS-9416580, July (1995). Print.

(Bachman and Drake, 1996) Drake, Richard M., and Robert E. Bachman. "NEHRP provisions for 1994 for nonstructural components." Journal of Architectural Engineering 2.1 (1996): 26-31. Print.

(Der Kiureghian et al., 1983) Der Kiureghian, Armen, Jerome L. Sackman, and Bahrain Nour-Omid. "Dynamic analysis of light equipment in structures: Response to stochastic input." Journal of Engineering Mechanics 109.1 (1983): 90-110. Print.

(Fathali and Lizundia, 2011) Fathali, Saeed, and Bret Lizundia. "Evaluation of current seismic design equations for nonstructural components in tall buildings using strong motion records." The Structural Design of Tall and Special Buildings 20.S1 (2011): 30-46. Print.

(Harding, 2011) Harding, Dan. "Rooftop vs. Concentrated Solar: 20 Points of Comparison." Nationwide Home Solar Power Contractors and Information. CalFinder Contractors.26 May 2011. < http://solar.calfinder.com/blog/solarpolitics/rooftop-vs-concentrated-solar-20-points-of-comparison> 
(Hicks, 2009) Hicks, Nathan Andrew. Solar Power for Deployment in Populated Areas. MA Thesis. California Polytechnic State University, San Luis Obispo, 2009. Print.

(Igusa and Der Kiureghian, 1985) Igusa, Takeru, Armen Der Kiureghian. "Stochastic response of systems with uncertain properties." Transactions of the 8th International Conference of Structural Mechanics in Reactor Technology, Paper M. Vol. 14. 1985. Print.

(Konno and Kimura, 1973) Konno, T., and E. Kimura. "Earthquake Effects on Steel Tower Structures atop Buildings." Preprints, Fifth World Conference on Earthquake Engineering. (1973): 10. Print.

(McClure et al., 2004) McClure, Ghyslaine, Laura Georgi, and Rola Assi. "Seismic considerations for telecommunication towers mounted on building rooftops." 13th World Conference on Earthquake Engineering. 2004. Print.

(Newmark, 1972) Newmark, N.M. "Earthquake response analysis of reactor structures." Nuclear engineering and design 20.2 (1972): 303-322. Print.

(Sackmann, 1996) Sackmann, Vincent. Prediction of natural frequencies and mode shapes of self-supporting lattice telecommunication towers. Department of Civil Engineering and Applied Mechanics, McGill University, 1996. Print.

(SHC, 2012) "Potential for Solar Heat in Industrial Processes." Solar Heating and Cooling Program (SHC). International Energy Agency. Web. 28 May 2012. $<$ http://www.iea-ship.org/documents/papersofnewsletterNo1.pdf $>$

(Singh et al., 2006) Singh, M.P., E.E Matheu, L.M. Moreschi, and L.E. Suárez. "Seismic Design Forces. I: Rigid Nonstructural Components." Journal of Structural Engineering, 132.10 (2006): 1524-1532. Print.

(Solarpaces, 2012) "Solar Polar Tower." Solar Paces. The International Energy Agency. Web. 28 May 2012.<www.solarpaces.orgCSP_Technologydocssolar_tower.pdf>

(Tso et al., 1992) Tso, W.K., T.J. Zhu, and A.C. Heidebrecht. "Engineering implication of ground motion A/V ratio." Soil Dynamics and Earthquake Engineering 11.3 (1992): 133-144. Print.

(Villaverde, 1997) Villaverde, Roberto. "Method to improve seismic provisions for nonstructural components in buildings." Journal of Structural Engineering 123.4 (1997): 432-439. Print. 


\section{APPENDIX A.0: MEMBER SIZES}

Appendix A.1: RECH Building Beam and Column Sizes

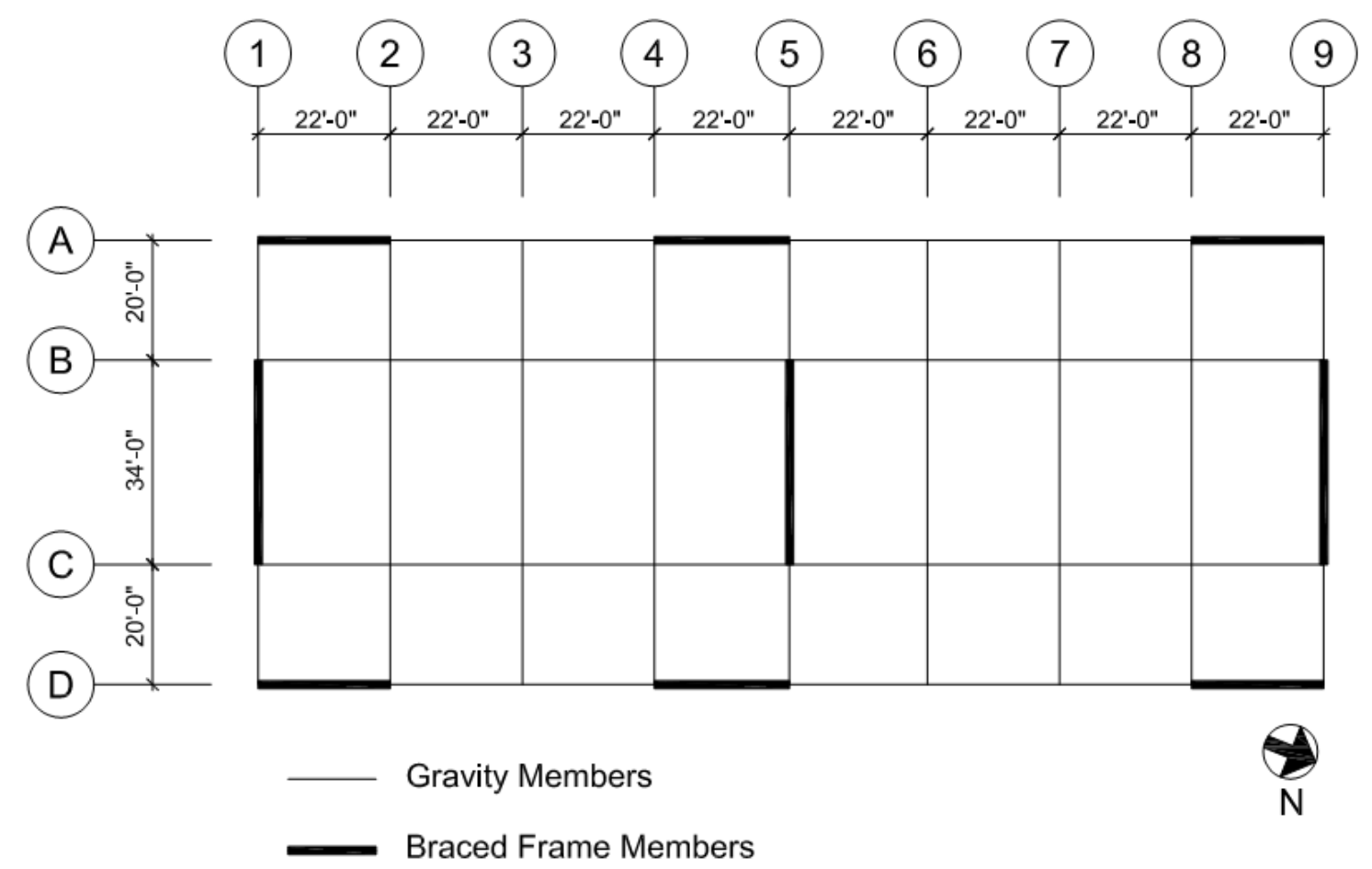

Figure BB: Roof and Floor Framing Plans of the RECH Building

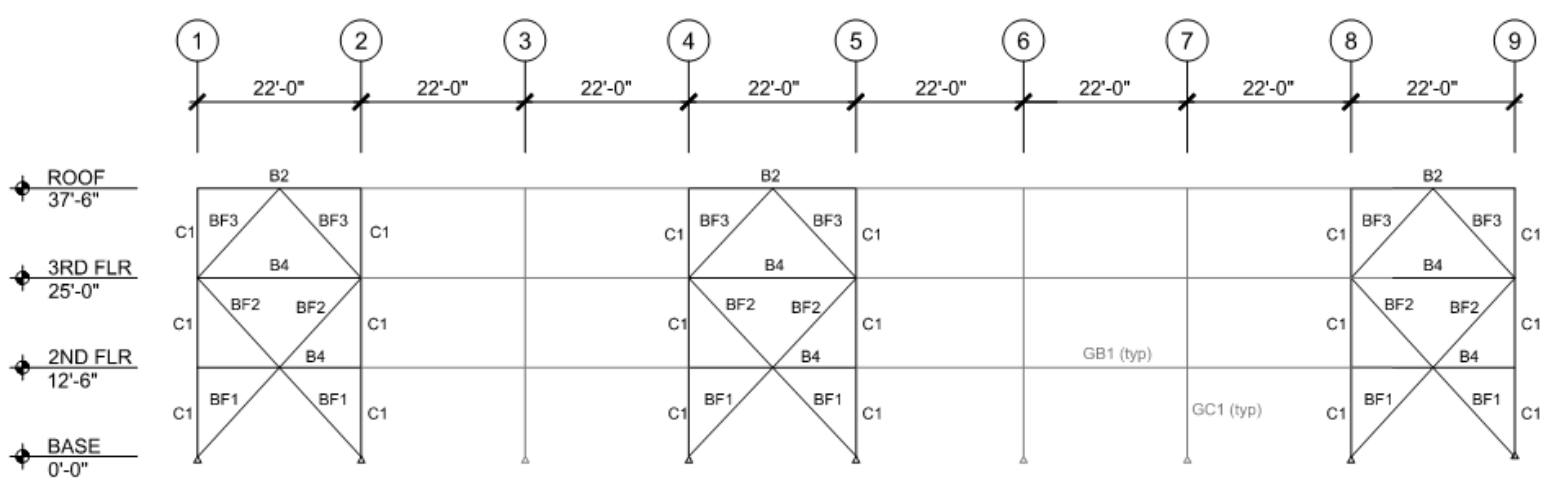

Figure CC: Braced Frame Elevation @ Gridlines A \& D 


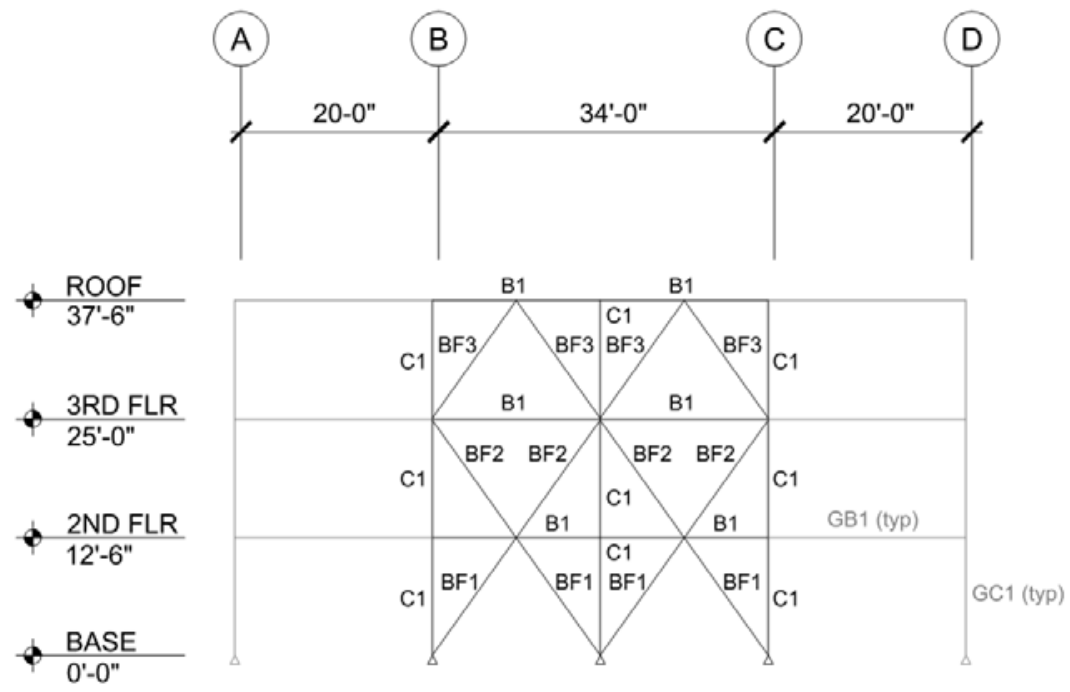

Figure DD: Braced Frame Elevation @ Gridlines 1, 5, \& 9

\begin{tabular}{|c|c|c|}
\hline \multicolumn{3}{|c|}{ Framing Members } \\
\hline Label & Type & Size \\
\hline B1 & Beam & W12x16 \\
\hline $\mathrm{B} 2$ & Beam & W12x19 \\
\hline B3 & Beam & $\mathrm{W} 14 \times 22$ \\
\hline B4 & Beam & $\mathrm{W} 16 \times 26$ \\
\hline BF1 & Brace & $\mathrm{TS} 5 \times 5 \times 1 / 2$ \\
\hline BF2 & Brace & $\mathrm{TS} 5 \times 5 \times 3 / 8$ \\
\hline BF3 & Brace & $\mathrm{TS} 5 \times 5 \times 5 / 16$ \\
\hline BF4 & Brace & TS6x6x1/2 \\
\hline $\mathrm{C} 1$ & Column & $\mathrm{TS} 7 \times 7 \times 1 / 2$ \\
\hline GB1 & Beam & W12x19 \\
\hline $\mathrm{GC} 1$ & Column & $\mathrm{TS} 7 \times 7 \times 1 / 2$ \\
\hline
\end{tabular}

Table 12: Braced Frame Member Sizes 


\section{APPENDIX B.0: MODAL INFORMATION}

\section{Appendix B.1: Modal Information for the RECH Building}

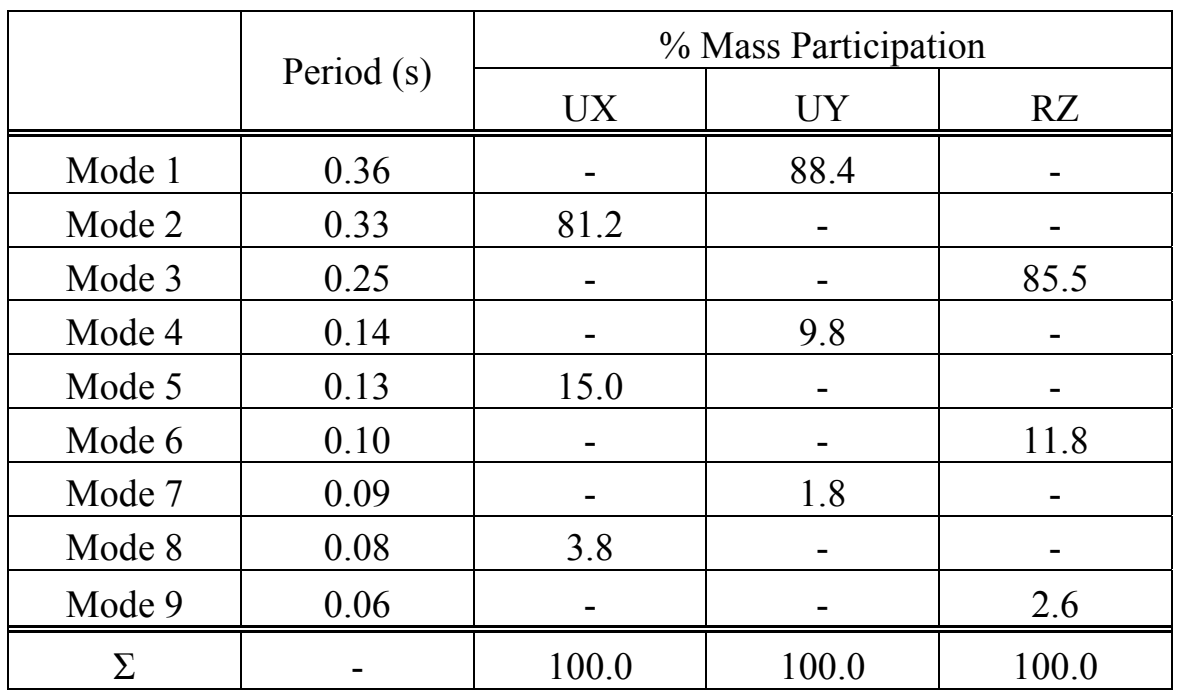

Table 13: Modal Periods and \% Mass Participation of the RECH Building

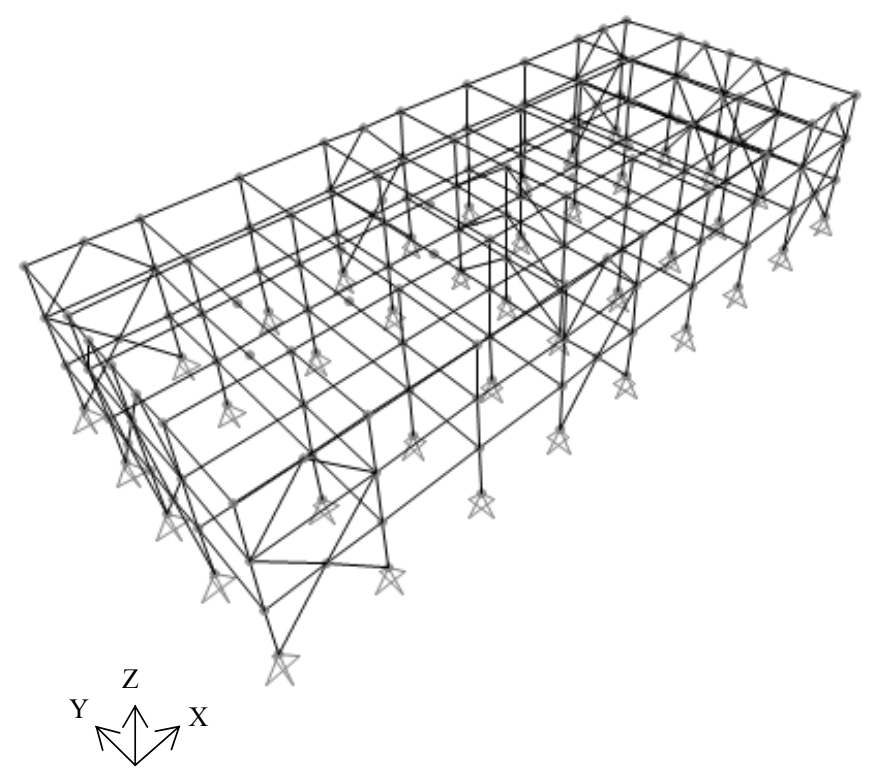

Figure EE: Finite Element Model of the RECH Building 

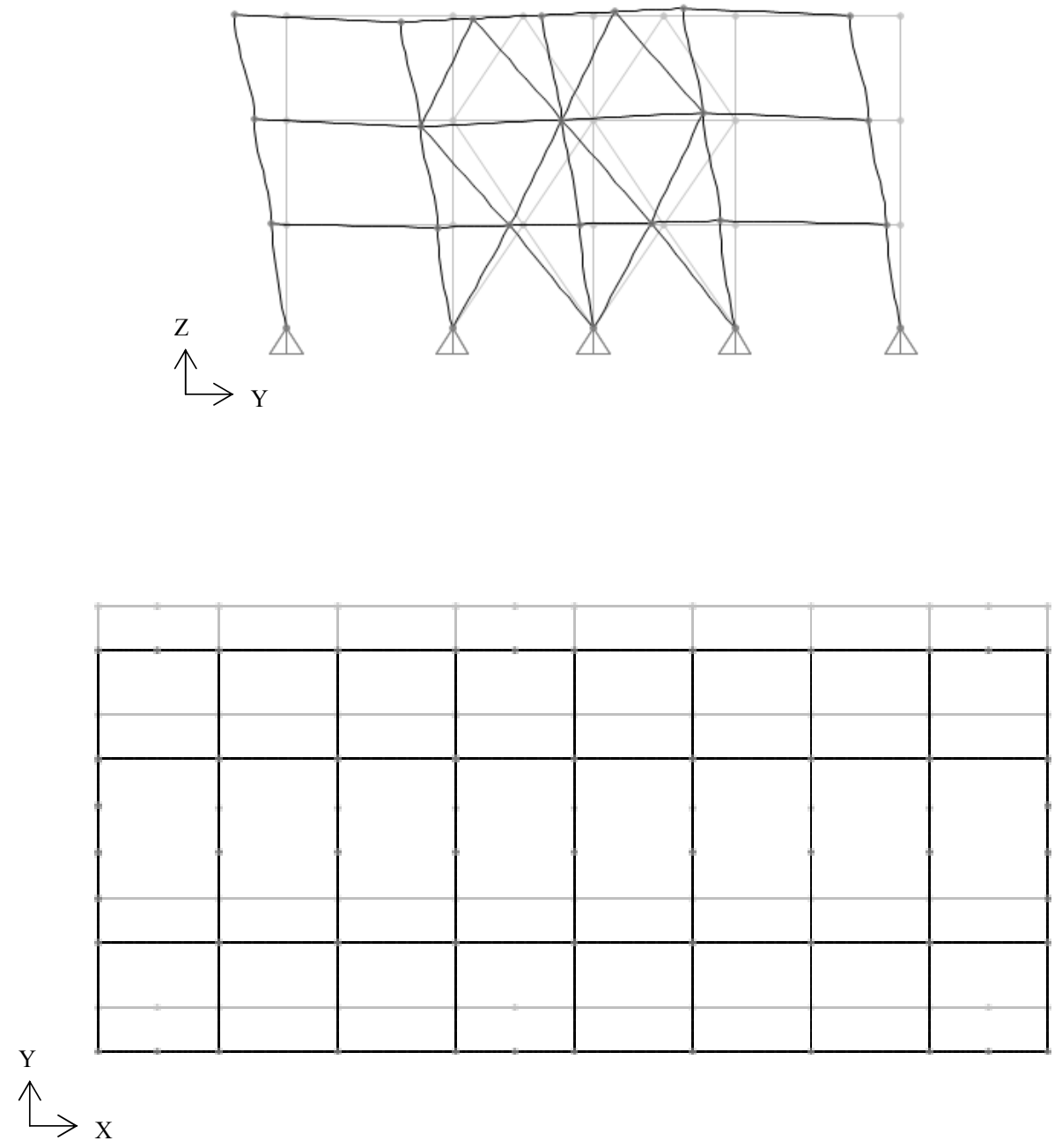

(a) Mode 1: Translation in Y Direction 

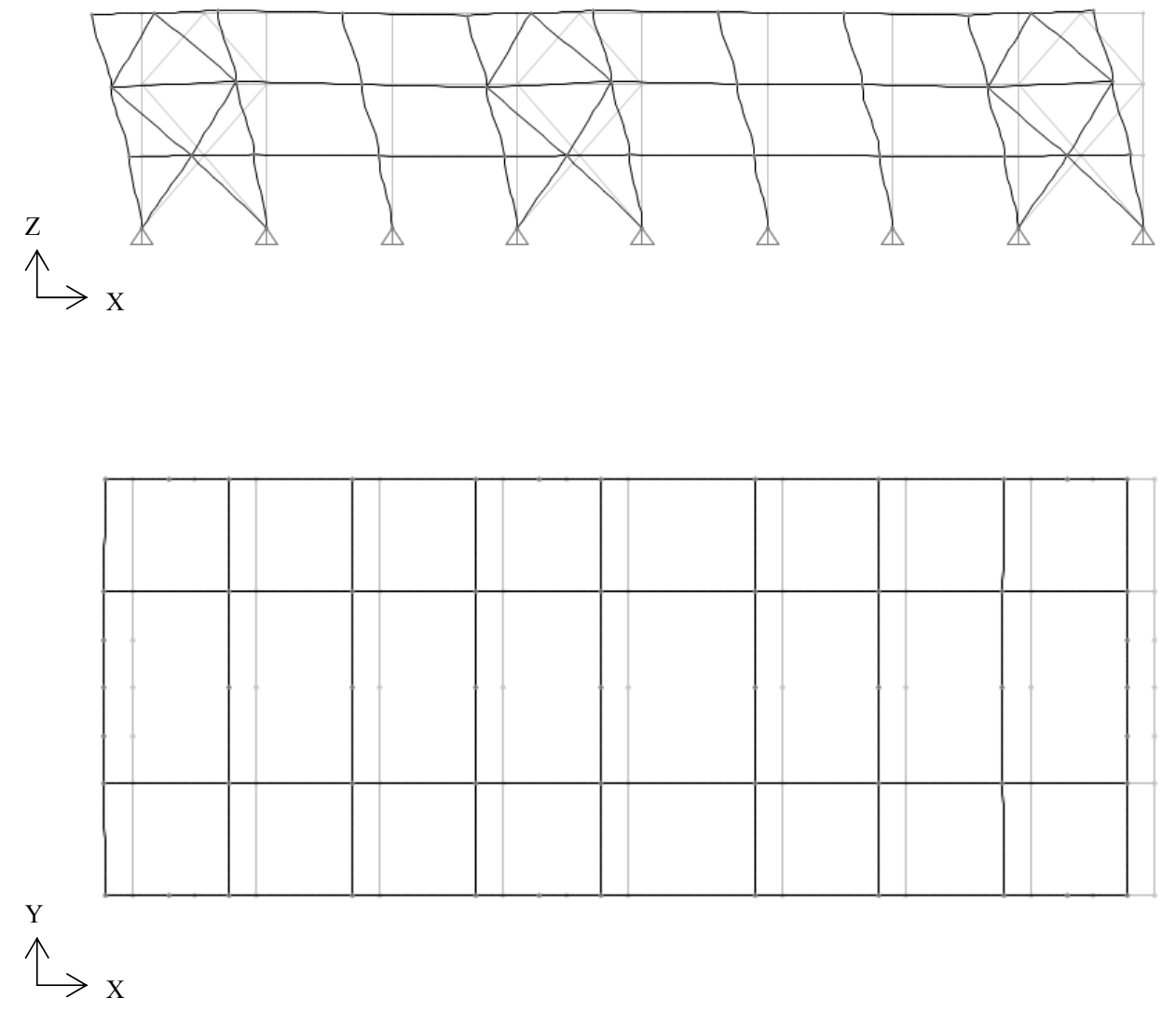

(b) Mode 2: Translation in X Direction 

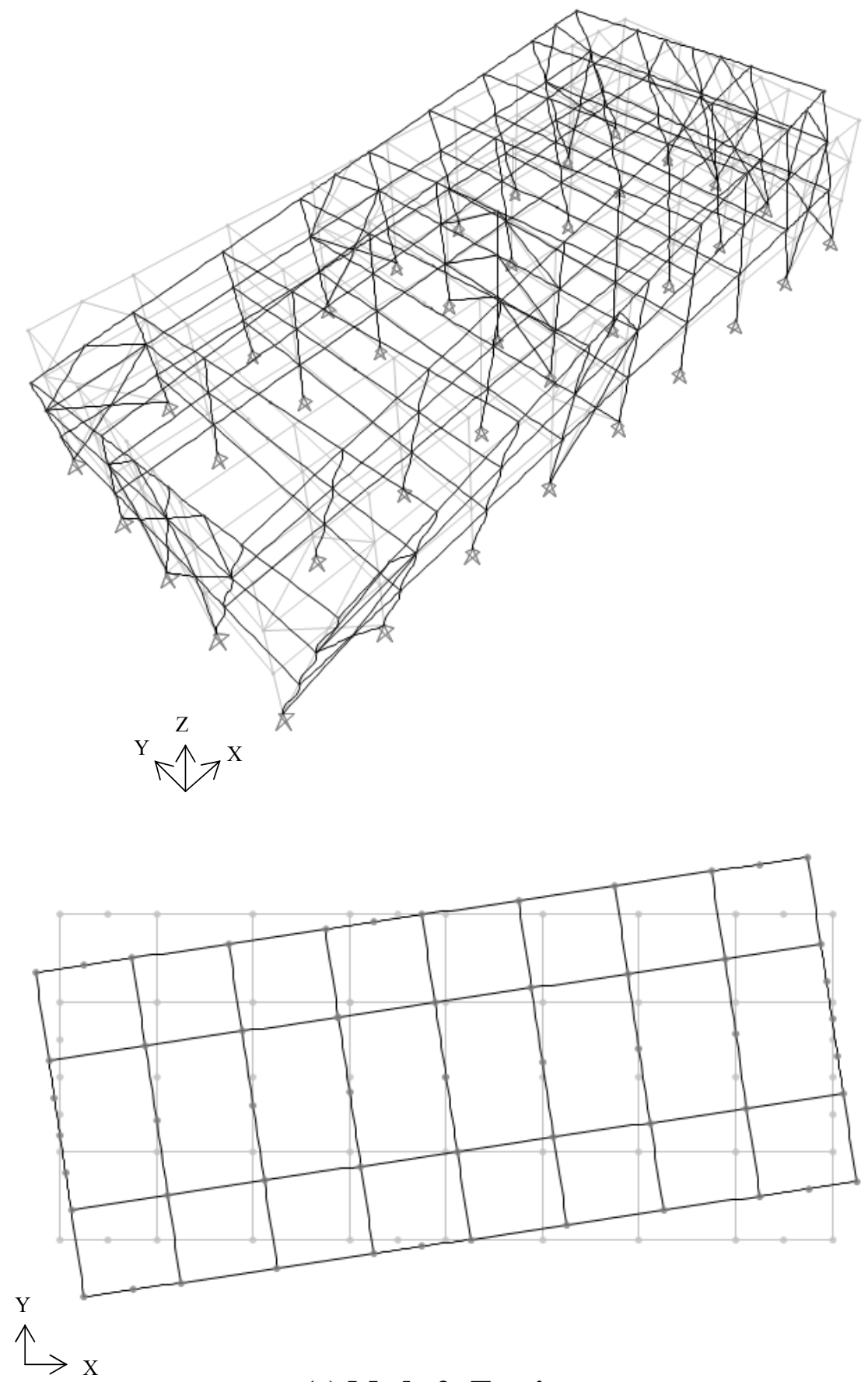

(c) Mode 2: Torsion 

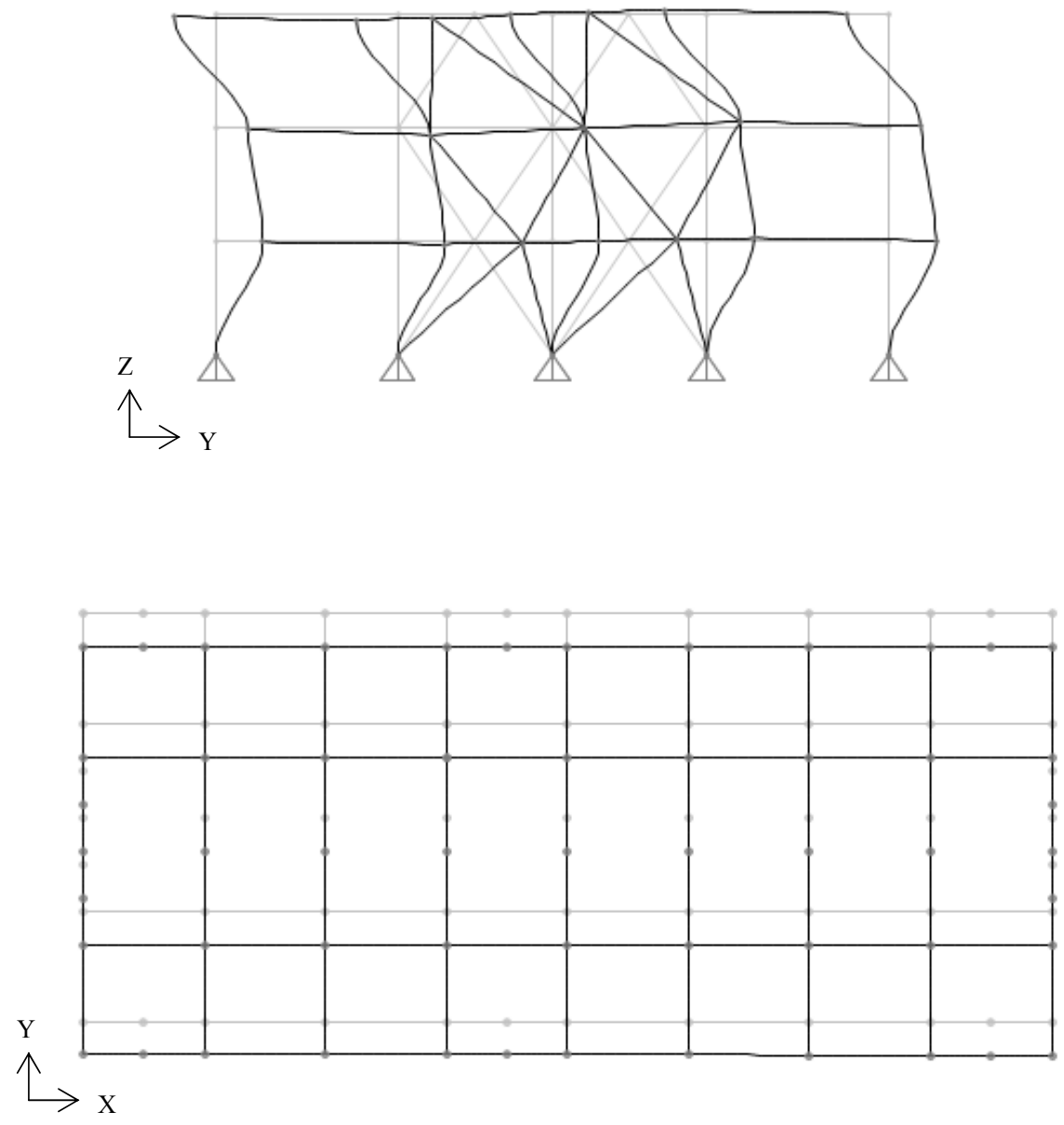

(d) Mode 4: Translation in Y Direction 

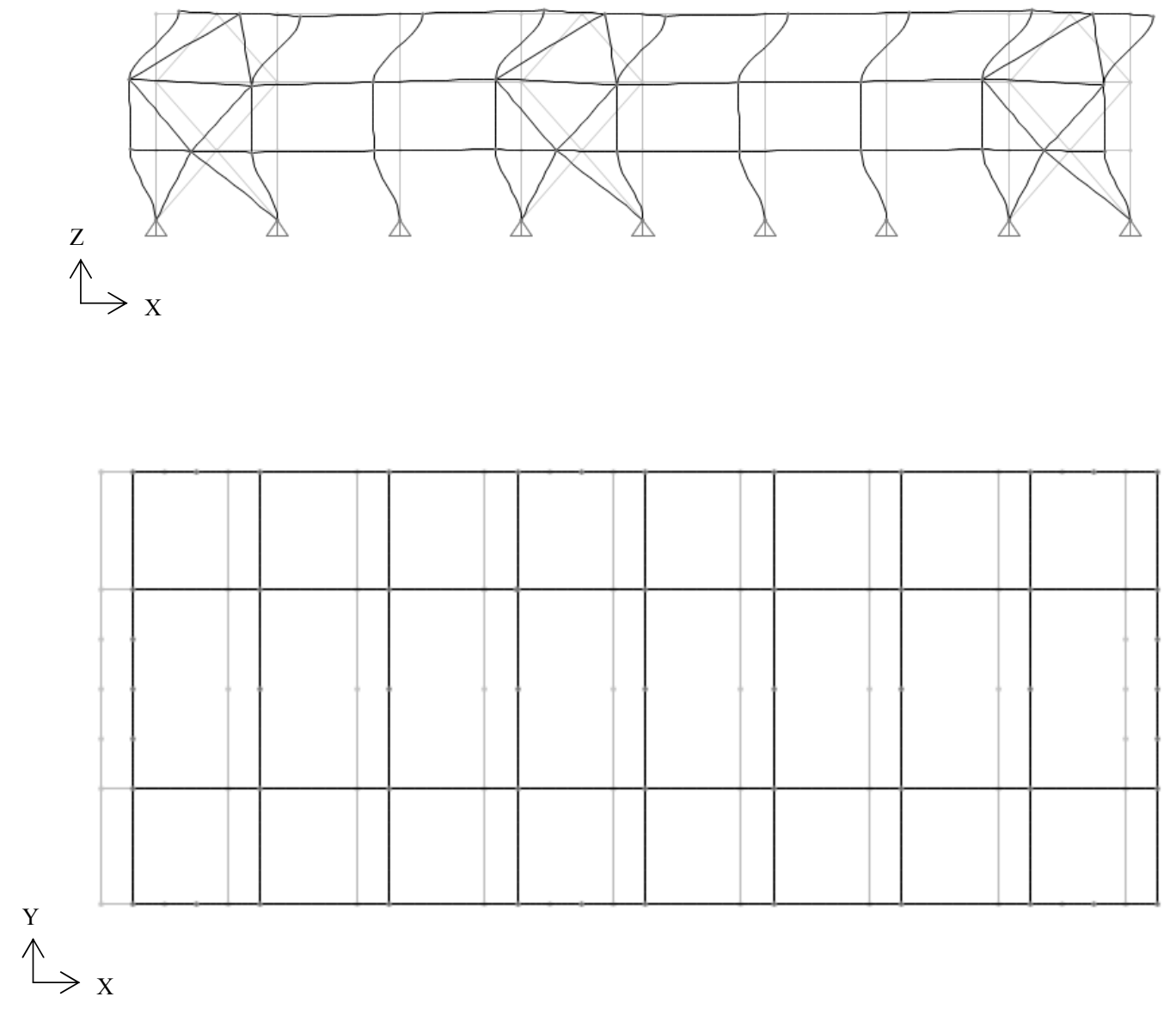

(e) Mode 5: Translation in X Direction 

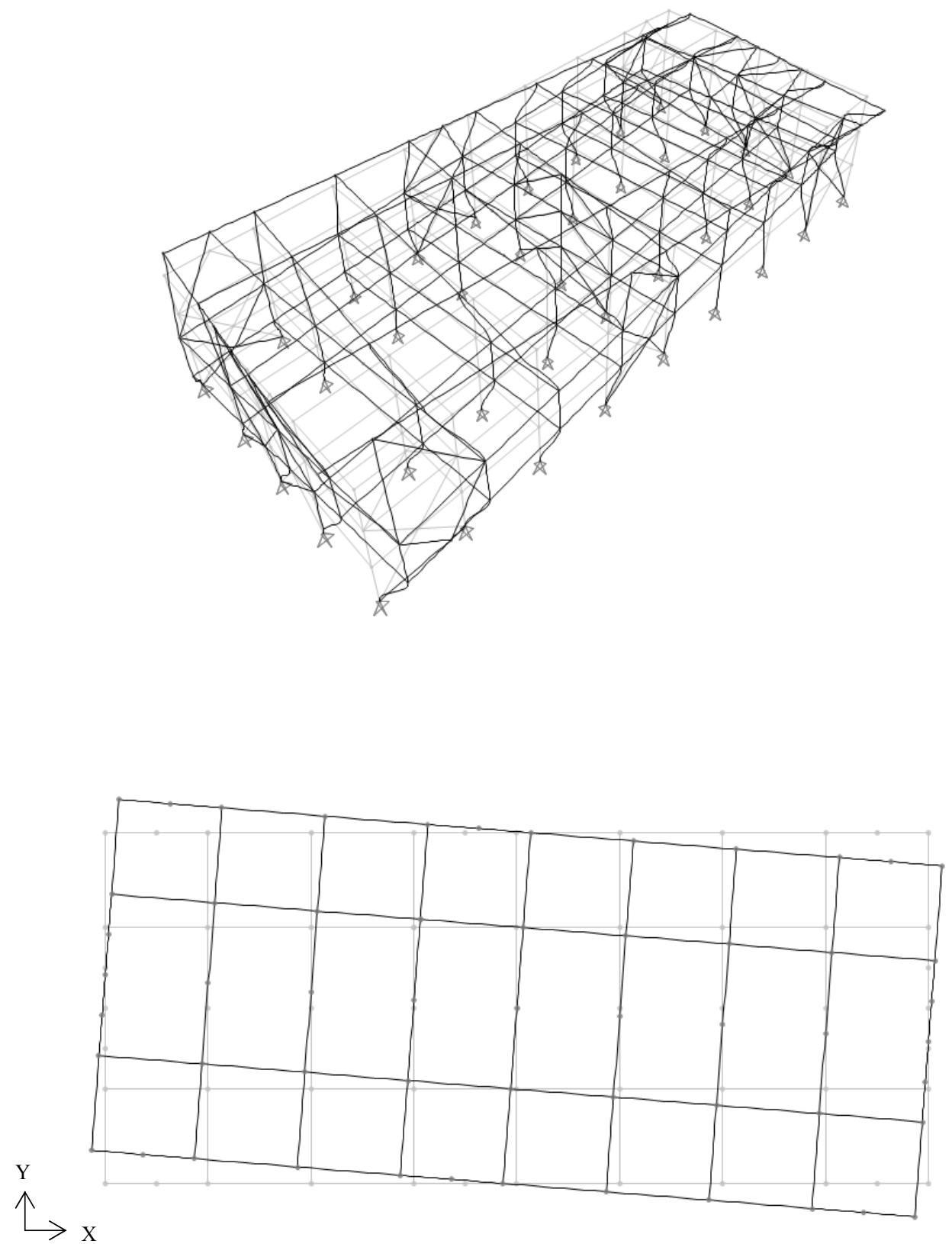

(f) Mode 6: Torsion 

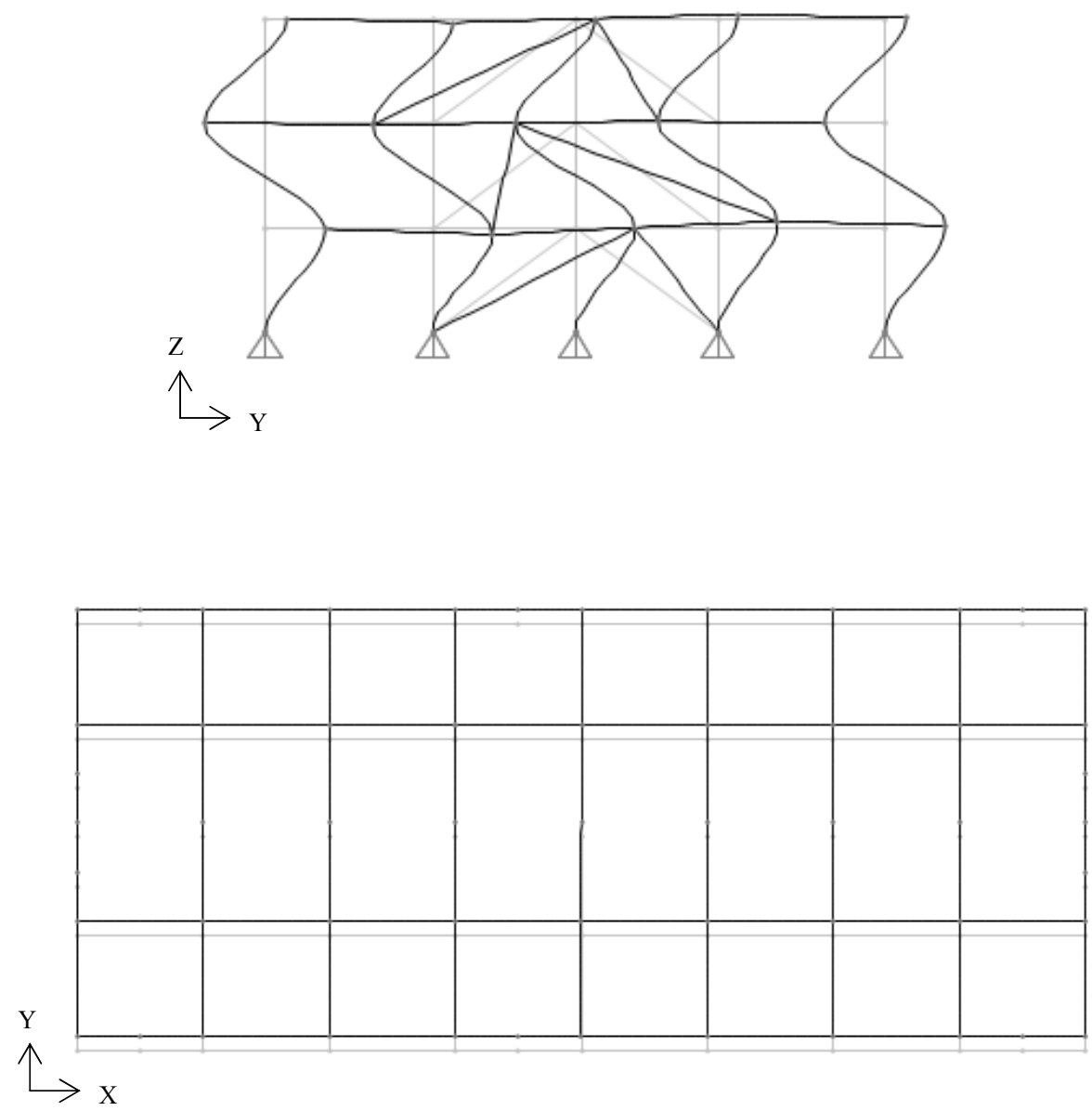

(g) Mode 7: Translation in Y Direction 

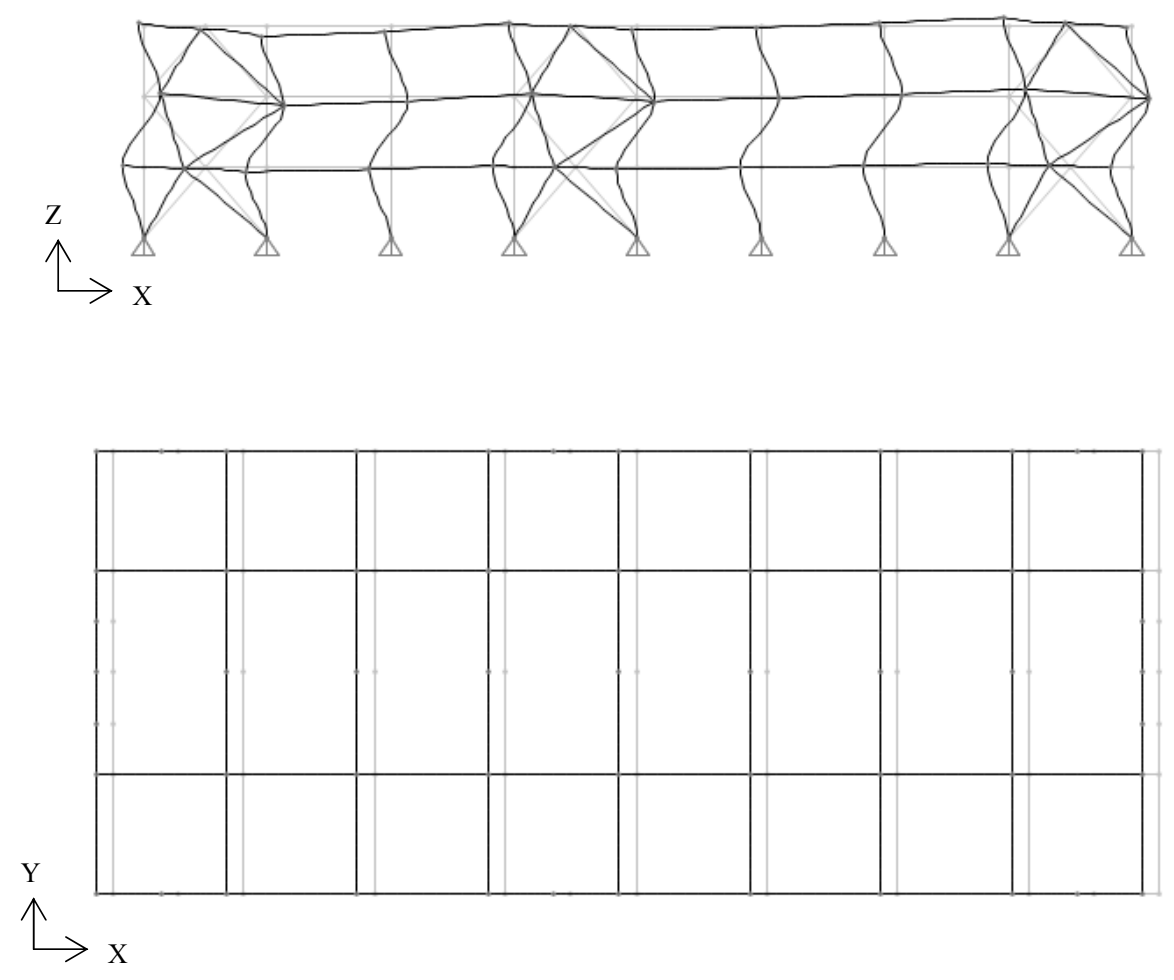

(H) Mode 8: Translation in X Direction 

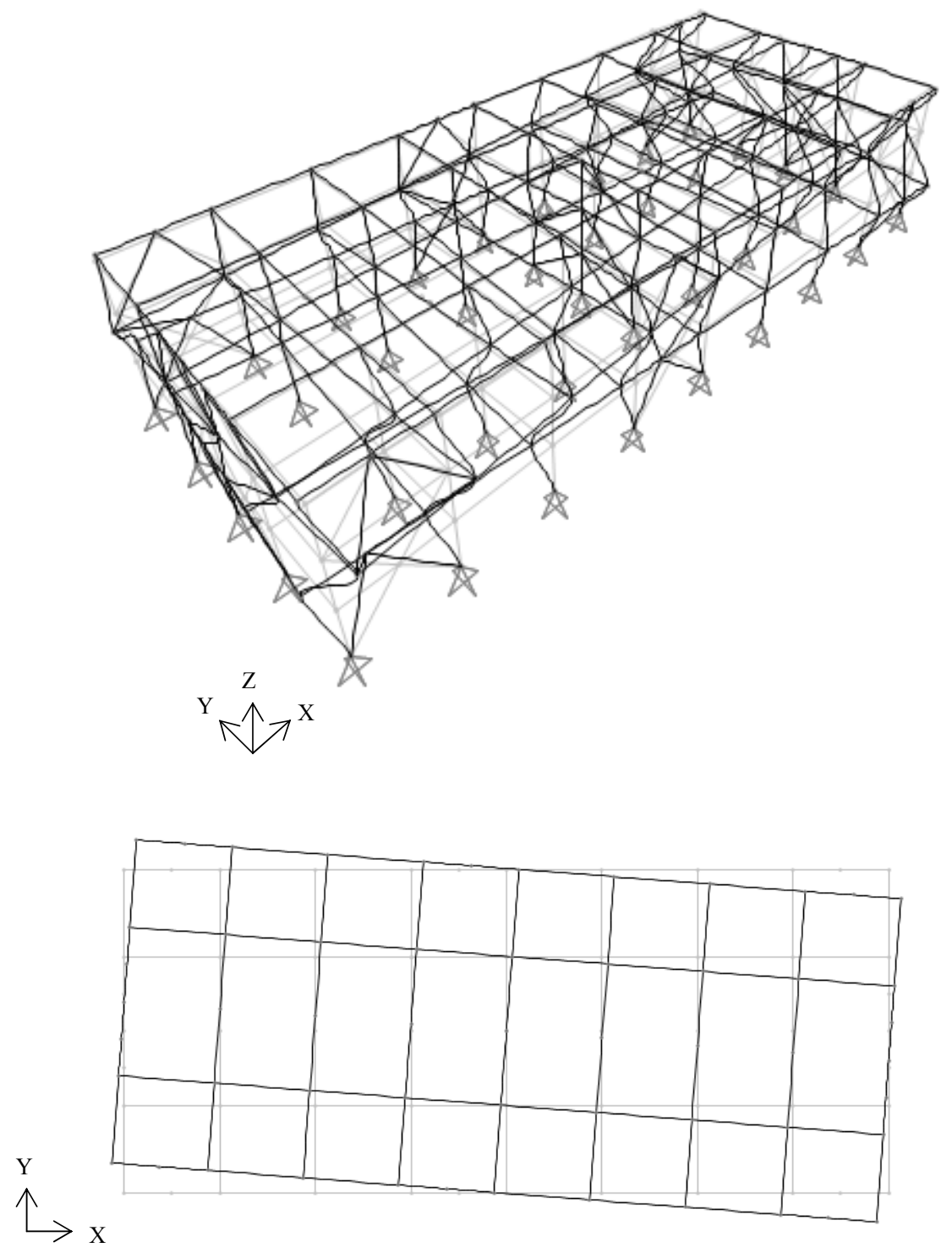

(f) Mode 9: Torsion

Figure FF: Mode Shapes of the RECH Building 
Appendix B.2: Modal Information for Tower 1

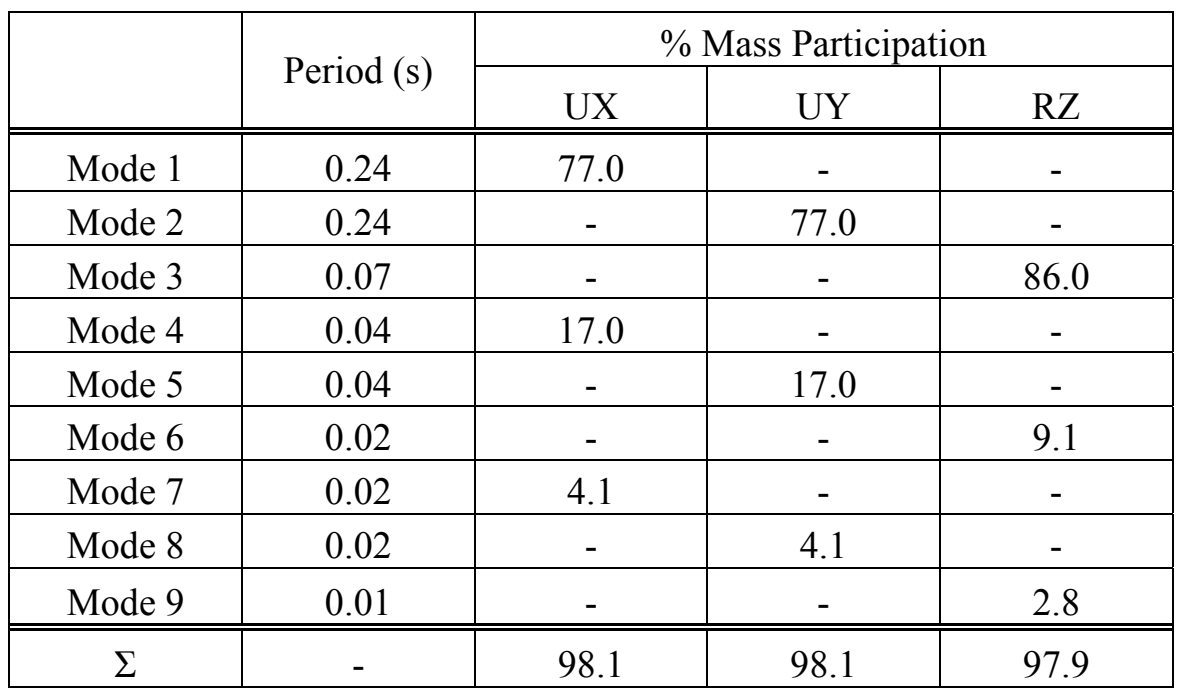

Table 14: Modal Periods and \% Mass Participation of Tower 1 Attached to Platform

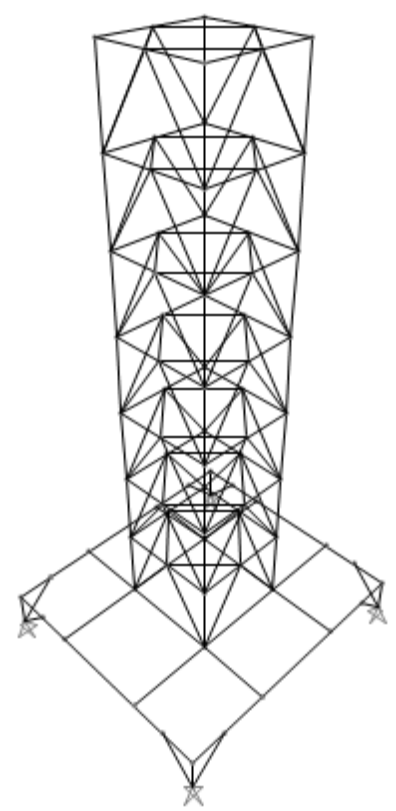

Figure GG: Finite Element Model of Tower 1 Attached to Platform 


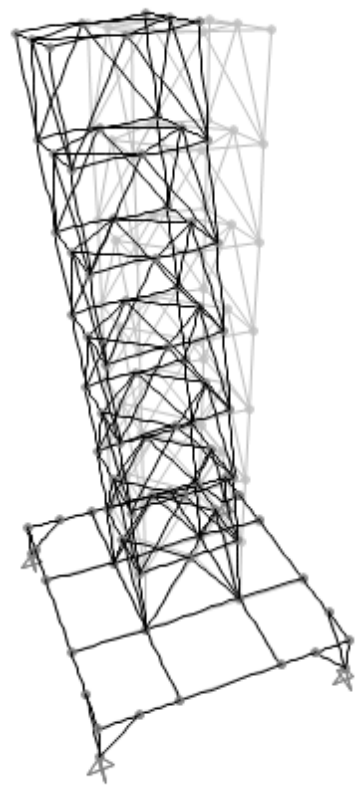

(a) Mode 1 \& Mode 2: Translation in X \& Y Directions

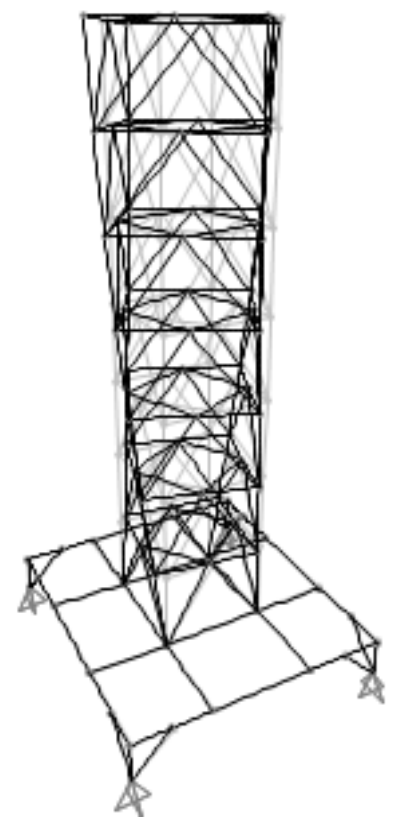

(b) Mode 3: Torsion 


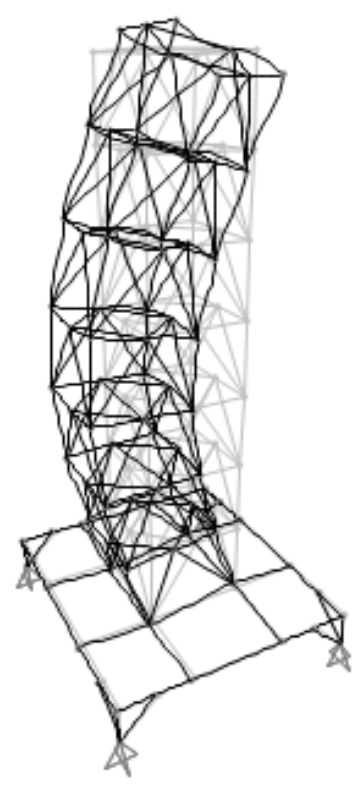

(c) Mode 4 \& Mode 5: Translation in X \& Y Directions

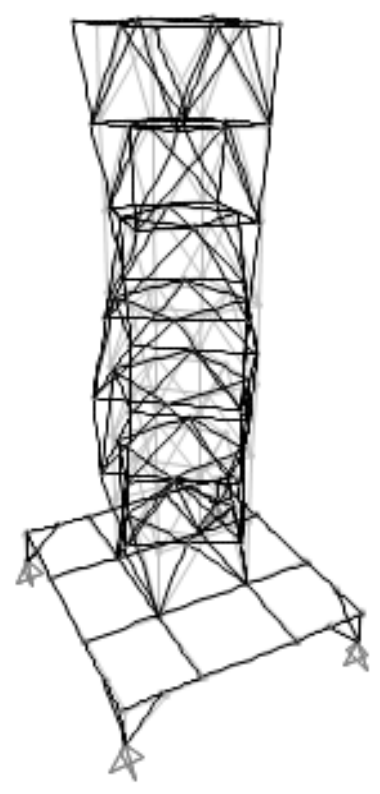

(d) Mode 6: Torsion 


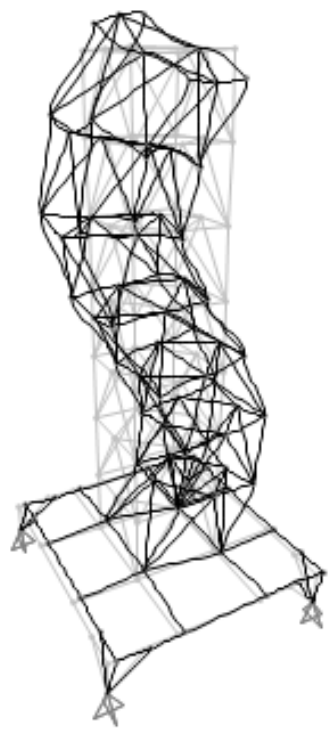

(e) Mode 7 \& Mode 8: Translation in X \& Y Directions

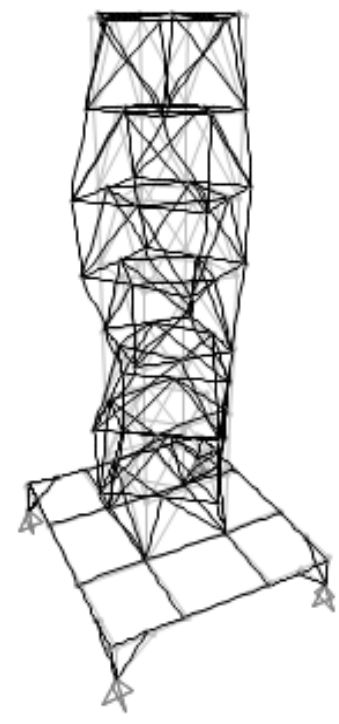

(f) Mode 9: Torsion

Figure HH: Mode Shapes of Tower 1 


\section{Appendix B.3: Modal Information for Tower 2}

\begin{tabular}{|c|c|c|c|c|}
\hline \multirow{2}{*}{} & \multirow{2}{*}{ Period (s) } & \multicolumn{3}{|c|}{ \% Mass Participation } \\
\cline { 3 - 5 } & & $\mathrm{UX}$ & $\mathrm{UY}$ & $\mathrm{RZ}$ \\
\hline \hline Mode 1 & 0.35 & 73.0 & - & - \\
\hline Mode 2 & 0.35 & - & 73.0 & - \\
\hline Mode 3 & 0.09 & - & - & 85.0 \\
\hline Mode 4 & 0.07 & 18.0 & - & - \\
\hline Mode 5 & 0.07 & - & 18.0 & - \\
\hline Mode 6 & 0.03 & - & - & 9.2 \\
\hline Mode 7 & 0.03 & 5.1 & - & - \\
\hline Mode 8 & 0.03 & - & 5.1 & - \\
\hline Mode 9 & 0.02 & - & - & 3.1 \\
\hline \hline ¿ & - & 96.1 & 96.1 & 97.2 \\
\hline
\end{tabular}

Table 15: Modal Periods and \% Mass Participation of Tower 2 Attached to the Platform

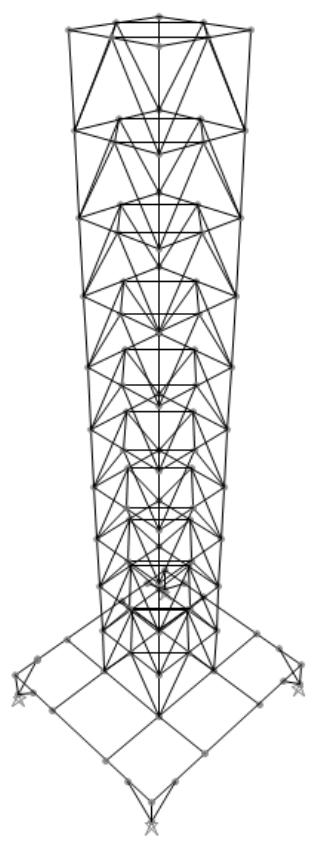

Figure II: Finite Element Model of Tower 2 Attached to the Platform 


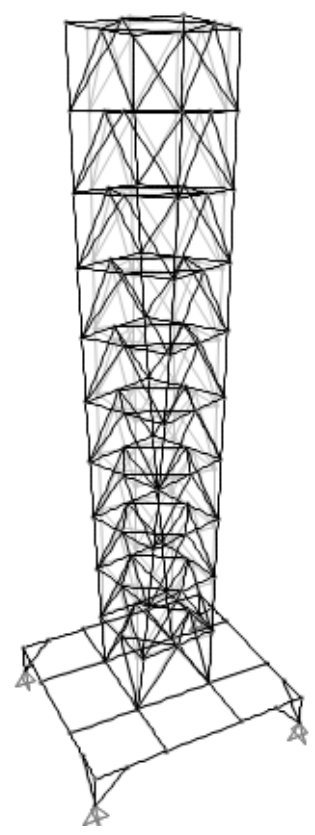

(a) Mode 1 \& Mode 2: Translation in X \& Y Directions

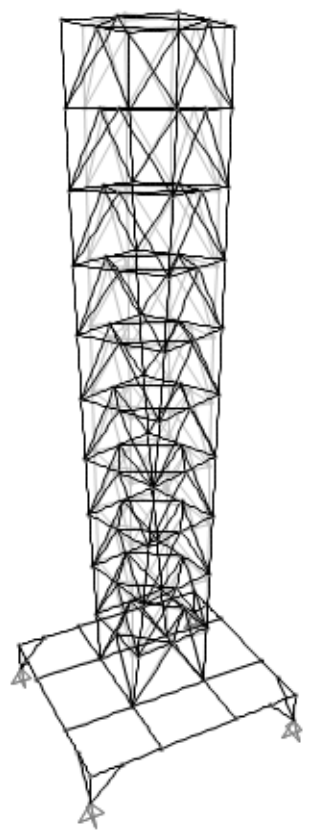

(b) Mode 3: Torsion 


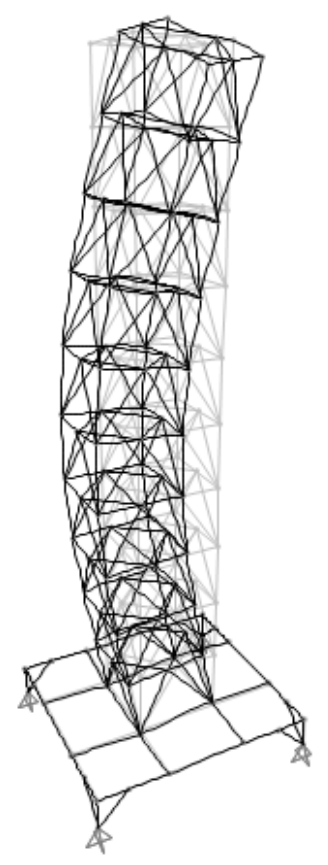

(c) Mode 4 \& Mode 5: Translation in X \& Y Directions

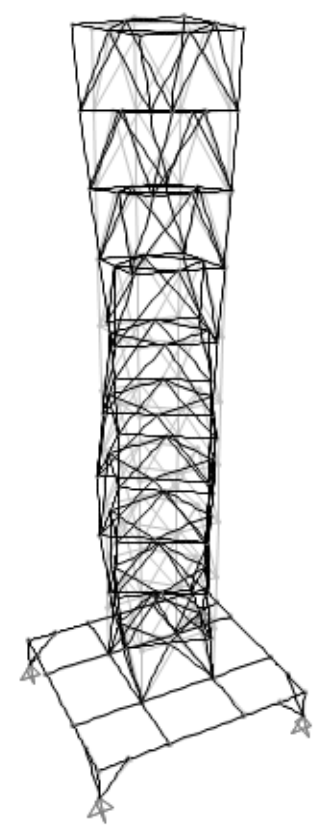

(d) Mode 6: Torsion 


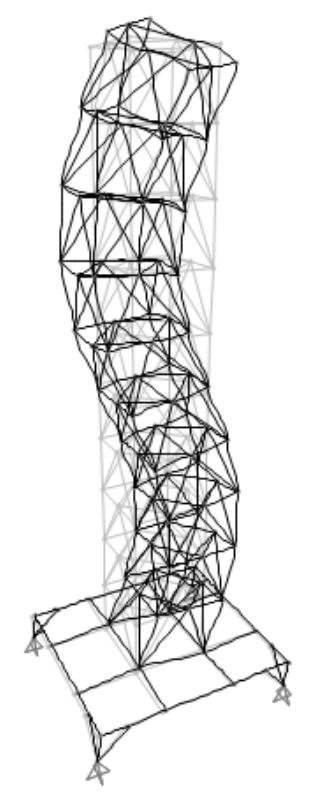

(e) Mode 7 \& Mode 8: Translation in X \& Y Directions

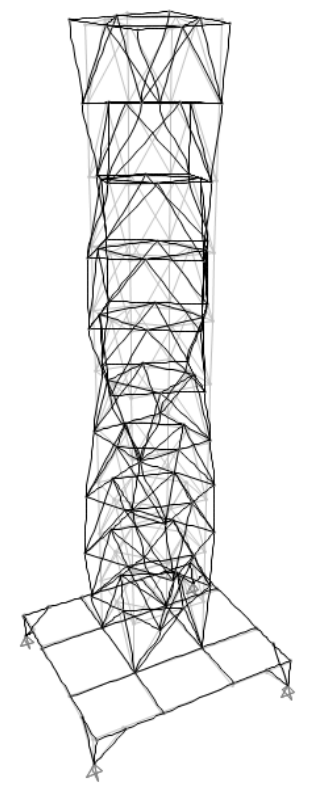

(f) Mode 9: Torsion

Figure JJ: Mode Shapes of Tower 2 


\section{Appendix B.4: Modal Information for Tower 3}

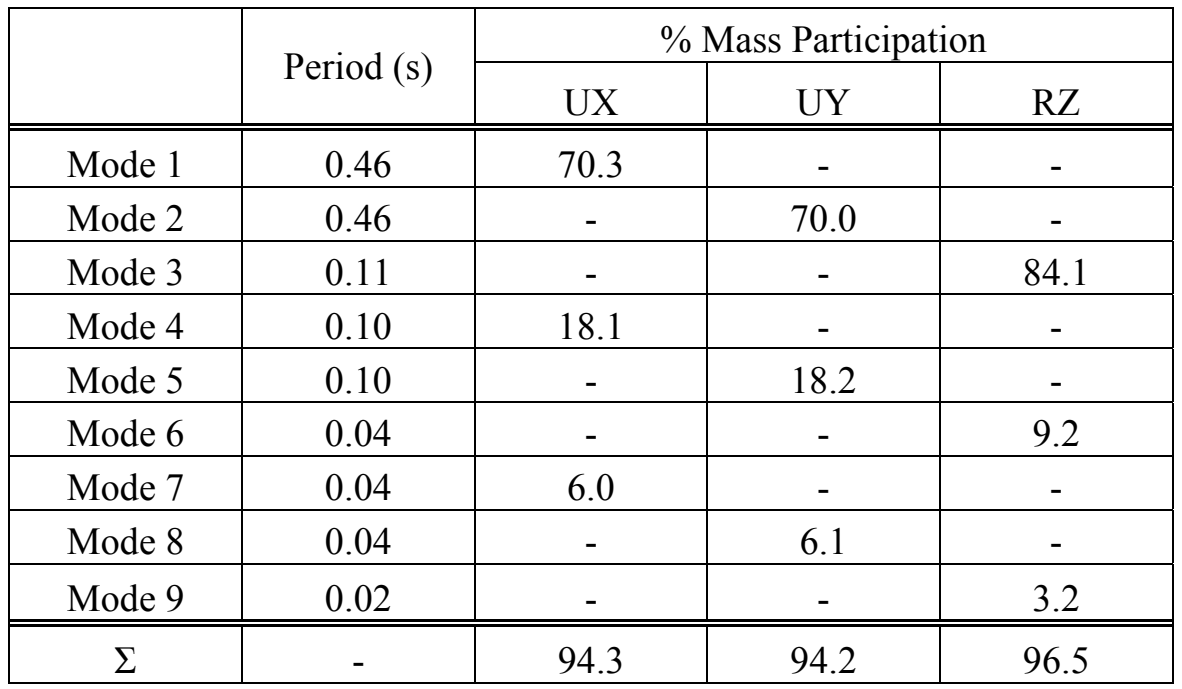

Table 16: Modal Periods and \% Mass Participation of Tower 3 Attached to the Platform

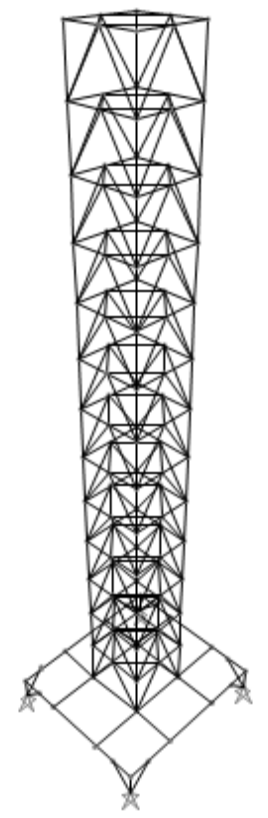

Figure KK: Finite Element Model of Tower 3 Attached to the Platform 


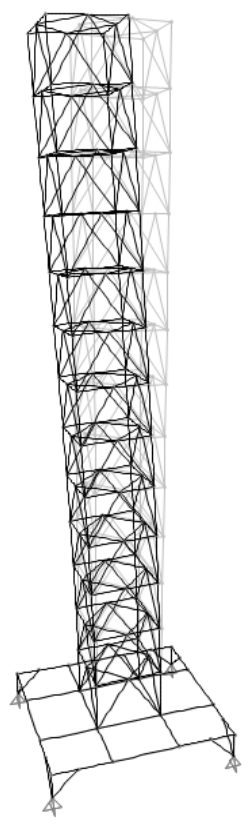

(a) Mode 1 \& Mode 2: Translation in X \& Y Directions

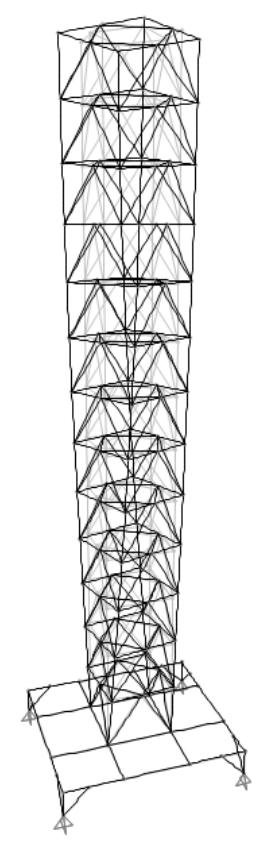

(b) Mode 3: Torsion 


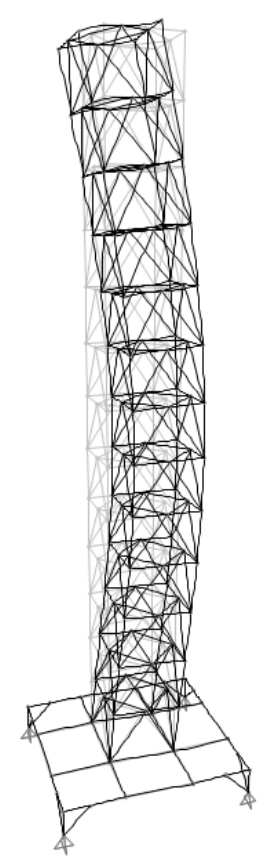

(c) Mode 4 \& Mode 5: Translation in X \& Y Directions

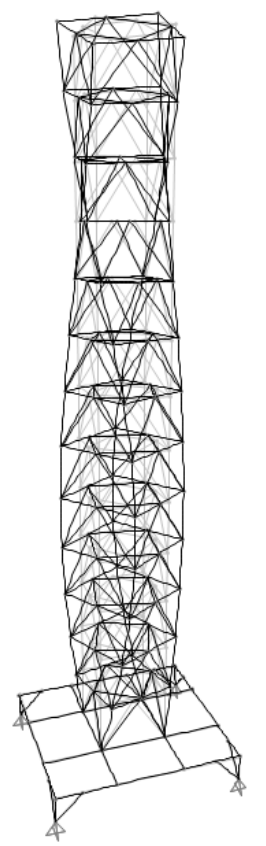

(d) Mode 6: Torsion 


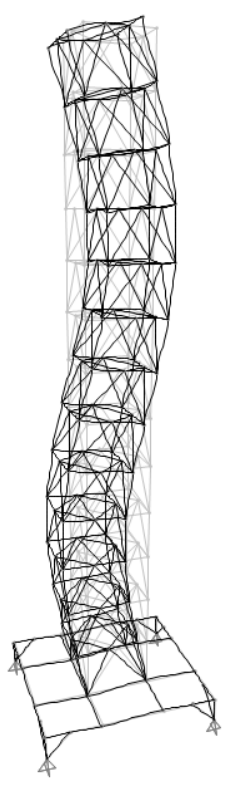

(e) Mode 7 \& Mode 8: Translation in X \& Y Directions

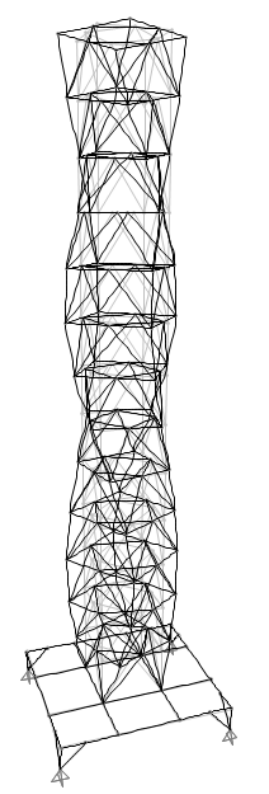

(f) Mode 9: Torsion

Figure LL: Mode Shapes of Tower 3 


\section{Appendix B.5: Modal Information for Tower 1 Attached to the RECH Building}

\begin{tabular}{|c|c|c|c|c|}
\hline \multirow{2}{*}{} & \multirow{2}{*}{ Period (s) } & \multicolumn{3}{|c|}{ \% Mass Participation } \\
\cline { 3 - 5 } & & UX & UY & RZ \\
\hline \hline Mode 1 & 0.36 & - & 87.5 & - \\
\hline Mode 2 & 0.34 & 79.1 & - & - \\
\hline Mode 3 & 0.27 & - & - & 63.0 \\
\hline Mode 4 & 0.24 & 2.0 & - & - \\
\hline Mode 5 & 0.23 & - & - & 22.3 \\
\hline Mode 6 & 0.14 & - & 9.7 & - \\
\hline Mode 7 & 0.13 & 14.8 & - & - \\
\hline Mode 8 & 0.10 & - & - & 11.7 \\
\hline Mode 9 & 0.09 & - & 1.8 & - \\
\hline Mode 10 & 0.08 & 3.5 & - & - \\
\hline Mode 11 & 0.06 & - & - & 2.5 \\
\hline \hline$\Sigma$ & - & 99.4 & 99.0 & 99.4 \\
\hline
\end{tabular}

Table 17: Modal Periods and \% Mass Participation of Tower 1 Attached to the RECH Building

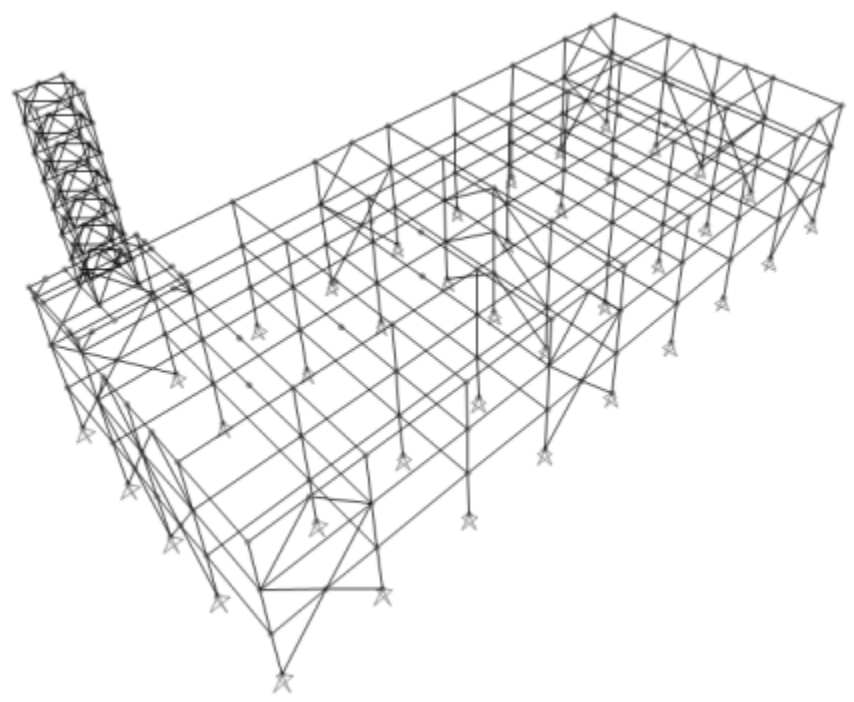

Figure MM: Finite Element Model of Tower 1 Attached to the RECH Building 


\section{Appendix B.6: Modal Information for Tower 2 Attached to the RECH Building}

\begin{tabular}{|c|c|c|c|c|}
\hline \multirow{2}{*}{} & \multirow{2}{*}{ Period (s) } & \multicolumn{3}{|c|}{ \% Mass Participation } \\
\cline { 3 - 5 } & & UX & UY & RZ \\
\hline \hline Mode 1 & 0.38 & - & 44 & 3 \\
\hline Mode 2 & 0.37 & 24 & - & - \\
\hline Mode 3 & 0.34 & - & 44 & 3 \\
\hline Mode 4 & 0.32 & 58 & - & - \\
\hline Mode 5 & 0.25 & - & - & 80 \\
\hline Mode 6 & 0.14 & - & 10 & - \\
\hline Mode 7 & 0.13 & 15 & - & - \\
\hline Mode 8 & 0.10 & - & - & 12 \\
\hline Mode 9 & 0.09 & - & 2 & - \\
\hline Mode 10 & 0.08 & 3 & - & - \\
\hline Mode 11 & 0.06 & - & - & 2 \\
\hline \hline$\Sigma$ & - & 100.5 & 99.5 & 99.9 \\
\hline
\end{tabular}

Table 18: Modal Periods and \% Mass Participation of Tower 2 Attached to the RECH Building

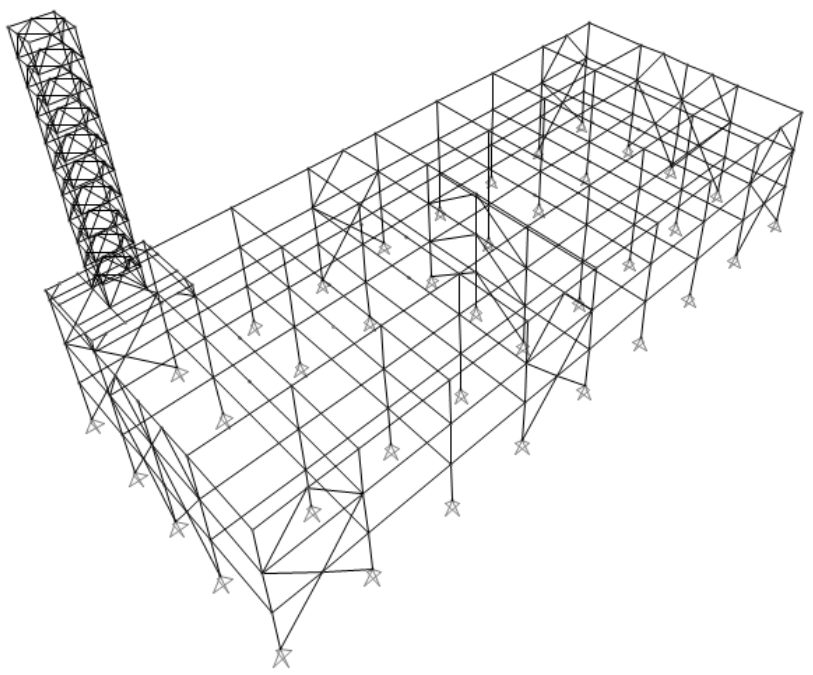

Figure NN: Finite Element Model of Tower 2 Attached to RECH Building 


\section{Appendix B.7: Modal Information for Tower 3 Attached to the RECH Building}

\begin{tabular}{|c|c|c|c|c|}
\hline \multirow{2}{*}{} & \multirow{2}{*}{ Period (s) } & \multicolumn{3}{|c|}{ \% Mass Participation } \\
\cline { 3 - 5 } & & UX & UY & RZ \\
\hline \hline Mode 1 & 0.47 & 4 & - & 1 \\
\hline Mode 2 & 0.47 & - & 4 & 2 \\
\hline Mode 3 & 0.35 & - & 84 & - \\
\hline Mode 4 & 0.33 & 77 & - & - \\
\hline Mode 5 & 0.25 & - & - & 82 \\
\hline Mode 6 & 0.14 & - & 10 & - \\
\hline Mode 7 & 0.13 & 15 & - & - \\
\hline Mode 8 & 0.11 & - & - & 11 \\
\hline Mode 9 & 0.09 & - & 2 & - \\
\hline Mode 10 & 0.08 & 3 & - & - \\
\hline Mode 11 & 0.06 & - & - & 3 \\
\hline \hline$\Sigma$ & - & 99.3 & 99.7 & 99.1 \\
\hline
\end{tabular}

Table 19: Modal Periods and \% Mass Participation of Tower 3 Attached to the RECH Building

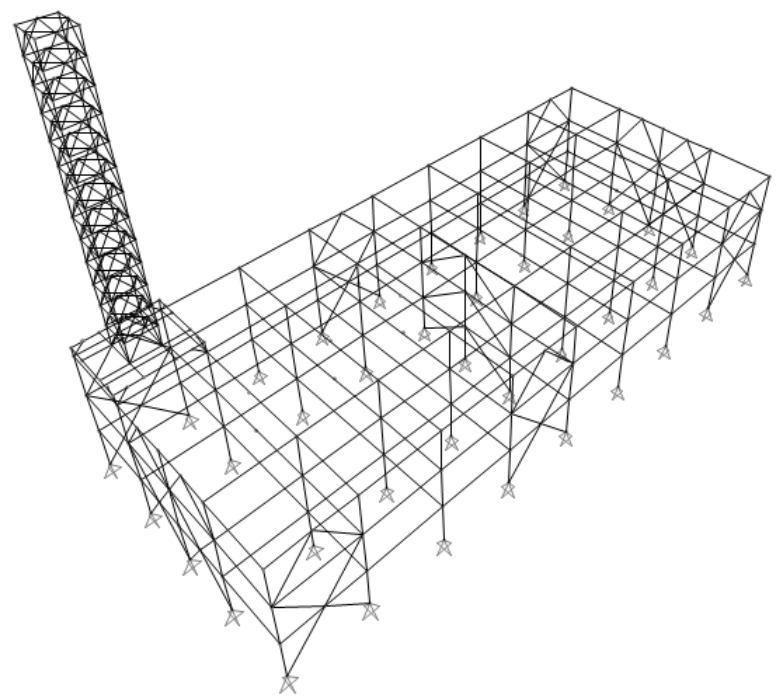

Figure OO: Finite Element Model of Tower 3 Attached to the RECH Building 


\section{APPENDIX C.0: NUMERICAL RESULTS}

\section{Appendix C.1: Earthquake Information}

\begin{tabular}{|c|c|c|c|}
\hline a/v Category & Load Case No. & Earthquake & $\begin{array}{l}\text { a/v ratio } \\
{[\mathrm{g} / \mathrm{m} / \mathrm{s}]}\end{array}$ \\
\hline \multirow{10}{*}{$\begin{array}{l}\text { Low a/v Ratio } \\
\mathrm{a} / \mathrm{v} \leq 0.8 \mathrm{~g} / \mathrm{m} / \mathrm{s}\end{array}$} & 1 & Landers & 0.29 \\
\hline & 2 & Loma Prieta & 0.37 \\
\hline & 3 & San Fernando & 0.43 \\
\hline & 4 & Loma Prieta & 0.48 \\
\hline & 5 & Loma Prieta & 0.50 \\
\hline & 6 & Loma Prieta & 0.52 \\
\hline & 7 & Northridge & 0.56 \\
\hline & 8 & Chalfant Valley & 0.59 \\
\hline & 9 & Loma Prieta & 0.62 \\
\hline & 10 & Loma Prieta & 0.68 \\
\hline \multirow{10}{*}{$\begin{array}{c}\text { Medium a/v } \\
\text { Ratio } \\
\mathrm{a} / \mathrm{v}>0.8 \mathrm{~g} / \mathrm{m} / \mathrm{s} \\
\mathrm{a} / \mathrm{v}<1.2 \mathrm{~g} / \mathrm{m} / \mathrm{s}\end{array}$} & 11 & Imperial Valley & 0.84 \\
\hline & 12 & Chalfant Valley & 0.88 \\
\hline & 13 & Gazli, USSR & 0.93 \\
\hline & 14 & Northridge & 0.95 \\
\hline & 15 & Nahanni, Canada & 0.98 \\
\hline & 16 & San Fernando & 1.00 \\
\hline & 17 & Coalinga & 1.01 \\
\hline & 18 & Helena, Montana & 1.05 \\
\hline & 19 & San Fernando & 1.11 \\
\hline & 20 & Santa Barbara & 1.14 \\
\hline \multirow{10}{*}{$\begin{array}{l}\text { High a/v Ratio } \\
\mathrm{a} / \mathrm{v} \geq 1.2 \mathrm{~g} / \mathrm{m} / \mathrm{s}\end{array}$} & 21 & Victoria, Mexico & 1.97 \\
\hline & 22 & San Fernando & 2.05 \\
\hline & 23 & Westmorland & 2.32 \\
\hline & 24 & Anza & 2.57 \\
\hline & 25 & Coyote Lake & 2.88 \\
\hline & 26 & Coalinga & 3.10 \\
\hline & 27 & Northern California & 3.25 \\
\hline & 28 & San Fernando & 3.48 \\
\hline & 29 & Whittier Narrows & 4.20 \\
\hline & 30 & Mammoth Lakes & 4.88 \\
\hline
\end{tabular}

Table 20: Earthquake Record Load Case Numbers 
Appendix C.0: Numerical Results 91

\section{Appendix C.2: Numerical Results for the Roof Amplification Factor}

\begin{tabular}{|c|c|c|c|c|c|c|}
\hline \multirow[b]{2}{*}{$\begin{array}{l}\text { Load } \\
\text { Case } \\
\text { No. }\end{array}$} & \multicolumn{3}{|c|}{ U1 } & \multicolumn{3}{|c|}{ U2 } \\
\hline & $\begin{array}{c}a_{\text {ground }} \\
{[\mathrm{g}]} \\
\end{array}$ & $\begin{array}{l}a_{\text {roof }} \\
{[\mathrm{g}]} \\
\end{array}$ & $\begin{array}{c}A_{r}=a_{\text {roof }} / a_{\text {ground }} \\
{[\mathrm{g} / \mathrm{g}]}\end{array}$ & $\begin{array}{c}a_{\text {ground }} \\
{[\mathrm{g}]} \\
\end{array}$ & $\begin{array}{r}a_{\text {roof }} \\
{[\mathrm{g}]} \\
\end{array}$ & $\begin{array}{c}A_{r}=a_{\text {roof }} / a_{\text {ground }} \\
{[g / g]}\end{array}$ \\
\hline 1 & 0.041 & 0.099 & 2.42 & 0.041 & 0.140 & 3.40 \\
\hline 2 & 0.088 & 0.335 & 3.80 & 0.088 & 0.411 & 4.67 \\
\hline 3 & 0.006 & 0.032 & 5.28 & 0.006 & 0.025 & 4.21 \\
\hline 4 & 0.061 & 0.125 & 2.05 & 0.061 & 0.180 & 2.94 \\
\hline 5 & 0.058 & 0.210 & 3.62 & 0.058 & 0.289 & 4.99 \\
\hline 6 & 0.194 & 0.625 & 3.22 & 0.194 & 0.581 & 3.00 \\
\hline 7 & 0.056 & 0.289 & 5.17 & 0.056 & 0.229 & 4.09 \\
\hline 8 & 0.037 & 0.128 & 3.46 & 0.037 & 0.203 & 5.49 \\
\hline 9 & 0.057 & 0.220 & 3.86 & 0.057 & 0.182 & 3.19 \\
\hline 10 & 0.110 & 0.378 & 3.44 & 0.110 & 0.284 & 2.58 \\
\hline 11 & 0.157 & 0.711 & 4.53 & 0.157 & 0.751 & 4.78 \\
\hline 12 & 0.056 & 0.152 & 2.71 & 0.056 & 0.238 & 4.26 \\
\hline 13 & 0.608 & 1.972 & 3.24 & 0.608 & 1.687 & 2.77 \\
\hline 14 & 0.060 & 0.070 & 1.16 & 0.060 & 0.047 & 0.79 \\
\hline 15 & 0.323 & 0.566 & 1.75 & 0.323 & 0.685 & 2.12 \\
\hline 16 & 0.009 & 0.035 & 3.88 & 0.009 & 0.025 & 2.75 \\
\hline 17 & 0.137 & 0.412 & 3.01 & 0.137 & 0.352 & 2.57 \\
\hline 18 & 0.173 & 0.462 & 2.67 & 0.173 & 0.545 & 3.15 \\
\hline 19 & 0.039 & 0.077 & 1.97 & 0.039 & 0.075 & 1.93 \\
\hline 20 & 0.072 & 0.140 & 1.95 & 0.072 & 0.110 & 1.53 \\
\hline 21 & 0.621 & 1.293 & 2.08 & 0.621 & 1.438 & 2.32 \\
\hline 22 & 0.090 & 0.279 & 3.10 & 0.090 & 0.198 & 2.20 \\
\hline 23 & 0.116 & 0.270 & 2.33 & 0.116 & 0.268 & 2.31 \\
\hline 24 & 0.131 & 0.304 & 2.32 & 0.131 & 0.268 & 2.05 \\
\hline 25 & 0.072 & 0.152 & 2.11 & 0.072 & 0.082 & 1.14 \\
\hline 26 & 0.062 & 0.115 & 1.85 & 0.062 & 0.147 & 2.38 \\
\hline 27 & 0.026 & 0.086 & 3.32 & 0.026 & 0.063 & 2.44 \\
\hline 28 & 0.212 & 0.458 & 2.16 & 0.212 & 0.262 & 1.24 \\
\hline 29 & 0.248 & 0.434 & 1.75 & 0.248 & 0.387 & 1.56 \\
\hline 30 & 0.078 & 0.101 & 1.30 & 0.078 & 0.059 & 0.76 \\
\hline
\end{tabular}

Table 21: Roof Amplification Factor for RECH Building without Tower Attached 
Appendix C.0: Numerical Results 92

\begin{tabular}{|c|c|c|c|c|c|c|}
\hline \multirow{2}{*}{$\begin{array}{c}\text { Load } \\
\begin{array}{c}\text { Case } \\
\text { No. }\end{array}\end{array}$} & $\mathrm{a}_{\text {ground }}$ & $\mathrm{a}_{\text {roof }}$ & $\mathrm{A}_{\mathrm{r}}=\mathrm{a}_{\text {roof }} / \mathrm{a}_{\text {ground }}$ & $\mathrm{a}_{\text {ground }}$ & $\mathrm{a}_{\text {roof }}$ & $\mathrm{A}_{\mathrm{r}}=\mathrm{a}_{\text {roof }} / \mathrm{a}_{\text {ground }}$ \\
\cline { 2 - 8 } & {$[\mathrm{g}]$} & {$[\mathrm{g}]$} & {$[\mathrm{g} / \mathrm{g}]$} & {$[\mathrm{g}]$} & {$[\mathrm{g}]$} & {$[\mathrm{g} / \mathrm{g}]$} \\
\hline \hline 1 & 0.041 & 0.101 & 2.47 & 0.041 & 0.135 & 3.29 \\
\hline 2 & 0.088 & 0.337 & 3.83 & 0.088 & 0.401 & 4.56 \\
\hline 3 & 0.006 & 0.026 & 4.26 & 0.006 & 0.023 & 3.90 \\
\hline 4 & 0.061 & 0.122 & 2.00 & 0.061 & 0.182 & 2.98 \\
\hline 5 & 0.058 & 0.204 & 3.53 & 0.058 & 0.292 & 5.03 \\
\hline 6 & 0.194 & 0.627 & 3.23 & 0.194 & 0.567 & 2.92 \\
\hline 7 & 0.056 & 0.266 & 4.74 & 0.056 & 0.252 & 4.50 \\
\hline 8 & 0.037 & 0.134 & 3.63 & 0.037 & 0.196 & 5.30 \\
\hline 9 & 0.057 & 0.180 & 3.15 & 0.057 & 0.182 & 3.19 \\
\hline 10 & 0.110 & 0.346 & 3.14 & 0.110 & 0.279 & 2.54 \\
\hline 11 & 0.157 & 0.666 & 4.24 & 0.157 & 0.752 & 4.79 \\
\hline 12 & 0.056 & 0.162 & 2.90 & 0.056 & 0.236 & 4.22 \\
\hline 13 & 0.608 & 1.991 & 3.27 & 0.608 & 1.705 & 2.80 \\
\hline 14 & 0.060 & 0.067 & 1.12 & 0.060 & 0.051 & 0.84 \\
\hline 15 & 0.323 & 0.533 & 1.65 & 0.323 & 0.703 & 2.18 \\
\hline 16 & 0.009 & 0.033 & 3.72 & 0.009 & 0.023 & 2.59 \\
\hline 17 & 0.137 & 0.381 & 2.78 & 0.137 & 0.335 & 2.44 \\
\hline 18 & 0.173 & 0.510 & 2.95 & 0.173 & 0.531 & 3.07 \\
\hline 19 & 0.039 & 0.077 & 1.98 & 0.039 & 0.073 & 1.87 \\
\hline 20 & 0.072 & 0.128 & 1.78 & 0.072 & 0.114 & 1.58 \\
\hline 21 & 0.621 & 1.293 & 2.08 & 0.621 & 1.516 & 2.44 \\
\hline 22 & 0.090 & 0.222 & 2.47 & 0.090 & 0.203 & 2.25 \\
\hline 23 & 0.116 & 0.264 & 2.27 & 0.116 & 0.279 & 2.41 \\
\hline 24 & 0.131 & 0.295 & 2.25 & 0.131 & 0.260 & 1.99 \\
\hline 25 & 0.072 & 0.136 & 1.89 & 0.072 & 0.087 & 1.21 \\
\hline 26 & 0.062 & 0.121 & 1.95 & 0.062 & 0.146 & 2.35 \\
\hline 27 & 0.026 & 0.078 & 3.01 & 0.026 & 0.059 & 2.26 \\
\hline 28 & 0.212 & 0.421 & 1.99 & 0.212 & 0.260 & 1.23 \\
\hline 29 & 0.248 & 0.426 & 1.72 & 0.248 & 0.386 & 1.56 \\
\hline 30 & 0.078 & 0.099 & 1.26 & 0.078 & 0.056 & 0.72 \\
\hline & & & & & & \\
\hline
\end{tabular}

Table 22: Roof Amplification Factor for Tower 1 Mounted on the RECH Building 
Appendix C.0: Numerical Results 93

\begin{tabular}{|c|c|c|c|c|c|c|}
\hline \multirow{2}{*}{$\begin{array}{c}\text { Load } \\
\text { Case } \\
\text { No. }\end{array}$} & $\mathrm{a}_{\text {ground }}$ & $\mathrm{a}_{\text {roof }}$ & $\mathrm{A}_{\mathrm{r}}=\mathrm{a}_{\text {roof }} / \mathrm{a}_{\text {ground }}$ & $\mathrm{a}_{\text {ground }}$ & $\mathrm{a}_{\text {roof }}$ & $\mathrm{A}_{\mathrm{r}}=\mathrm{a}_{\text {roof }} / \mathrm{a}_{\text {ground }}$ \\
\cline { 2 - 8 } & {$[\mathrm{g}]$} & {$[\mathrm{g}]$} & {$[\mathrm{g} / \mathrm{g}]$} & {$[\mathrm{g}]$} & {$[\mathrm{g}]$} & {$[\mathrm{g} / \mathrm{g}]$} \\
\hline \hline 1 & 0.041 & 0.085 & 2.06 & 0.041 & 0.112 & 2.73 \\
\hline 2 & 0.088 & 0.333 & 3.78 & 0.088 & 0.342 & 3.89 \\
\hline 3 & 0.006 & 0.032 & 5.33 & 0.006 & 0.017 & 2.81 \\
\hline 4 & 0.061 & 0.136 & 2.24 & 0.061 & 0.151 & 2.47 \\
\hline 5 & 0.058 & 0.177 & 3.06 & 0.058 & 0.215 & 3.71 \\
\hline 6 & 0.194 & 0.480 & 2.47 & 0.194 & 0.505 & 2.60 \\
\hline 7 & 0.056 & 0.262 & 4.69 & 0.056 & 0.225 & 4.02 \\
\hline 8 & 0.037 & 0.110 & 2.96 & 0.037 & 0.136 & 3.68 \\
\hline 9 & 0.057 & 0.243 & 4.26 & 0.057 & 0.156 & 2.74 \\
\hline 10 & 0.110 & 0.318 & 2.89 & 0.110 & 0.243 & 2.21 \\
\hline 11 & 0.157 & 0.541 & 3.45 & 0.157 & 0.507 & 3.23 \\
\hline 12 & 0.056 & 0.129 & 2.30 & 0.056 & 0.197 & 3.52 \\
\hline 13 & 0.608 & 1.650 & 2.71 & 0.608 & 1.644 & 2.70 \\
\hline 14 & 0.060 & 0.075 & 1.25 & 0.060 & 0.051 & 0.85 \\
\hline 15 & 0.323 & 0.559 & 1.73 & 0.323 & 0.571 & 1.77 \\
\hline 16 & 0.009 & 0.030 & 3.38 & 0.009 & 0.022 & 2.45 \\
\hline 17 & 0.137 & 0.330 & 2.41 & 0.137 & 0.284 & 2.07 \\
\hline 18 & 0.173 & 0.363 & 2.10 & 0.173 & 0.449 & 2.59 \\
\hline 19 & 0.039 & 0.068 & 1.74 & 0.039 & 0.065 & 1.66 \\
\hline 20 & 0.072 & 0.149 & 2.07 & 0.072 & 0.114 & 1.58 \\
\hline 21 & 0.621 & 1.312 & 2.11 & 0.621 & 1.086 & 1.75 \\
\hline 22 & 0.090 & 0.286 & 3.17 & 0.090 & 0.190 & 2.11 \\
\hline 23 & 0.116 & 0.253 & 2.18 & 0.116 & 0.244 & 2.10 \\
\hline 24 & 0.131 & 0.267 & 2.04 & 0.131 & 0.244 & 1.87 \\
\hline 25 & 0.072 & 0.126 & 1.74 & 0.072 & 0.092 & 1.28 \\
\hline 26 & 0.062 & 0.098 & 1.59 & 0.062 & 0.120 & 1.94 \\
\hline 27 & 0.026 & 0.069 & 2.65 & 0.026 & 0.065 & 2.48 \\
\hline 28 & 0.212 & 0.438 & 2.06 & 0.212 & 0.281 & 1.32 \\
\hline 29 & 0.248 & 0.381 & 1.54 & 0.248 & 0.414 & 1.67 \\
\hline \hline 30 & 0.078 & 0.095 & 1.22 & 0.078 & 0.056 & 0.72 \\
\hline \hline
\end{tabular}

Table 23: Roof Amplification Factor for Tower 2 Mounted on the RECH Building 
Appendix C.0: Numerical Results 94

\begin{tabular}{|c|c|c|c|c|c|c|}
\hline \multirow[b]{2}{*}{$\begin{array}{l}\text { Load } \\
\text { Case } \\
\text { No. }\end{array}$} & \multicolumn{3}{|c|}{ U1 } & \multicolumn{3}{|c|}{ U2 } \\
\hline & $\begin{array}{c}\mathrm{a}_{\text {ground }} \\
{[\mathrm{g}]} \\
\end{array}$ & $\begin{array}{l}\mathrm{a}_{\text {roof }} \\
{[\mathrm{g}]} \\
\end{array}$ & $\begin{array}{c}A_{r}=a_{\text {roof }} / a_{\text {ground }} \\
{[\mathrm{g} / \mathrm{g}]}\end{array}$ & $\begin{array}{r}a_{\text {ground }} \\
{[\mathrm{g}]} \\
\end{array}$ & $\begin{array}{r}a_{\text {roof }} \\
{[\mathrm{g}]} \\
\end{array}$ & $\begin{array}{c}\mathrm{A}_{\mathrm{r}}=\mathrm{a}_{\mathrm{roof}} / \mathrm{a}_{\text {ground }} \\
{[\mathrm{g} / \mathrm{g}]}\end{array}$ \\
\hline 1 & 0.041 & 0.094 & 2.29 & 0.041 & 0.136 & 3.32 \\
\hline 2 & 0.088 & 0.323 & 3.67 & 0.088 & 0.405 & 4.61 \\
\hline 3 & 0.006 & 0.033 & 5.43 & 0.006 & 0.025 & 4.19 \\
\hline 4 & 0.061 & 0.127 & 2.09 & 0.061 & 0.173 & 2.84 \\
\hline 5 & 0.058 & 0.200 & 3.45 & 0.058 & 0.278 & 4.80 \\
\hline 6 & 0.194 & 0.600 & 3.09 & 0.194 & 0.570 & 2.94 \\
\hline 7 & 0.056 & 0.287 & 5.12 & 0.056 & 0.217 & 3.87 \\
\hline 8 & 0.037 & 0.124 & 3.35 & 0.037 & 0.200 & 5.40 \\
\hline 9 & 0.057 & 0.227 & 3.99 & 0.057 & 0.177 & 3.11 \\
\hline 10 & 0.110 & 0.373 & 3.39 & 0.110 & 0.286 & 2.60 \\
\hline 11 & 0.157 & 0.690 & 4.40 & 0.157 & 0.712 & 4.54 \\
\hline 12 & 0.056 & 0.147 & 2.63 & 0.056 & 0.230 & 4.11 \\
\hline 13 & 0.608 & 1.876 & 3.08 & 0.608 & 1.646 & 2.71 \\
\hline 14 & 0.060 & 0.071 & 1.19 & 0.060 & 0.047 & 0.78 \\
\hline 15 & 0.323 & 0.568 & 1.76 & 0.323 & 0.658 & 2.04 \\
\hline 16 & 0.009 & 0.034 & 3.79 & 0.009 & 0.025 & 2.81 \\
\hline 17 & 0.137 & 0.412 & 3.01 & 0.137 & 0.353 & 2.58 \\
\hline 18 & 0.173 & 0.435 & 2.51 & 0.173 & 0.549 & 3.17 \\
\hline 19 & 0.039 & 0.074 & 1.90 & 0.039 & 0.073 & 1.88 \\
\hline 20 & 0.072 & 0.141 & 1.95 & 0.072 & 0.108 & 1.50 \\
\hline 21 & 0.621 & 1.302 & 2.10 & 0.621 & 1.353 & 2.18 \\
\hline 22 & 0.090 & 0.285 & 3.17 & 0.090 & 0.190 & 2.11 \\
\hline 23 & 0.116 & 0.259 & 2.23 & 0.116 & 0.256 & 2.21 \\
\hline 24 & 0.131 & 0.293 & 2.24 & 0.131 & 0.261 & 2.00 \\
\hline 25 & 0.072 & 0.150 & 2.08 & 0.072 & 0.079 & 1.10 \\
\hline 26 & 0.062 & 0.111 & 1.79 & 0.062 & 0.143 & 2.31 \\
\hline 27 & 0.026 & 0.084 & 3.25 & 0.026 & 0.065 & 2.49 \\
\hline 28 & 0.212 & 0.460 & 2.17 & 0.212 & 0.258 & 1.22 \\
\hline 29 & 0.248 & 0.422 & 1.70 & 0.248 & 0.380 & 1.53 \\
\hline 30 & 0.078 & 0.100 & 1.28 & 0.078 & 0.059 & 0.76 \\
\hline
\end{tabular}

Table 24: Roof Amplification Factor for Tower 3 Mounted on the RECH Building 
Appendix C.0: Numerical Results 95

Appendix C.3: Numerical Results for the Tower Amplification Factor

\begin{tabular}{|c|c|c|c|c|c|c|}
\hline \multirow{2}{*}{$\begin{array}{c}\text { Load } \\
\text { Case } \\
\text { No. }\end{array}$} & $\begin{array}{c}\mathrm{F}_{\mathrm{tb}} \\
{[\mathrm{lbs}]}\end{array}$ & $\begin{array}{c}\mathrm{a}_{\mathrm{tb}} \\
{[\mathrm{g}]}\end{array}$ & $\begin{array}{c}\mathrm{A}_{\mathrm{t}}=\mathrm{F}_{\mathrm{tb}} /\left(\mathrm{W}_{\mathrm{t}} \times \mathrm{a}_{\mathrm{tb}}\right) \\
{[\mathrm{lbs} / \mathrm{lbs}]}\end{array}$ & $\begin{array}{c}\mathrm{F}_{\mathrm{tb}} \\
{[\mathrm{lbs}]}\end{array}$ & $\begin{array}{c}\mathrm{a}_{\mathrm{tb}} \\
{[\mathrm{g}]}\end{array}$ & $\begin{array}{c}\mathrm{A}_{\mathrm{t}}=\mathrm{F}_{\mathrm{tb}} /\left(\mathrm{W}_{\mathrm{t}} \times \mathrm{a}_{\mathrm{tb}}\right) \\
{[\mathrm{lbs} / \mathrm{lbs}]}\end{array}$ \\
\hline \hline 1 & 1103 & 0.103 & 2.3 & 1100 & 0.150 & 1.6 \\
\hline 2 & 3556 & 0.341 & 2.3 & 3326 & 0.438 & 1.7 \\
\hline 3 & 312 & 0.026 & 2.6 & 239 & 0.027 & 1.9 \\
\hline 4 & 1237 & 0.123 & 2.2 & 1409 & 0.195 & 1.6 \\
\hline 5 & 2838 & 0.206 & 3.0 & 2609 & 0.326 & 1.7 \\
\hline 6 & 6323 & 0.642 & 2.2 & 4644 & 0.608 & 1.7 \\
\hline 7 & 2657 & 0.270 & 2.1 & 2193 & 0.298 & 1.6 \\
\hline 8 & 1195 & 0.137 & 1.9 & 1513 & 0.211 & 1.6 \\
\hline 9 & 2109 & 0.184 & 2.5 & 1581 & 0.187 & 1.9 \\
\hline 10 & 4490 & 0.352 & 2.8 & 2313 & 0.291 & 1.7 \\
\hline 11 & 8362 & 0.682 & 2.7 & 6647 & 0.806 & 1.8 \\
\hline 12 & 2404 & 0.163 & 3.2 & 1937 & 0.262 & 1.6 \\
\hline 13 & 25218 & 2.036 & 2.7 & 16826 & 1.754 & 2.1 \\
\hline 14 & 1036 & 0.068 & 3.3 & 533 & 0.056 & 2.1 \\
\hline 15 & 8403 & 0.539 & 3.4 & 5729 & 0.803 & 1.6 \\
\hline 16 & 328 & 0.034 & 2.1 & 198 & 0.025 & 1.7 \\
\hline 17 & 3965 & 0.386 & 2.2 & 2663 & 0.350 & 1.7 \\
\hline 18 & 4841 & 0.514 & 2.1 & 4826 & 0.581 & 1.8 \\
\hline 19 & 792 & 0.077 & 2.2 & 610 & 0.075 & 1.8 \\
\hline 20 & 2866 & 0.126 & 5.0 & 1626 & 0.124 & 2.9 \\
\hline 21 & 15343 & 1.296 & 2.6 & 10773 & 1.644 & 1.4 \\
\hline 22 & 3153 & 0.227 & 3.0 & 2255 & 0.244 & 2.0 \\
\hline 23 & 3672 & 0.264 & 3.0 & 2481 & 0.290 & 1.9 \\
\hline 24 & 3538 & 0.304 & 2.5 & 2364 & 0.300 & 1.7 \\
\hline 25 & 2162 & 0.139 & 3.4 & 807 & 0.089 & 2.0 \\
\hline 26 & 1082 & 0.123 & 1.9 & 1110 & 0.150 & 1.6 \\
\hline 27 & 985 & 0.078 & 2.7 & 433 & 0.062 & 1.5 \\
\hline 28 & 3244 & 0.428 & 1.7 & 1687 & 0.294 & 1.3 \\
\hline 29 & 4886 & 0.432 & 2.5 & 3316 & 0.401 & 1.8 \\
\hline 30 & 1376 & 0.098 & 3.1 & 444 & 0.062 & 1.6 \\
\hline & & & & & & \\
\hline
\end{tabular}

Table 25: Tower Amplification Factor for Tower 1 Mounted on the RECH Building 
Appendix C.0: Numerical Results 96

\begin{tabular}{|c|c|c|c|c|c|c|}
\hline \multirow{2}{*}{$\begin{array}{c}\text { Load } \\
\text { Case } \\
\text { No. }\end{array}$} & \multicolumn{3}{|c|}{ U1 } & \multicolumn{3}{|c|}{$\mathrm{U} 2$} \\
\hline & $\begin{array}{c}\mathrm{F}_{\mathrm{tb}} \\
{[\mathrm{lbs}]} \\
\end{array}$ & $\begin{array}{r}\mathrm{a}_{\mathrm{tb}} \\
{[\mathrm{g}]} \\
\end{array}$ & $\begin{array}{c}\mathrm{A}_{\mathrm{t}}=\mathrm{F}_{\mathrm{tb}} /\left(\mathrm{W}_{\mathrm{t}} \times \mathrm{a}_{\mathrm{tb}}\right) \\
{[\mathrm{lbs} / \mathrm{lbs}]}\end{array}$ & $\begin{array}{c}\mathrm{F}_{\mathrm{tb}} \\
{[\mathrm{lbs}]}\end{array}$ & $\begin{array}{r}\mathrm{a}_{\mathrm{tb}} \\
{[\mathrm{g}]} \\
\end{array}$ & $\begin{array}{c}\mathrm{A}_{\mathrm{t}}=\mathrm{F}_{\mathrm{tb}} /\left(\mathrm{W}_{\mathrm{t}} \times \mathrm{a}_{\mathrm{tb}}\right) \\
{[\mathrm{lbs} / \mathrm{lbs}]}\end{array}$ \\
\hline 1 & 2539 & 0.086 & 4.9 & 3251 & 0.118 & 4.5 \\
\hline 2 & 6325 & 0.337 & 3.1 & 9231 & 0.348 & 4.4 \\
\hline 3 & 491 & 0.032 & 2.5 & 437 & 0.018 & 4.1 \\
\hline 4 & 2904 & 0.138 & 3.5 & 4496 & 0.159 & 4.7 \\
\hline 5 & 4782 & 0.181 & 4.4 & 5994 & 0.252 & 3.9 \\
\hline 6 & 9531 & 0.484 & 3.2 & 12257 & 0.554 & 3.6 \\
\hline 7 & 4831 & 0.266 & 3.0 & 4165 & 0.262 & 2.6 \\
\hline 8 & 3223 & 0.112 & 4.7 & 3791 & 0.155 & 4.0 \\
\hline 9 & 3774 & 0.244 & 2.5 & 4162 & 0.164 & 4.2 \\
\hline 10 & 5137 & 0.318 & 2.7 & 4920 & 0.259 & 3.1 \\
\hline 11 & 13206 & 0.537 & 4.0 & 13449 & 0.526 & 4.2 \\
\hline 12 & 3975 & 0.130 & 5.0 & 5525 & 0.209 & 4.4 \\
\hline 13 & 32903 & 1.678 & 3.2 & 41833 & 1.599 & 4.3 \\
\hline 14 & 890 & 0.076 & 1.9 & 816 & 0.052 & 2.6 \\
\hline 15 & 12127 & 0.566 & 3.5 & 13648 & 0.713 & 3.1 \\
\hline 16 & 547 & 0.031 & 2.9 & 470 & 0.021 & 3.7 \\
\hline 17 & 6895 & 0.330 & 3.4 & 7196 & 0.295 & 4.0 \\
\hline 18 & 7609 & 0.370 & 3.4 & 11148 & 0.432 & 4.2 \\
\hline 19 & 1363 & 0.069 & 3.2 & 1697 & 0.064 & 4.4 \\
\hline 20 & 1889 & 0.152 & 2.1 & 2246 & 0.114 & 3.2 \\
\hline 21 & 25339 & 1.343 & 3.1 & 28440 & 1.212 & 3.9 \\
\hline 22 & 3683 & 0.291 & 2.1 & 3586 & 0.242 & 2.4 \\
\hline 23 & 4050 & 0.263 & 2.5 & 5631 & 0.258 & 3.6 \\
\hline 24 & 5817 & 0.272 & 3.5 & 6064 & 0.250 & 4.0 \\
\hline 25 & 1628 & 0.128 & 2.1 & 1756 & 0.094 & 3.1 \\
\hline 26 & 2177 & 0.103 & 3.5 & 3541 & 0.125 & 4.6 \\
\hline 27 & 1052 & 0.070 & 2.5 & 907 & 0.071 & 2.1 \\
\hline 28 & 4934 & 0.461 & 1.8 & 4525 & 0.302 & 2.5 \\
\hline 29 & 5327 & 0.394 & 2.2 & 7475 & 0.421 & 2.9 \\
\hline 30 & 962 & 0.102 & 1.6 & 981 & 0.066 & 2.4 \\
\hline
\end{tabular}

Table 26: Tower Amplification Factor for Tower 2 Mounted on the RECH Building 


\begin{tabular}{|c|c|c|c|c|c|c|}
\hline \multirow{2}{*}{$\begin{array}{c}\text { Load } \\
\text { Case } \\
\text { No. }\end{array}$} & \multicolumn{3}{|c|}{ U1 } & \multicolumn{3}{|c|}{$\mathrm{U} 2$} \\
\hline & $\begin{array}{c}\mathrm{F}_{\mathrm{tb}} \\
{[\mathrm{lbs}]} \\
\end{array}$ & $\begin{array}{c}\mathrm{a}_{\mathrm{tb}} \\
{[\mathrm{g}]} \\
\end{array}$ & $\begin{array}{c}\mathrm{At}=\mathrm{F}_{\mathrm{tb}} /\left(\mathrm{W}_{\mathrm{t}} \times \mathrm{a}_{\mathrm{tb}}\right) \\
{[\mathrm{lbs} / \mathrm{lbs}]}\end{array}$ & $\begin{array}{c}\mathrm{F}_{\mathrm{tb}} \\
{[\mathrm{lbs}]} \\
\end{array}$ & $\begin{array}{c}\mathrm{a}_{\mathrm{tb}} \\
{[\mathrm{g}]} \\
\end{array}$ & $\begin{array}{c}\mathrm{At}=\mathrm{F}_{\mathrm{tb}} /\left(\mathrm{W}_{\mathrm{t}} \times \mathrm{a}_{\mathrm{tb}}\right) \\
{[\mathrm{lbs} / \mathrm{lbs}]}\end{array}$ \\
\hline 1 & 1395 & 0.094 & 2.0 & 1584 & 0.142 & 1.5 \\
\hline 2 & 3579 & 0.324 & 1.5 & 3824 & 0.407 & 1.2 \\
\hline 3 & 180 & 0.033 & 0.7 & 199 & 0.027 & 1.0 \\
\hline 4 & 976 & 0.128 & 1.0 & 1115 & 0.182 & 0.8 \\
\hline 5 & 1444 & 0.201 & 0.9 & 1765 & 0.300 & 0.8 \\
\hline 6 & 4041 & 0.602 & 0.9 & 4403 & 0.572 & 1.0 \\
\hline 7 & 2092 & 0.288 & 1.0 & 2392 & 0.252 & 1.3 \\
\hline 8 & 1821 & 0.124 & 1.9 & 2206 & 0.212 & 1.4 \\
\hline 9 & 1026 & 0.228 & 0.6 & 1035 & 0.176 & 0.8 \\
\hline 10 & 3366 & 0.373 & 1.2 & 3893 & 0.299 & 1.7 \\
\hline 11 & 4154 & 0.693 & 0.8 & 4424 & 0.746 & 0.8 \\
\hline 12 & 1489 & 0.148 & 1.3 & 1560 & 0.242 & 0.8 \\
\hline 13 & 12498 & 1.884 & 0.9 & 15159 & 1.692 & 1.2 \\
\hline 14 & 441 & 0.072 & 0.8 & 445 & 0.047 & 1.2 \\
\hline 15 & 4709 & 0.570 & 1.1 & 4928 & 0.739 & 0.9 \\
\hline 16 & 249 & 0.034 & 1.0 & 294 & 0.026 & 1.5 \\
\hline 17 & 4383 & 0.414 & 1.4 & 4931 & 0.374 & 1.7 \\
\hline 18 & 4843 & 0.437 & 1.5 & 5632 & 0.547 & 1.4 \\
\hline 19 & 494 & 0.075 & 0.9 & 544 & 0.073 & 1.0 \\
\hline 20 & 1070 & 0.141 & 1.0 & 1090 & 0.111 & 1.3 \\
\hline 21 & 11368 & 1.311 & 1.1 & 12514 & 1.408 & 1.2 \\
\hline 22 & 911 & 0.287 & 0.4 & 876 & 0.208 & 0.6 \\
\hline 23 & 2332 & 0.260 & 1.2 & 2635 & 0.257 & 1.3 \\
\hline 24 & 1678 & 0.294 & 0.7 & 1602 & 0.271 & 0.8 \\
\hline 25 & 744 & 0.151 & 0.7 & 579 & 0.088 & 0.9 \\
\hline 26 & 511 & 0.112 & 0.6 & 686 & 0.146 & 0.6 \\
\hline 27 & 269 & 0.085 & 0.4 & 219 & 0.070 & 0.4 \\
\hline 28 & 2095 & 0.465 & 0.6 & 1572 & 0.278 & 0.7 \\
\hline 29 & 2467 & 0.425 & 0.8 & 2712 & 0.377 & 0.9 \\
\hline 30 & 532 & 0.101 & 0.7 & 489 & 0.066 & 1.0 \\
\hline
\end{tabular}

Table 27: Tower Amplification Factor for Tower 3 Mounted on the RECH Building 
Appendix C.0: Numerical Results 98

Appendix C.4: Results for the Rooftop Solar Tower Amplification Factor

\begin{tabular}{|c|c|c|c|c|c|c|}
\hline \multirow{2}{*}{$\begin{array}{c}\text { Load Case } \\
\text { No. }\end{array}$} & \multicolumn{3}{|c|}{ U1 } & \multicolumn{3}{|c|}{ U2 } \\
\hline & $A_{r}$ & $A_{t}$ & $A_{z}=A_{r} \times A_{t}$ & $A_{r}$ & $A_{t}$ & $\mathrm{~A}_{\mathrm{z}}=\mathrm{A}_{\mathrm{r}} \times \mathrm{A}_{\mathrm{t}}$ \\
\hline 1 & 2.47 & 1.80 & 4.44 & 3.29 & 1.33 & 4.38 \\
\hline 2 & 3.83 & 2.07 & 7.91 & 4.56 & 1.30 & 5.95 \\
\hline 3 & 4.26 & 2.24 & 9.52 & 3.90 & 1.48 & 5.76 \\
\hline 4 & 2.00 & 1.74 & 3.48 & 2.98 & 1.37 & 4.09 \\
\hline 5 & 3.53 & 1.99 & 7.03 & 5.03 & 1.40 & 7.06 \\
\hline 6 & 3.23 & 1.95 & 6.31 & 2.92 & 1.43 & 4.17 \\
\hline 7 & 4.74 & 1.77 & 8.40 & 4.50 & 1.26 & 5.68 \\
\hline 8 & 3.63 & 1.60 & 5.83 & 5.30 & 1.33 & 7.03 \\
\hline 9 & 3.15 & 2.07 & 6.54 & 3.19 & 1.52 & 4.86 \\
\hline 10 & 3.14 & 2.11 & 6.63 & 2.54 & 1.54 & 3.90 \\
\hline 11 & 4.24 & 1.88 & 7.97 & 4.79 & 1.40 & 6.68 \\
\hline 12 & 2.90 & 2.09 & 6.04 & 4.22 & 1.24 & 5.25 \\
\hline 13 & 3.27 & 1.95 & 6.38 & 2.80 & 1.56 & 4.38 \\
\hline 14 & 1.12 & 4.62 & 5.20 & 0.84 & 2.42 & 2.04 \\
\hline 15 & 1.65 & 2.53 & 4.18 & 2.18 & 1.32 & 2.87 \\
\hline 16 & 3.72 & 1.74 & 6.49 & 2.59 & 1.42 & 3.68 \\
\hline 17 & 2.78 & 1.80 & 5.01 & 2.44 & 1.35 & 3.30 \\
\hline 18 & 2.95 & 1.65 & 4.88 & 3.07 & 1.51 & 4.62 \\
\hline 19 & 1.98 & 2.13 & 4.20 & 1.87 & 1.58 & 2.95 \\
\hline 20 & 1.78 & 4.13 & 7.35 & 1.58 & 2.50 & 3.96 \\
\hline 21 & 2.08 & 2.41 & 5.02 & 2.44 & 1.36 & 3.32 \\
\hline 22 & 2.47 & 2.58 & 6.35 & 2.25 & 1.55 & 3.49 \\
\hline 23 & 2.27 & 2.89 & 6.55 & 2.41 & 1.70 & 4.08 \\
\hline 24 & 2.25 & 1.97 & 4.43 & 1.99 & 1.35 & 2.68 \\
\hline 25 & 1.89 & 2.18 & 4.11 & 1.21 & 1.74 & 2.10 \\
\hline 26 & 1.95 & 1.49 & 2.91 & 2.35 & 1.40 & 3.28 \\
\hline 27 & 3.01 & 2.28 & 6.85 & 2.26 & 1.10 & 2.50 \\
\hline 28 & 1.99 & 1.97 & 3.91 & 1.23 & 1.15 & 1.41 \\
\hline 29 & 1.72 & 1.75 & 3.00 & 1.56 & 1.50 & 2.33 \\
\hline 30 & 1.26 & 3.26 & 4.12 & 0.72 & 1.73 & 1.25 \\
\hline
\end{tabular}

Table 28: Rooftop Solar Tower Amplification Factor for Tower 1 Mounted on the RECH Building 
Appendix C.0: Numerical Results 99

\begin{tabular}{|c|c|c|c|c|c|c|}
\hline \multirow{2}{*}{$\begin{array}{c}\text { Load Case } \\
\text { No. }\end{array}$} & \multicolumn{3}{|c|}{ U1 } & \multicolumn{3}{|c|}{$\mathrm{U} 2$} \\
\hline & $\mathrm{A}_{\mathrm{r}}$ & $A_{t}$ & $A_{z}=A_{r} \times A_{t}$ & $\mathrm{~A}_{\mathrm{r}}$ & $A_{t}$ & $A_{z}=A_{r} \times A_{t}$ \\
\hline 1 & 2.06 & 4.88 & 10.08 & 2.73 & 4.55 & 12.43 \\
\hline 2 & 3.78 & 3.09 & 11.68 & 3.89 & 4.36 & 16.95 \\
\hline 3 & 5.33 & 2.51 & 13.37 & 2.81 & 4.08 & 11.45 \\
\hline 4 & 2.24 & 3.47 & 7.76 & 2.47 & 4.66 & 11.52 \\
\hline 5 & 3.06 & 4.36 & 13.33 & 3.71 & 3.91 & 14.50 \\
\hline 6 & 2.47 & 3.24 & 8.01 & 2.60 & 3.64 & 9.46 \\
\hline 7 & 4.69 & 2.98 & 13.99 & 4.02 & 2.61 & 10.52 \\
\hline 8 & 2.96 & 4.74 & 14.04 & 3.68 & 4.02 & 14.81 \\
\hline 9 & 4.26 & 2.54 & 10.83 & 2.74 & 4.17 & 11.43 \\
\hline 10 & 2.89 & 2.65 & 7.68 & 2.21 & 3.13 & 6.91 \\
\hline 11 & 3.45 & 4.05 & 13.95 & 3.23 & 4.21 & 13.58 \\
\hline 12 & 2.30 & 5.01 & 11.52 & 3.52 & 4.36 & 15.36 \\
\hline 13 & 2.71 & 3.22 & 8.75 & 2.70 & 4.30 & 11.63 \\
\hline 14 & 1.25 & 1.94 & 2.42 & 0.85 & 2.58 & 2.19 \\
\hline 15 & 1.73 & 3.52 & 6.10 & 1.77 & 3.15 & 5.57 \\
\hline 16 & 3.38 & 2.92 & 9.86 & 2.45 & 3.66 & 8.96 \\
\hline 17 & 2.41 & 3.44 & 8.27 & 2.07 & 4.02 & 8.32 \\
\hline 18 & 2.10 & 3.38 & 7.10 & 2.59 & 4.24 & 11.01 \\
\hline 19 & 1.74 & 3.23 & 5.61 & 1.66 & 4.36 & 7.25 \\
\hline 20 & 2.07 & 2.05 & 4.24 & 1.58 & 3.24 & 5.12 \\
\hline 21 & 2.11 & 3.10 & 6.56 & 1.75 & 3.86 & 6.75 \\
\hline 22 & 3.17 & 2.08 & 6.61 & 2.11 & 2.44 & 5.13 \\
\hline 23 & 2.18 & 2.53 & 5.53 & 2.10 & 3.59 & 7.54 \\
\hline 24 & 2.04 & 3.52 & 7.19 & 1.87 & 3.99 & 7.43 \\
\hline 25 & 1.74 & 2.09 & 3.65 & 1.28 & 3.07 & 3.93 \\
\hline 26 & 1.59 & 3.47 & 5.51 & 1.94 & 4.64 & 9.00 \\
\hline 27 & 2.65 & 2.46 & 6.53 & 2.48 & 2.10 & 5.21 \\
\hline 28 & 2.06 & 1.76 & 3.63 & 1.32 & 2.47 & 3.26 \\
\hline 29 & 1.54 & 2.22 & 3.41 & 1.67 & 2.92 & 4.87 \\
\hline 30 & 1.22 & 1.55 & 1.90 & 0.72 & 2.45 & 1.76 \\
\hline
\end{tabular}

Table 29: Rooftop Solar Tower Amplification Factor for Tower 2 Mounted on the RECH Building 
Appendix C.0: Numerical Results 100

\begin{tabular}{|c|c|c|c|c|c|c|}
\hline \multirow{2}{*}{$\begin{array}{c}\text { Load Case } \\
\text { No. }\end{array}$} & \multicolumn{3}{|c|}{ U1 } & \multicolumn{3}{|c|}{ U2 } \\
\hline & $A_{r}$ & $A_{t}$ & $A_{z}=A_{r} \times A_{t}$ & $A_{r}$ & $A_{t}$ & $A_{z}=A_{r} \times A_{t}$ \\
\hline 1 & 2.29 & 1.95 & 4.47 & 3.32 & 1.46 & 4.86 \\
\hline 2 & 3.67 & 1.45 & 5.33 & 4.61 & 1.24 & 5.70 \\
\hline 3 & 5.43 & 0.72 & 3.93 & 4.19 & 0.97 & 4.08 \\
\hline 4 & 2.09 & 1.01 & 2.10 & 2.84 & 0.81 & 2.29 \\
\hline 5 & 3.45 & 0.95 & 3.27 & 4.80 & 0.77 & 3.72 \\
\hline 6 & 3.09 & 0.88 & 2.73 & 2.94 & 1.01 & 2.97 \\
\hline 7 & 5.12 & 0.96 & 4.90 & 3.87 & 1.25 & 4.84 \\
\hline 8 & 3.35 & 1.93 & 6.45 & 5.40 & 1.37 & 7.41 \\
\hline 9 & 3.99 & 0.59 & 2.36 & 3.11 & 0.77 & 2.40 \\
\hline 10 & 3.39 & 1.19 & 4.02 & 2.60 & 1.71 & 4.44 \\
\hline 11 & 4.40 & 0.79 & 3.47 & 4.54 & 0.78 & 3.54 \\
\hline 12 & 2.63 & 1.33 & 3.50 & 4.11 & 0.85 & 3.49 \\
\hline 13 & 3.08 & 0.87 & 2.69 & 2.71 & 1.18 & 3.19 \\
\hline 14 & 1.19 & 0.81 & 0.96 & 0.78 & 1.24 & 0.97 \\
\hline 15 & 1.76 & 1.09 & 1.91 & 2.04 & 0.88 & 1.79 \\
\hline 16 & 3.79 & 0.96 & 3.63 & 2.81 & 1.51 & 4.26 \\
\hline 17 & 3.01 & 1.39 & 4.19 & 2.58 & 1.73 & 4.47 \\
\hline 18 & 2.51 & 1.46 & 3.66 & 3.17 & 1.35 & 4.30 \\
\hline 19 & 1.90 & 0.87 & 1.66 & 1.88 & 0.99 & 1.85 \\
\hline 20 & 1.95 & 1.00 & 1.95 & 1.50 & 1.29 & 1.94 \\
\hline 21 & 2.10 & 1.14 & 2.39 & 2.18 & 1.17 & 2.55 \\
\hline 22 & 3.17 & 0.42 & 1.32 & 2.11 & 0.55 & 1.17 \\
\hline 23 & 2.23 & 1.18 & 2.63 & 2.21 & 1.35 & 2.97 \\
\hline 24 & 2.24 & 0.75 & 1.68 & 2.00 & 0.78 & 1.55 \\
\hline 25 & 2.08 & 0.65 & 1.35 & 1.10 & 0.87 & 0.96 \\
\hline 26 & 1.79 & 0.60 & 1.08 & 2.31 & 0.62 & 1.43 \\
\hline 27 & 3.25 & 0.42 & 1.36 & 2.49 & 0.41 & 1.02 \\
\hline 28 & 2.17 & 0.59 & 1.29 & 1.22 & 0.74 & 0.90 \\
\hline 29 & 1.70 & 0.76 & 1.30 & 1.53 & 0.95 & 1.45 \\
\hline 30 & 1.28 & 0.69 & 0.88 & 0.76 & 0.98 & 0.75 \\
\hline
\end{tabular}

Table 30: Rooftop Solar Tower Amplification Factor for Tower 3 Mounted on the RECH Building 